US Army Corps

of Engineers ${ }_{\circledast}$

Engineer Research and

Development Center

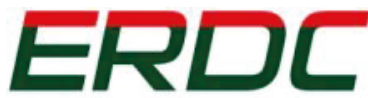

INNOVATIVE SOLUTIONS for a safer, better world

\title{
Energy Dissipation in Carbon Nanotube
} Forests through the Control of Morphology and Layered Forests with Intercalated Metal Films
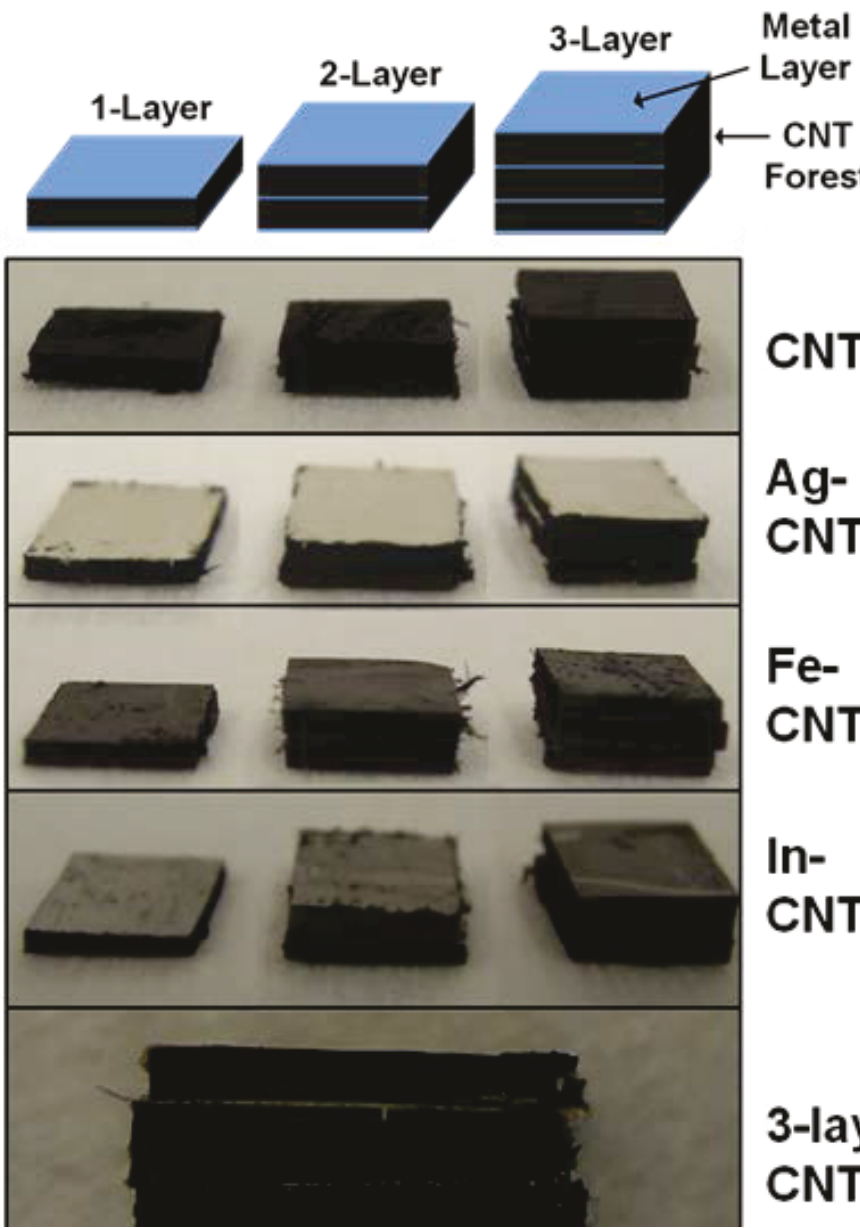

CNT

Ag-

CNT

Fe-

CNT

In-

CNT

3-layer

CNT-Ag 
The U.S. Army Engineer Research and Development Center (ERDC) solves the nation's toughest engineering and environmental challenges. ERDC develops innovative solutions in civil and military engineering, geospatial sciences, water resources, and environmental sciences for the Army, the Department of Defense, civilian agencies, and our nation's public good. Find out more at www.erdc.usace.army.mil.

To search for other technical reports published by ERDC, visit the ERDC online library at http://acwc.sdp.sirsi.net/client/default. 


\section{Energy Dissipation in Carbon Nanotube Forests through the Control of Morphology and Layered Forests with Intercalated Metal Films}

Matthew W. Brenner and Veera M. Boddu

U.S. Army Engineer Research and Development Center (ERDC)

Construction Engineering Research Laboratory (CERL)

2902 Newmark Dr.

Champaign, IL 61824

Final Report

Approved for public release; distribution is unlimited.

Prepared for Headquarters, U.S. Army Corps of Engineers

Washington, DC 20314-1000

Under 6.1 (Basic Research) Program “Functionally Graded Materials for High Energy Dissipation" and the Postgraduate Research Participation Program at ERDC-CERL 


\section{Abstract}

The high mechanical strength and low density of carbon nanotubes (CNTs) make them ideal candidates to be incorporated into composites to increase their mechanical strength. This work investigated the effect of process parameters on the energy dissipation and other mechanical properties of forests of carbon nanotubes grown on various substrates by synthesizing vertically aligned CNT forests under the same conditions using three different carbon sources: $\mathrm{m}$-xylene, toluene, and benzene. Results indicate that substituents on the benzene ring increase entanglement in the CNT forests. When compressed to a strain of 0.67 , the toluene CNTs absorbed more energy than the m-xylene CNTs. Vertically aligned forests of CNTs were also synthesized to study their quasi-static mechanical properties in a layered configuration with metallization. The top and bottom surfaces of CNT forests were metalized with $\mathrm{Ag}$, Fe, and In using paste, sputtering, and thermal evaporation, respectively. Stacks of one, two, and three layers of these forests were assembled and compressed to measure their mechanical properties. Successive stacking of CNT forests was found to reduce global buckling events, which is enhanced with a thick Ag deposition on the CNT forest surface. Young's modulus increased as the number of layers was increased.

DISCLAIMER: The contents of this report are not to be used for advertising, publication, or promotional purposes. Citation of trade names does not constitute an official endorsement or approval of the use of such commercial products. All product names and trademarks cited are the property of their respective owners. The findings of this report are not to be construed as an official Department of the Army position unless so designated by other authorized documents.

DESTROY THIS REPORT WHEN NO LONGER NEEDED. DO NOT RETURN IT TO THE ORIGINATOR. 


\section{Contents}

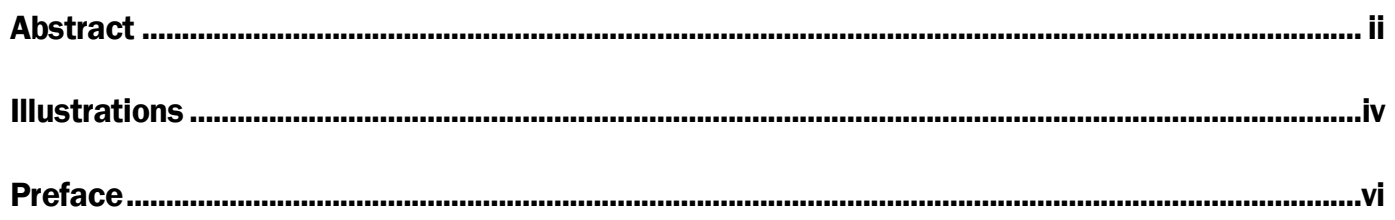

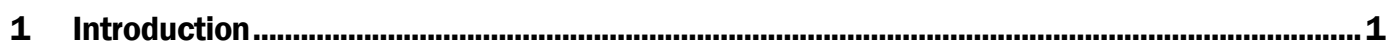

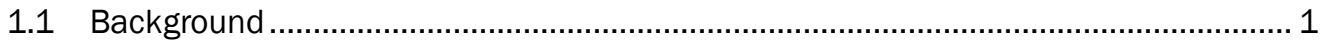

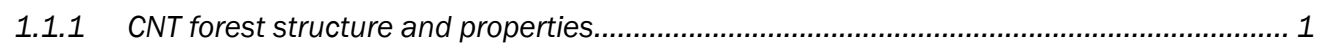

1.1.2 CNT forests intercalated with metal films.................................................................... 2

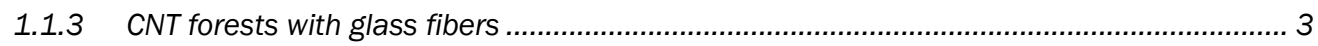

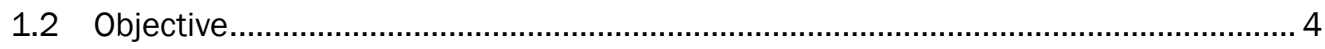

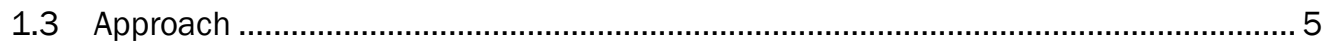

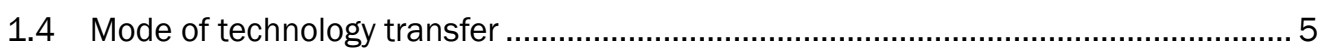

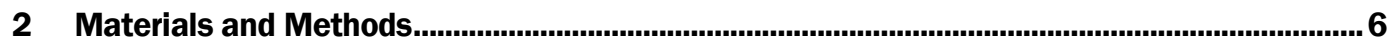

2.1 CNT specimen preparation for morphology study.................................................. 6

2.2 Preparation of CNT specimen intercalated with metal films.................................... 8

2.3 Preparation of CNT specimen with glass fabric ................................................. 11

2.4 Gathering stress vs. strain data using an Instron single column testing

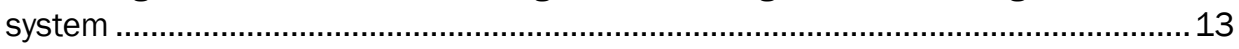

2.5 Determining CNT structure via scanning electron microscopy .............................. 15

2.6 Determining CNT properties via transmission electron microscopy (TEM) ..............15

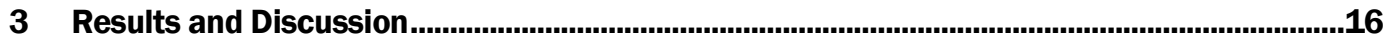

3.1 Control of CNT morphology and energy dissipation using process parameters ................................................................................................... 16

3.1.1 Synthesis from aromatic carbon precursors ............................................................... 16

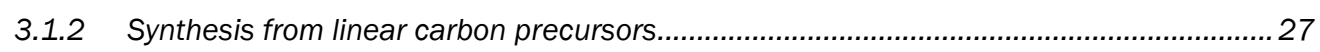

3.1.3 Synthesis on Si substrates with metal film ................................................................... 30

3.2 Energy dissipation and cushioning in intercalated CNT forests with metal

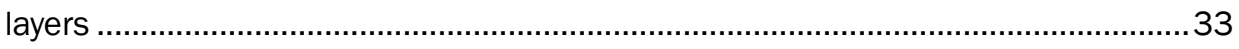

3.3 Morphology of CNT forests grown on glass fibers in a two-zone furnace ................43

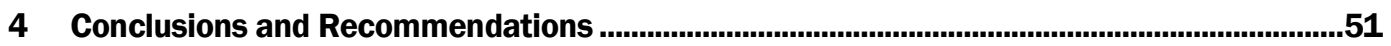

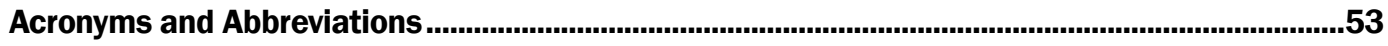

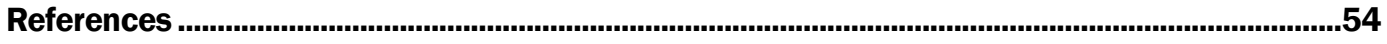

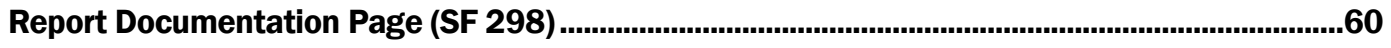




\section{Illustrations}

\section{Figures}

2-1 (a) Schematic of CNT synthesis (b) optical image of sample fabrication setup ..............................

2-2 Schematic and typical optical images of four combinations of multilayered stacks of CNTs with various metals

2-3 (a) Experimental setup used for CVD synthesis of CNTs on glass fibers, (b) Desized glass fabric used as the substrate for CNT synthesis

2-4 Experimental setup used for measuring the force vs. displacement of the three types of CNT forests grown on Si wafers, each fabricated with a distinct carbon precursor

2-5 Optical image of Instron column used to measure stress vs. strain curves

2-6 Experimental setup used for measuring the force vs. displacement of the multilayered CNT forests

3-1 SEM images of the side view of CNT forests at a tilt angle of 45 degrees fabricated with (a) $m$-xylene, (b) toluene, and (c) benzene,(d)-(f) SEM images of the CNT forests from (a)-(c) at a higher magnification showing the forest structure for CNTs made from (d) $m$-xylene, (e) toluene, and (f) benzene.

3-2 TEM images of CNTs fabricated with (a) $m$-xylene, (b) toluene, and (c) benzene, (d)-(f) TEM images of CNTs at a higher magnification showing a hollow inner core and wall structure for CNTs made with (d) $m$-xylene, (e) toluene, and (f) benzene

3-3 Chemical structures of the catalyst ferrocene (top) and the three aromatic carbon precursors $m$-xylene, toluene, and benzene (bottom)

3-4 Stress vs. strain for CNT forests fabricated from $m$-xylene, toluene, and benzene, (a)(c) Cycles 2-12 of the stress vs. strain diagrams of CNTs forests compressed to a strain of 0.25, (d)-(f) Cycles 2-12 of the stress vs. strain diagrams of CNTs forests compressed to a strain of 0.67 . Insets: the first cycle of the stress vs. strain diagrams of CNT forests compressed to a strain of 0.67

3-5 SEM images of CNT forests before and after compression at a tilt angle of 45 degrees for forests grown with carbon precursors: (a) m-xylene, (b) toluene, and (c) benzene. The left (right) column is before (after) the first compression cycle. Insets of (b): a zoomed in image at a tilt angle of 55 degrees showing multiple global buckling folds

3-6 Energy dissipation and restitution vs. cycle number for CNT forests fabricated from $m$ xylene, toluene, and benzene. (a) Energy dissipation plotted at $25 \%$ compression for the three carbon sources. (b) Energy dissipation plotted at $67 \%$ compression for the three carbon sources, (c) Restitution plotted for the three carbon sources at $25 \%$ compression, (d) Restitution plotted for the three carbon sources at $67 \%$ compression.

3-7 Chemical structures of two linear molecules: acetonitrile and acetylene used as carbon precursors for the CVD synthesis of CNTs

3-8 SEM images of CNTs grown with acetonitrile as the carbon precursor ......................................... 29

3-9 SEM images of CNTs grown with acetylene as the carbon precursor ............................................. 30

3-10 SEM images of CNTs with $100 \mathrm{~nm}$ of Al sputter coated on the surface......................................... 31

3-11 SEM images of CNTs grown on various thin films of metals ........................................................32

3-12 SEM images of CNTs grown on bulk stainless steel and titanium............................................... 33

3-13 SEM images of various metals (none, Ag, Fe, and In) deposited on the surface of a CNT forest. Column 1 shows the surface of metal deposition. Column 2 shows a side 


\section{Figures}

view of the CNT-metal interface tilted at $30^{\circ}$. Column 3 shows the tilted side view of the Ag-CNT interface: general view (top), middle layer (row 2), top layer (row 3), and zoomed in view of the middle layer showing the Ag connection to CNTs (bottom)

3-14 Stress vs. strain plots of the first (black) and fifth (red) cycles for all four sample types including $1 \mathrm{~L}, 2 \mathrm{~L}$, and $3 \mathrm{~L}$ samples for the mid-range density samples

3-15 Young's modulus vs. stack number for the first cycle for each of four CNT forests, each

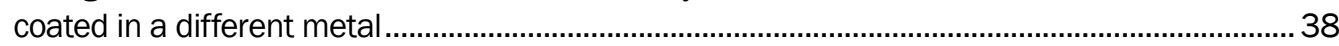

3-16 Energy and Energy density vs. layer number for CNT forests coated with no metal, Ag, $\mathrm{Fe}$, and In for the (a) first cycle (b) fifth cycle. 39

3-17 Optical images of typical CNT-metal intercalated samples after compression testing.................41

3-18 SEM images of typical CNT-metal intercalated samples after compression testing. The scale bar in all images is $100 \mu \mathrm{m}$

3-19 Optical images of CNTs grown on glass fabrics in a two tmperature zone furnace at a Zone 1 temperature of $800{ }^{\circ} \mathrm{C}$ and various Zone 2 temperatures

3-20 SEM images of CNTs grown on glass fabrics in a two temperature zone furnace at a Zone 1 temperature of $800{ }^{\circ} \mathrm{C}$ and various Zone 2 temperatures . 46

3-21 Optical images of CNTs grown on glass fabrics in a two temperature zone furnace at a Zone 2 temperature of $540^{\circ} \mathrm{C}$ and various Zone 1 temperatures

3-22 SEM images of CNTs grown on glass fabrics in a two temperature zone furnace at Zone 1 temperatures of $850,900,550$ and $500{ }^{\circ} \mathrm{C}$ with a Zone 2 temperature of $540{ }^{\circ} \mathrm{C}$

3-23 SEM images of CNTs grown on glass fabrics in a two temperature zone furnace at Zone 1 temperatures of $600,700,750$, and $800{ }^{\circ} \mathrm{C}$ with a Zone 2 temperature of $540{ }^{\circ} \mathrm{C}$. 


\section{Preface}

This research was supported in part through 6.1 (Basic Research) Program "Functionally Graded Materials for High Energy Dissipation," and in part by an appointment to the Postgraduate Research Participation Program at the U.S. Army Engineer Research and Development Center, Construction Engineering Research Laboratory (ERDC-CERL) administered by the Oak Ridge Institute for Science and Education through an interagency agreement between the U.S. Department of Energy and ERDC-CERL. The technical reviewer was Dr. James K. Hay, CEERD-CNE.

The work was performed by the Environmental Processes (CNE) Branch of the Installations Division (CN), Construction Engineering Research Laboratory (CERL). The CERL Principal Investigator was Matthew W. Brenner. At the time of publication, Garth Anderson was Acting Chief, CNE and Michelle Hanson was Chief, CN. The associated Technical Director was Alan Anderson. The Deputy Director of CERL was Dr. Kirankumar V. Topudurti, and the Director was Dr. Ilker R. Adiguzel.

COL Jeffrey R. Eckstein was Commander of ERDC, and Dr. Jeffery P. Holland was the Director. 


\section{Introduction}

\subsection{Background}

\subsubsection{CNT forest structure and properties}

Carbon nanotubes (CNTs) were discovered by Iijima (1991) and since then have attracted a great deal of attention due to their remarkable thermal, optical, electrical, and mechanical properties. CNTs have found many potential applications (Rakov 2013; Baughman, Zakhidov, and de Heer 2002) as chemical sensors (Kong et al. 2000), transistors (Tans et al. 1997; Tans, Verschueren, and Dekker 1998), field emitters (Fan et al. 1999), electromagnetic shielding ( $\mathrm{Li}$ et al. 2006), and atomic force microscopy and scanning tunneling microscopy probe tips (Hafner et al. 2001; Hafner, Cheung, and Lieber 1999). Their exceptional mechanical properties include a high elastic modulus, strength (Wong, Sheehan, and Lieber 1997), energy absorption (Cao et al. 2005), and large buckling and fracture strains (Treacy, Ebbesen, and Gibson 1996; Wong, Sheehan, and Lieber 1997; Falvo et al. 1997). Due to their high mechanical strength and low density they have been incorporated into composites to increase their mechanical strength (Ci et al. 2008; Veedu et al. 2006; Coleman, Khan, and Blau 2006; Iijima 1991; Chou et al. 2010).

Many methods are used to fabricate CNTs, including chemical vapor deposition (CVD) (Joseyacaman et al. 1993; Endo et al. 1995), plasma-enhanced CVD (PE-CVD) (Ren et al. 1991), arc discharge (Ebbesen and Ajayan 1992), laser ablation (Thess et al. 1996), and flame synthesis (Vander Wal, Ticich, and Curtis 2000). Each of these methods involves the diffusion of carbon into a catalyst material to produce a CNT. The CVD method is widely used as there is flexibility in choosing the process parameters to produce high yields of high quality, vertically aligned CNT forests.

Numerous studies have demonstrated that CNTs of varying structure and strength can be produced by controlling the catalyst, substrate, temperature, and the pressure and total carrier gas flow rate (Seah, Chai, and Mohamed 2011). The choice of carbon precursor on CNT properties has also been widely studied (Lee et al. 2003; Lee et al. 2003; Meysami et al. 2013; Pinault et al. 2005). Many of these experiments have investigated the impact of various carbon precursors and their mixtures on structural and 
chemical properties of CNTs such as morphology, diameter, defect density, and yield, as well as the optimal process temperature, chemical species present during pyrolysis, and carbon source interactions with the catalyst.

The compressibility, impact resistance, modulus, restitution, elasticity, and other mechanical properties of CNT forests are also of great interest and have been extensively studied (Cao et al. 2005; Daraio et al. 2006; Ginga, Chen, and Sitaraman 2014). However, relatively few studies have investigated the correlation between the carbon precursor and the mechanical properties of CNT forest including energy dissipation.

This work investigated how the carbon source impacts the structure and the resulting mechanical properties of the CNT forest, specifically the gross mechanical properties of the self-assembled CNT forest and not on the properties of individual CNTs. Three aromatic carbon sources were studied: benzene and two benzene derivates: toluene and $m$-xylene. The effect of two linear structured carbon precursors, acetonitrile and acetylene, on the CNT forest morphology were also studied.

\subsubsection{CNT forests intercalated with metal films}

To further enhance energy dissipation for impact protection of structures, layered CNT forests intercalated with metal films were studied Boddu and Brenner 2016). Layered composite materials are often employed for impact protection and vibration damping (Han and Sun 2001). CNTs are an excellent candidate for these materials and have been employed in layered composite structures. In one study (Yamamoto, Thevamaran, and Daraio 2012; Thevamaran, Yamamoto, and Daraio 2012), CNTs were separated from their underlying substrate and assembled into a periodic structure with intercalated polycarbonate disks. Dynamic measurements were performed and it was found that the presence of CNTs improved the energy dissipation properties over the polycarbonate particles alone. The wave velocity was controllable with the precompression loading.

One group (Zhang et al. 2009) intercalated about 3000 layers of CNTs with exfoliated inorganic vermiculite. They found their composites to have high energy absorption and cushioning properties. Another group (Lattanzi et al. 2012) formed a sandwich composite out of a thin PDMS layer and bucky paper with a CNT forest in the middle. They found a decrease in the stress level with time and an increase in stress with increasing strain. Furthermore, the presence of the polymer on the top and bottom surfaces 
of the CNT forest resulted in zigzag buckles that were driven outward. When these sandwiches are stacked into multilayer structures, the polymer film reinforces the CNT forests (Misra et al. 2011). They found that the stiffness was higher for a four layer stack compared to a single layer and that the four layer structure reached a lower maximum stress for the same strain. The dynamic response revealed a lower peak force as the number of layers was increased from one to four . Raney et al. (2011) investigated the modeling of CNT forests intercalated with copper foils as a series of springs with masses.

Many of these experiments that have investigated the mechanical properties of multilayered CNT composites use nonanchored metal, polycarbonate material, or a compliant polymer as the intercalated material. These loose foils are thick and transfer stress well, but are not anchored to the CNT tips for added strength while the polymer anchors the CNTs; consequently, due to its low stiffness, it is not as good for stress transfer.

However, few studies have investigated the mechanical properties of a multilayered CNT forests with intercalated and anchored hard materials such as a metal film. This work investigated how the number of layers and type of metal impact the energy dissipation and cushioning under quasi-static compressive loading to strains of 0.7. The energy density is relatively independent of metal and layer number while fracturing is reduced with thicker metal coating and a larger number of layers. All samples show exceptional energy dissipation properties and a large recovery after compression.

\subsubsection{CNT forests with glass fibers}

The principal role of glass fibers are to serve as reinforcements that provide mechanical strength, stiffness, and improved thermal expansion of composites (Strong and Ploskonka 2008). Glass fiber reinforced polymer (GFRP) composites have excellent mechanical properties; they are lightweight and have high Young's modulus, strength, stiffness, toughness, interlaminar shear strength. These composites are used in a wide variety of structural applications including aerospace, automotive, civil, and the sporting industry (Strong and Ploskonka 2008; Khan Kim 2011; Padaki et al. 2008; Lannucci and Willows 2007). CNTs can be added to these GFRP composites as reinforcement agents (Khan Kim 2011; Chou et al. 2010; Zeng et al. 2010; Askari and Ghasemi-Nejhad 2012; Garcia et al. 2008; Sun et al. 2009; Pandya and Nail 2015) due to their high modulus, large buckling and fracture strains, large strength, and low density (Treacy, 
Ebbesen, and Gibson 1996; Wong, Sheehan, and Lieber 1997; Falvo et al. 1997; Arash, Wang, and Varadan 2014). The addition of CNTs also provides other improved properties of composites such as electrical conductivity, thermal conductivity, wear resistance, and electromagnetic shielding (Chou et al. 2010; Ma, et al. 2010; Thostenson, Reng, and Chou 2001; Baughman, Zakhidov, and de Heer 2002; Li et al. 2006; Chen et al. 2014).

A variety of methods exist to incorporate CNTs into a composite to improve the composite's mechanical properties. Most of them involve some method of mixing or dispersing CNTs in the resin and then using this mixture as the matrix element in the composite. This method has some drawbacks including CNT alignment, dispersion, and adhesion of the CNTs in the polymer matrix (Thostenson, Reng, and Chou 2001; Ajayan and Tour 2007; Coleman et al. 2006; Thostenson, $\mathrm{Li}$, and Chou 2005). A more recent approach is to grow CNTs directly on the fabric material so that the CNT nano-reinforcements are anchored on the fiber surface. The first experiments were done using a CVD technique where CNTs were grown on carbon fibers (Thostenson et al. 2002). This method has the potential to increase the fiber-matrix interfacial adhesion (Lachman et al. 2013), improve the composite interlaminar shear stress, and improve the toughness. The CNTs at the fiber/matrix interface also stiffen the matrix material and increase the reinforcement surface area; both of these properties result in improved stress transfer.

To achieve these beneficial properties, high quality CNTs must be grown on the glass fiber surface under conditions that do not deteriorate the mechanical properties of the fibers themselves. Thus, low temperatures are needed to minimize damage done to the growth substrate. To achieve this, this work used a two-zone furnace, in which the first zone is used for the decomposition of the carbon source and catalyst, and the second zone is used to preheat the substrate (Nessim et al. 2011; Takeda et al. 2005; Lee et al. 2001).

\subsection{Objective}

The objective of this work was to explore the effect of process parameters on the energy dissipation and other mechanical properties of forests of carbon nanotubes grown on various substrates. 


\subsection{Approach}

The objective of this work was achieved through the following activities:

1. Vertically aligned CNT forests were synthesized under the same conditions using three different carbon sources: $m$-xylene, toluene, and benzene. The CNT forests were grown using the floating catalyst chemical vapor deposition (FC-CVD) method with ferrocene as the catalyst source. The diameters and average number of walls of the individual CNTs fabricated from each carbon source were measured for each carbon source.

2. The structure of each forest was observed using scanning electron microscope (SEM) images to verify that the carbon precursors with more substituted benzene derivatives result in CNT forests with a larger entangled structure. Stress vs. strain was measured in compression to correlate the structure of the forests to their mechanical properties.

3. Vertically aligned CNT forests were synthesized and separated from their underlying Si substrate. Various metals including Ag, Fe, and In were deposited on the top and bottom of these CNT forests by paste, sputtering, and thermal evaporation, respectively. Stacks of one, two, and three of these metalized CNTs were arranged and compressed to explore their mechanical properties. These were then compared to nonmetalized CNTs stacks.

4. Results were analyzed, conclusions were drawn, and recommendations were formulated for further work.

\subsection{Mode of technology transfer}

This report will be made accessible through the World Wide Web at URL: http://libweb.erdc.usace.army.mil 


\section{Materials and Methods}

\subsection{CNT specimen preparation for morphology study}

The CNTs were fabricated using the well-established FC-CVD method (Seah, Chai, and Mohamed 2011; Andrews et al. 1999) on silicon wafers (Wafer World, Inc., 100mm diameter, Type P Boron doped [100] orientation, Palm Beach County, FL) in a quartz reactor (2 in. [50.8mm] in diameter and 38 in. [965 mm] long). Ferrocene (98\%, Sigma Aldrich, St. Louis, MO) was dissolved in three different carbon precursor solvents: m-xylene (anhydrous $\geq 99 \%$, Sigma Aldrich, St. Louis, MO), toluene (Assay 99.9\%, Fisher Scientific, Fair Lawn, NJ), and benzene (99\% ACS reagent, Sigma Aldrich, St. Louis, MO). The concentration of ferrocene was $5 \%$ by weight. While the furnace (MTI GSL-1500x Furnace, Richmond, CA) was heated, the quartz tube was flushed with $\mathrm{N}_{2}$ (S.J. Smith Welding Supply, ultra-high purity, Davenport, IA).

Once the process temperature was reached, with the quartz tube tilted at a 2-degree angle to facilitate CNT growth on the Si surface and prevent clogging at the injection point, the precursor solution was pumped into the quartz tube using an Ismatec Ecoline pump (Wertheim, Germany) and the $\mathrm{H}_{2}$ (Specialty Gases of America, ultra-high purity 99.999\%, Toledo, $\mathrm{OH}$ ) gas flow was turned on. A heating tape was wrapped around the inlet portion of the quartz tube to preheat the gases to $150^{\circ} \mathrm{C}$ and to aid in the vaporization of the carbon source and ferrocene solution. After the growth was complete, the solution flow, $\mathrm{H}_{2}$ flow, and furnace power was turned off so the tube could cool to room temperature under the flow of $\mathrm{N}_{2}$ gas. All CNTs that grew on the sides or bottom of the silicon wafer were removed with a razor blade to prepare the sample for measurement and analysis. Figure 2-1 shows a schematic representation and photograph of the experimental setup for CNT synthesis. 
Figure 2-1. (a) Schematic of CNT synthesis (b) optical image of sample fabrication setup.

(a)

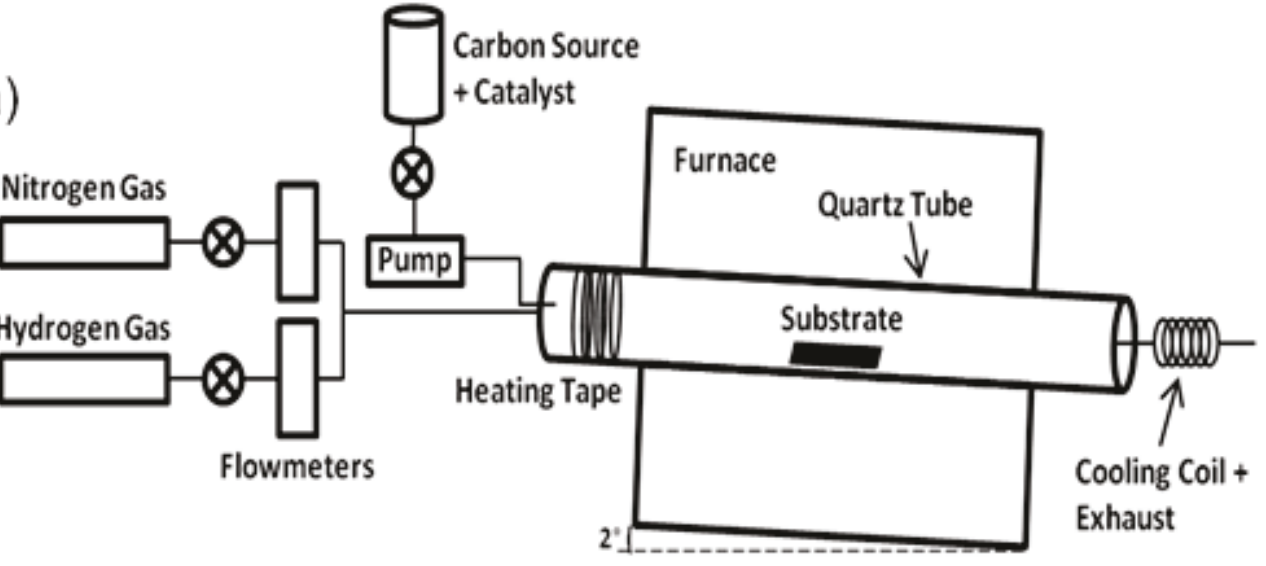

(b)

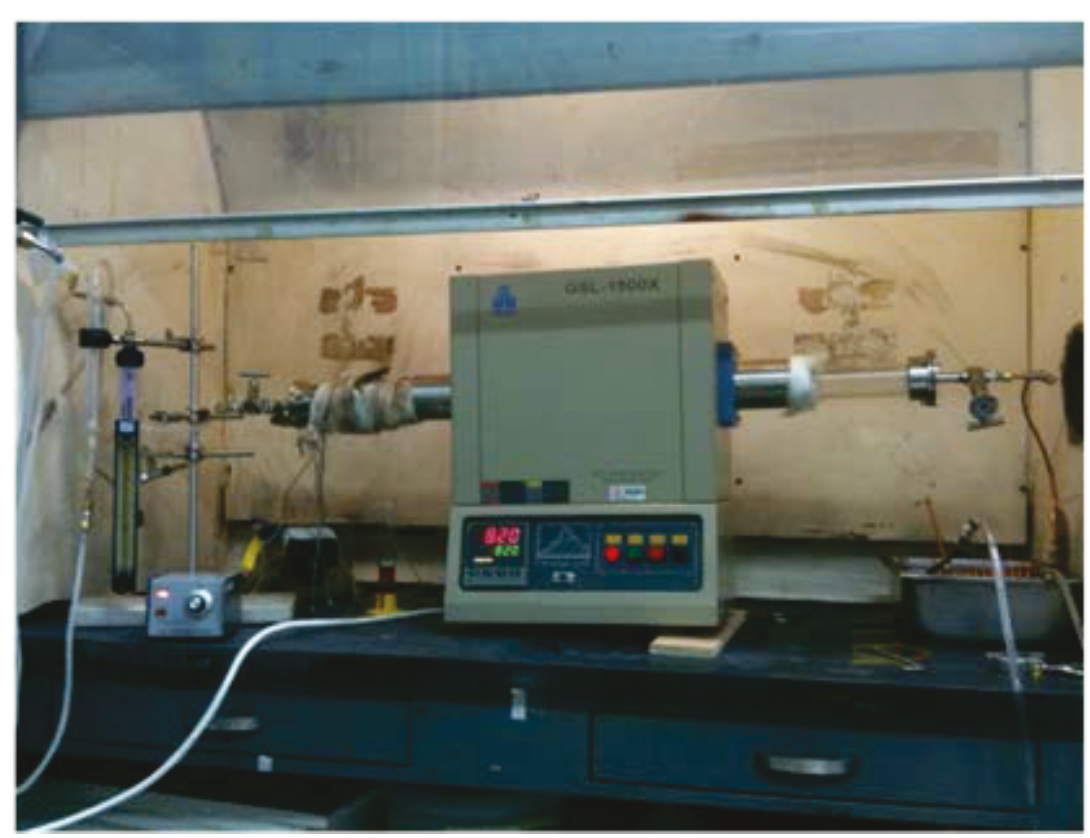

Since the properties of CNTs depend on various process parameters, the temperature, $\mathrm{N}_{2}$ flow rate, $\mathrm{H}_{2}$ flow rate, ferrocene catalyst concentration, carbon precursor/catalyst flow rate, and process time were all kept constant for each experiment involving a different carbon precursor. The process parameters used to achieve uniform and high quality growth of CNT forests using all carbon sources were:

$$
\begin{aligned}
\text { temperature } & =820{ }^{\circ} \mathrm{C} \\
\text { flow rate of } \mathrm{N}_{2} \text { gas } & =200 \mathrm{~mL} / \mathrm{min} \\
\text { flow rate of } \mathrm{H}_{2} \text { gas } & =200 \mathrm{~mL} / \mathrm{min} \\
\text { flow rate of precursor solution } & =16 \mathrm{~mL} / \mathrm{hr} \\
\text { concentration of ferrocene } & =5 \% \text { by weight } \\
\text { process time } & =60 \mathrm{~min} .
\end{aligned}
$$


Under these process parameters, consistent and repeatable growth of CNT forests has been achieved with all three carbon sources.

\subsection{Preparation of CNT specimen intercalated with metal films}

The individual CNTs forests to be used in the intercalated samples were fabricated using a method similar to that outlined above. The Si substrates were cut to a size of about $6 \times 60 \mathrm{~mm}$ and a $2.5 \%$ by weight solution of ferrocene dissolved in $m$-xylene was used as the carbon precursor. A heating tape was wrapped around the inlet portion of the quartz tube to preheat the gases to $300{ }^{\circ} \mathrm{C}$ and to aid in the vaporization of the carbon source and ferrocene solution. A process temperature of $800{ }^{\circ} \mathrm{C}$ was used and the flow rate of $\mathrm{H}_{2}$ gas, $\mathrm{N}_{2}$ gas, and the precursor solution were set to $200 \mathrm{~mL} / \mathrm{min}$, $400 \mathrm{~mL} / \mathrm{min}$, and $17-20 \mathrm{~mL} / \mathrm{hr}$, respectively. The process was run for 30 min. After the process time expired, the precursor solution and $\mathrm{H}_{2}$ flow were turned off while the $\mathrm{N}_{2}$ flow rate was set to $1000 \mathrm{~mL} / \mathrm{min}$ to flush the residual chemical species from the reactor. The CNT sample was left in this condition at $800{ }^{\circ} \mathrm{C}$ for $20 \mathrm{~min}$. This process served to weaken the bond of the CNT forest to the underlying Si substrate (Huang et al. 2010). Trace amounts of $\mathrm{O}_{2}$ in the reactor and etching from residual $\mathrm{H}_{2}$ indicate that the likely mechanism of this loosening effect was oxidation of the catalyst layer. After this time, the heating tape and furnace power were shut off so the tube could cool to room temperature under the flow of $\mathrm{N}_{2}$ gas.

CNTs primarily grew on the top surface on the Si substrate. The CNT layer was removed as an entire forest by sliding a thin razor blade between the CNT forest and the underlying Si substrate. Due to slight etching of the Fe catalyst layer, which was directly on top of the Si substrate, the CNT layer easily was removed intact with no damage (Figure 2-2). The CNT forest was then cut into approximately $6 \times 6 \mathrm{~mm}$ squares and weighed using a microbalance (Sartorius, Bradford, MA). Their densities were calculated according to:

$$
\rho=m / A t
$$

where:

$$
\begin{aligned}
\rho & =\text { the forest density } \\
m & =\text { the forest mass } \\
A & =\text { the cross-sectional area of the forest } \\
t & =\text { the forest thickness. }
\end{aligned}
$$


It is well known that the density, and therefore the mechanical properties, of a CNT forest grown using the FC-CVD method has a varying density as a function of length down the tube (Misra et al. 2011; Lattanzi et al. 2014). To account for this variation, the forests were grouped into three categories: Category I having densities between $\sim 0.078-0.087 \mathrm{~g} / \mathrm{cm}^{3}$; Category II having densities between $\sim 0.087-0.099 \mathrm{~g} / \mathrm{cm}^{3}$; and Category III having densities between $\sim 0.099-0.114 \mathrm{~g} / \mathrm{cm}^{3}$.

Three different metals including iron, indium, and silver were intercalated between CNT forest layers. A fourth set of samples included stacked CNT forests with no intercalation. This was used as the control sample to study the effect of the various metal layers on the mechanical properties of the multilayered samples. For each of the four sample types studied here, a stack of singled, double, and triple layered CNTs was assembled with the metal intercalated between each layer and on the bottom and top of the end layers (Figure 2-2). Three samples for each metal type and layer number were fabricated and measured, one from each density category.

Sputtering, evaporation, and metallic pastes were used to form the metal layers of the metal layer intercalated CNT forest samples. Metal was deposited on both faces of each individual 6x6-mm CNT forest layer. The iron layers were deposited using DC magnetron sputtering (AJA International Inc., North Scituate, MA). An iron thickness of $250 \mathrm{~nm}$ was deposited on each side of the CNT forest under an Ar pressure of $2 \mathrm{mT}$, a flow rate of $20 \mathrm{~mL} / \mathrm{min}$, and a power of $250 \mathrm{~W}$, which resulted in a deposition rate of $0.9 \AA / \mathrm{s}$. The indium layers were deposited using thermal evaporation.

The evaporation was processed using about $0.1 \mathrm{~g}$ of In (99.98-99.99\% pure, Kurt Lesker, Jefferson Hills, PA) placed in an aluminum oxide crucible surrounded by a tungsten crucible basket heater at a chamber pressure of less than $1 \times 10^{-5}$ Torr and a power of $1250 \mathrm{~W}$. An indium thickness of $250 \mathrm{~nm}$ was deposited on each side of the CNT forest. Finally, the silver layers were deposited using silver paste (SPI Conductive Silver Paste Plus, SPI Supplies, West Chester, PA). To form the 1-layer samples, a thin layer of Ag paste was applied to each side of the single layer CNT forest, which was dried in air at room temperature over a period of $24 \mathrm{hrs}$. To form the 2-layer samples, a layer of Ag paste was applied to the top of one CNT forest while another one was placed on top. 
Figure 2-2. Schematic and typical optical images of four combinations of multilayered stacks of CNTs with various metals.

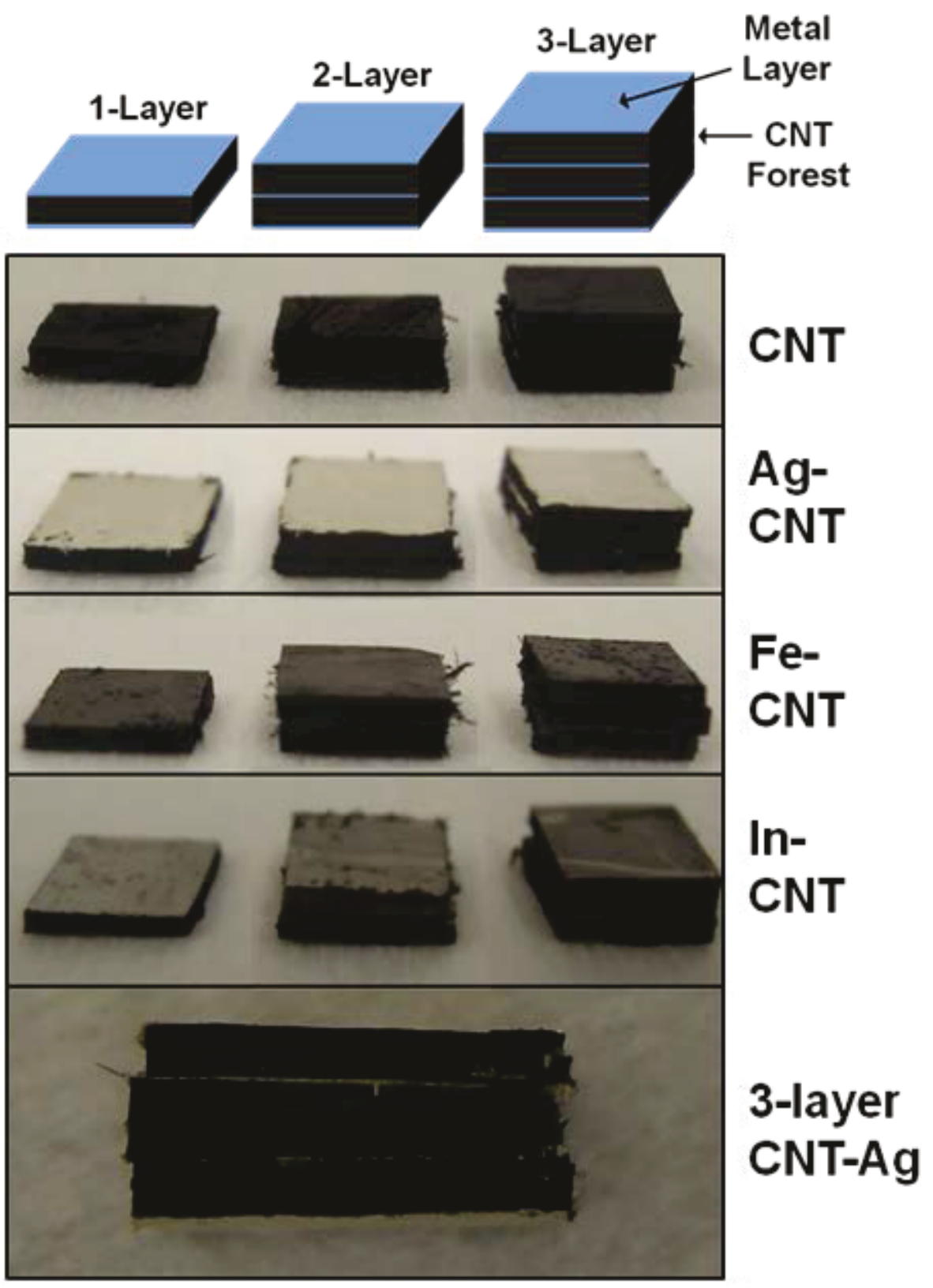

The samples were then compressed with $0.35 \mathrm{~N}$ of force and allowed to dry in air at room temperature for $24 \mathrm{hrs}$. The top and bottom surfaces of the 2layered samples were then coated in Ag paste and allowed to dry for $24 \mathrm{hrs}$ in the same manner as before. From the 3-layer Ag paste samples, the same process was followed as that used to form the 2-layer samples except an additional layer was added before curing. After the initial $24 \mathrm{hrs}$ cure at room temperature, all $\mathrm{Ag}$ paste samples were than cured at $90{ }^{\circ} \mathrm{C}$ for $20 \mathrm{~min}$ and $175{ }^{\circ} \mathrm{C}$ for $20 \mathrm{~min}$, per the manufacturers' recommendation. 


\subsection{Preparation of CNT specimen with glass fabric}

Forests of CNTs were grown on glass fibers woven into commercially available glass fabrics (Fiber Glast Development Corp., Brookville, $\mathrm{OH}$ ). The glass fabrics (GF) were used as the substrate for CNT growth. The GF sheet (Figure 2-3) is a plain weave fabric with $629 \times 551$ threads/m, a thickness of $0.36 \mathrm{~mm}$, a weight density of $339 \mathrm{~g} / \mathrm{m}^{2}$, and a measured fiber diameter of $8.9 \pm 1.1 \mu \mathrm{m}$. The GF material was chosen as the substrate for CNT growth due to its large surface to volume ratio, which results in a greater density of anchored CNT growth. The GF sheet contains a sizing component that is a coating over the surface of each glass fiber that adds strength and improves the adhesion to the resin system (Peipetis and Galiotis 1996, Yang and Pitchumani 2000). The sizing prevents the attached growth of CNTs on the surface of the glass fabrics. A desizing process (described below) was used on the GF to remove the sizing compound from the fabric surface.

The GF sheet was cut to a size of about $35 \times 35 \mathrm{~cm}$ and placed in a container that was filled with a $4 \%$ by wt. solution of hydrofluoric acid (KMG Electronics Chemical Inc. Houston, TX). After a 1 min wetting time, the fabric was gently rolled with a paint roller for 4 min to break up and loosen the sizing compound. The exposure to hydrofluoric acid served to both remove the desizing material and slightly etch the glass fiber to prepare its surface for CNT growth. The container was then agitated and the GF sheet was removed and rinsed with running tap water for about $5 \mathrm{~min}$. The GF sheet was then dried at room temperature for at least $12 \mathrm{hrs}$. The fabric was then trimmed to eliminate edge fraying and cut into rectangles with a size of $2.5 \times 7.5 \mathrm{~cm}$ for CVD synthesis. The fabrics were then soaked in a $50 \mathrm{~mm}$ solution of iron(III) nitrate $\left(\mathrm{Fe}\left(\mathrm{NO}_{3}\right)_{3} \cdot 9 \mathrm{H}_{2} \mathrm{O}\right)$ dissolved in 2-propanol for 5 min to deposit Fe catalyst (Yamamoto et al. 2009) directly on the surface of the GF sheet. The fabrics were then placed horizontally on a drying rack for at least $24 \mathrm{hrs}$ to dry.

The GF samples were then loaded into a quartz tube that was in Zone 2 of the 2-zone furnace. Figure 2-3(a) shows the entire CNT synthesis setup. After the entire system was flushed with over $1000 \mathrm{~mL} / \mathrm{min}$ of $\mathrm{N}_{2}$ gas for at least $5 \mathrm{~min}$, the preheating tape was set to $300{ }^{\circ} \mathrm{C}$ while Zone 1 was heated to a temperature of $T_{1}$ and Zone 2 was heated to a temperature of $T_{2}$. 
Figure 2-3. (a) Experimental setup used for CVD synthesis of CNTs on glass fibers, (b) Desized glass fabric used as the substrate for CNT synthesis.

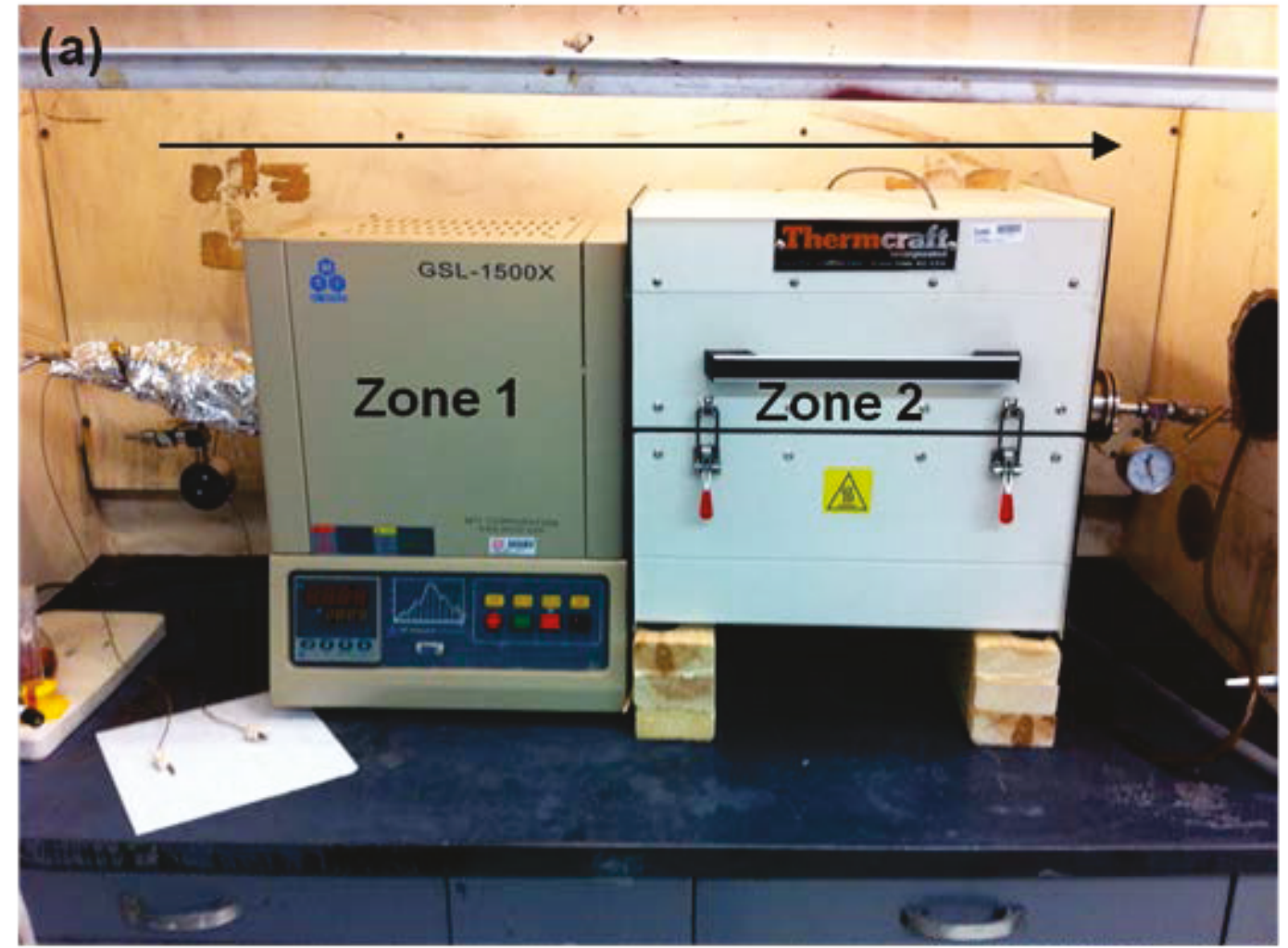

(b)

\section{1 in}

Once all temperatures were stabilized within $1{ }^{\circ} \mathrm{C}$ of the set temperature, the $\mathrm{N}_{2}$ and $\mathrm{H}_{2}$ flow rates were set to $200 \mathrm{~mL} / \mathrm{min}$ and $200 \mathrm{~mL} / \mathrm{min}$, respectively and the $2.5 \%$ by weight solution of ferrocene in $m$-xylene was pumped into the quartz tube at between $15-17 \mathrm{~mL} / \mathrm{hr}$ for a total process time of $60 \mathrm{~min}$. The preheating vaporized the solution and the $\mathrm{N}_{2}$ and $\mathrm{H}_{2}$ carried it into heating Zone 1 . This zone was typically set to the higher temperature between the two zones and served the purpose of decomposing the $m$-xylene and ferrocene, which was then carried into Zone 2 where the actual CNT synthesis occurred on the GF substrate. Zone 2 was fixed at a lower temperature than Zone 1 to minimize damage to the GF substrate. At first, $\mathrm{T}_{1}$ was set to $800{ }^{\circ} \mathrm{C}$ while $\mathrm{T}_{2}$ was varied between 515 and $665{ }^{\circ} \mathrm{C}$ 
to determine the minimum temperature CNTs would grow with a $\mathrm{T}_{1}$ value of $800{ }^{\circ} \mathrm{C}$. Then, with $\mathrm{T}_{2}$ set to $540{ }^{\circ} \mathrm{C}$ near the cutoff temperature for CNT growth, $\mathrm{T}_{1}$ was varied between 500 and $900{ }^{\circ} \mathrm{C}$ to determine how $\mathrm{T}_{1}$ affects the quality and morphology of the resulting CNT forests grown on the glass fibers.

\subsection{Gathering stress vs. strain data using an Instron single column testing system}

The stress vs. strain data for the morphology study were obtained using an Instron 3342 Single Column Testing System (Norwood, MA) in compression mode. The measured samples, which consisted of the base Si wafer with the as grown CNT forest on top, had in-plane dimensions of about $1 \times 1$ in. (25x25 mm). The sample was placed near the center of the wide bottom platen without being confined to the surface. The top compression surface was a cylindrical stainless steel platen machined to dimensions of $5 \mathrm{~mm}$ in length and $1 \mathrm{~mm}$ in diameter. The top platen was slowly lowered until it contacted the top CNT forest surface (using a force limit of approximately $0.001 \mathrm{~N}$ ) somewhere near the middle of the forest. The sample was then compressed at a rate of $2 \mathrm{~mm} / \mathrm{min}$, at the same location, for 12 cycles while measuring force vs. displacement. Figure 2-4 shows the measurement schematic.

Figure 2-4. Experimental setup used for measuring the force vs. displacement of the three types of CNT forests grown on Si wafers, each fabricated with a distinct carbon precursor.

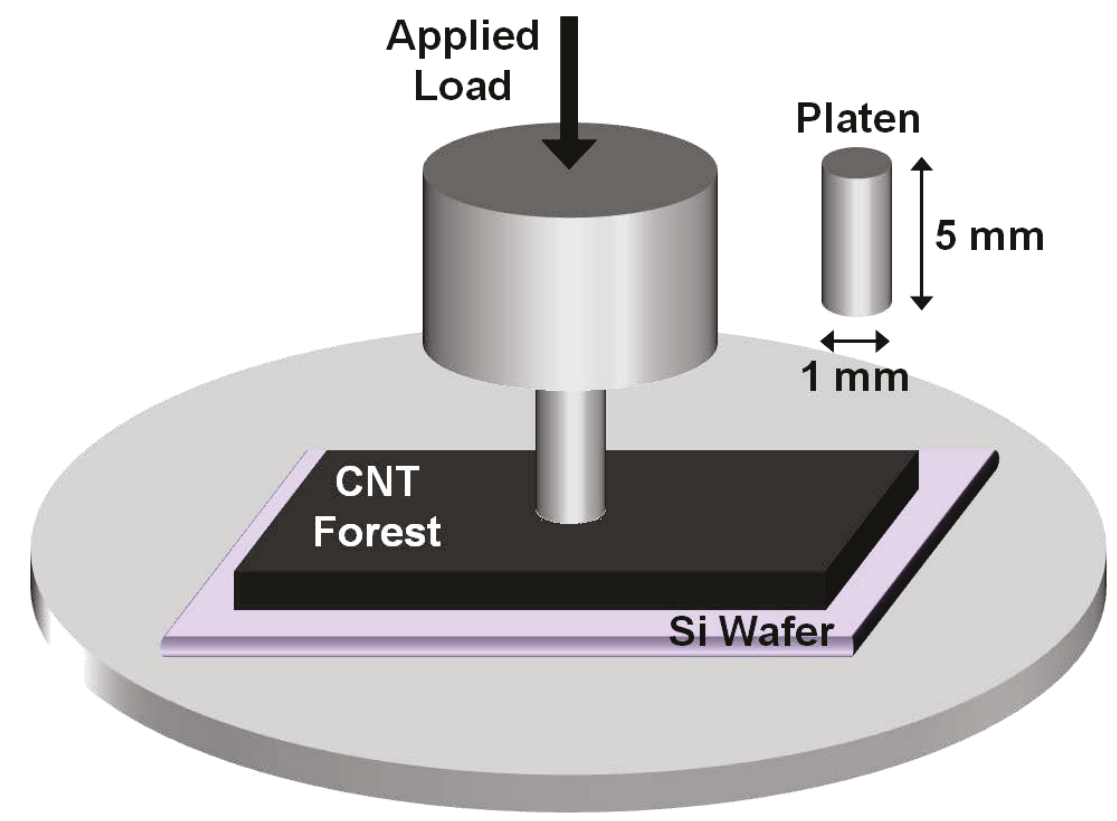


Figure 2-5. Optical image of Instron column used to measure stress vs. strain curves.

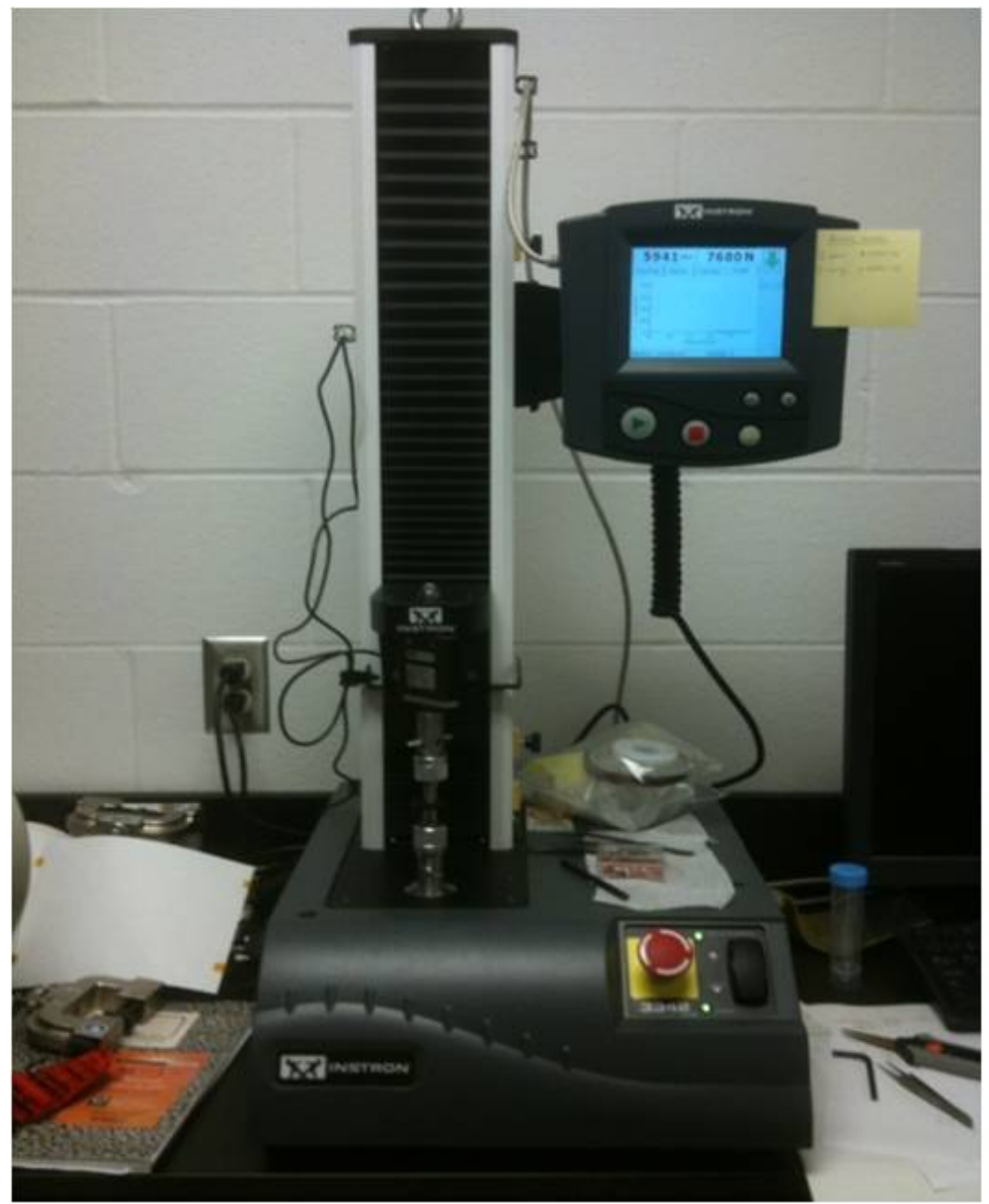

The stress vs. strain data for the CNT forests intercalated with metal films were also obtained using an Instron 3342 Single Column Testing System (Norwood, MA) in compression mode (Figure 2-5). The measured samples had in-plane dimensions of about $6 \times 6 \mathrm{~mm}$. The sample was placed near the center of the wide bottom platen without being confined to the surface. The top compression surface was a cylindrical stainless steel platen machined to a diameter of $25 \mathrm{~mm}$. The top platen was slowly lowered until it contacted the top CNT forest surface (using a force limit of approximately $0.1 \mathrm{~N}$ ). The entire sample was then uniformly compressed at a rate of $1.5 \mathrm{~mm} / \mathrm{min}$ for five cycles while measuring force vs. displacement. Figure 2-6 shows the measurement schematic. 
Figure 2-6. Experimental setup used for measuring the force vs. displacement of the multilayered CNT forests.

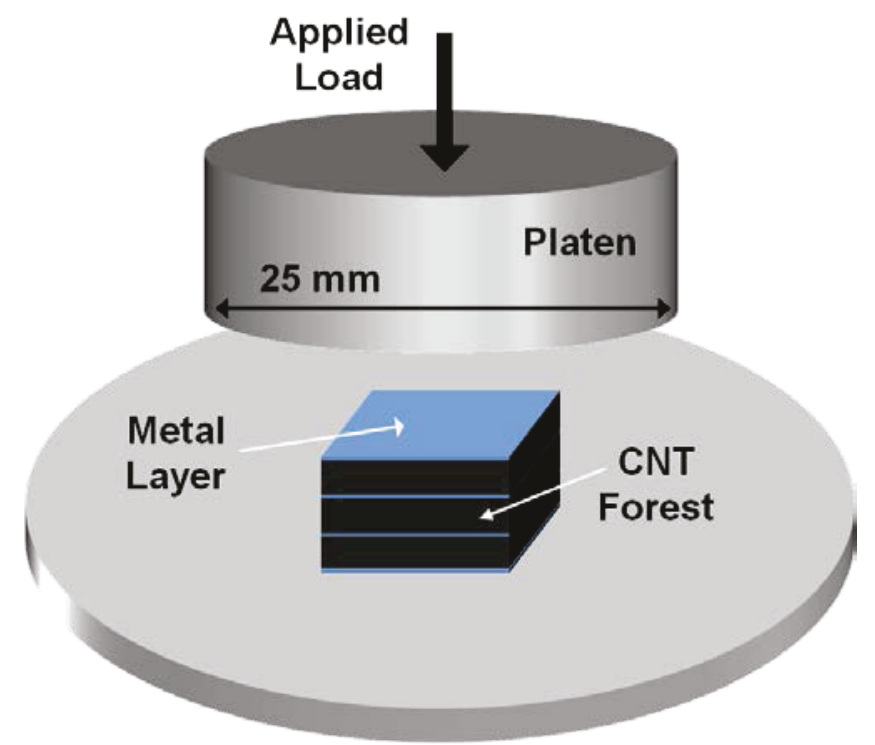

\subsection{Determining CNT structure via scanning electron microscopy}

SEM images were obtained with the Hitachi S480o High Resolution SEM to visually determine the CNT macrostructure, forest height, average nanotube diameter, and forest quality. The JEOL JSM 6390 SEM (JEOL USA Inc., Peabody, MA ) was used to characterize the buckling and plastic deformation resulting from the compression experiments. Both of these SEMs were used to visually determine the CNT macrostructure, forest height, average nanotube diameter, and forest quality of the intercalated samples. The SEM images were also used to characterize the buckling and plastic deformation resulting from the compression experiments for these samples.

\subsection{Determining CNT properties via transmission electron microscopy (TEM)}

The wall spacing, wall number, and nanotube quality were determined from TEM images using the JEOL $2010 \mathrm{~F}$ (S) TEM. The TEM samples were prepared by first scratching off a small sample of the CNT forest and then sonicating it in isopropanol (Reagent ACS, Acros, New Jersey) for 5 min to separate the nanotubes. One drop of the solution was then placed on a Lacey Formvar/Carbon 200 mesh copper TEM grid (Ted Pella Inc., Redding, CA) and allowed to dry in air for a minimum of $24 \mathrm{hrs}$. 


\section{Results and Discussion}

\subsection{Control of CNT morphology and energy dissipation using process parameters}

\subsubsection{Synthesis from aromatic carbon precursors}

The growth of CNTs occurs under a variety of process conditions that can affect the purity, length, width, yield, and alignment of the resultant CNTs. It is therefore important to establish a sufficient set of process parameters tuned to produce CNTs suitable for study. The goal of this work was to produce strong and resilient, vertically aligned CNTs using each of three carbon sources while exactly maintaining the process conditions of temperature, $\mathrm{N}_{2}$ flow rate, $\mathrm{H}_{2}$ flow rate, ferrocene catalyst concentration, carbon source/catalyst flow rate, tilt of tube, process time, catalyst material, and other process conditions.

A range of parameters has been tried to accomplish this goal. When processing with m-xylene at temperatures between 875 and $940{ }^{\circ} \mathrm{C}$, CNTs did grow, but additionally, a large amount of amorphous carbon grew that decreased with a reduction in temperature. This effect has been observed in the literature (Vander Wal, Ticich, and Curtis 2000) and is a result of the noncatalytic decomposition of m-xylene. At temperatures between 700 and $820^{\circ} \mathrm{C}$, vertically aligned forests of CNTs were observed to grow. Over a growth period of $60 \mathrm{~min}$, the total length of CNTs increases continuously over this range of temperature indicating that the growth rate also continuously increases.

The flow rate of the carrier gas affects the residence time of the carbon source in the process zone of the quartz tube and thus has an effect on the rate and the resultant length of the CNT forest over a period of time. Total flow rates of $\mathrm{N}_{2}$ and $\mathrm{H}_{2}$ have been used, up to $2700 \mathrm{~mL} / \mathrm{min}$, which result in shorter forests compared with a slower flow rate of $400 \mathrm{~mL} / \mathrm{min}$ under the same conditions. It is expected that, for these same conditions at sufficiently lower flow rates, the growth rate and the total height of the forest should begin to decrease.

The CVD reaction or process time also controls the height of the CNT forests. Process times between 45 and 90 min were tried. In this range, the $\mathrm{CNT}$ forests are longer at greater processing times. As longer process times 
are used, it are expected that the height of the forest should saturate due to the inability of the vapor species to diffuse through the forest to generate further growth. The catalytic concentration is expected to change the diameter of the nanotubes since a higher concentration should result in larger catalytic particles and thus larger nanotubes. Based on these investigations, the optimum process parameters to achieve uniform and high quality growth of CNT forests using all carbon sources are:

$$
\begin{aligned}
\text { Temperature } & =820^{\circ} \mathrm{C} \\
\text { flow rate of nitrogen gas } & =200 \mathrm{~mL} / \mathrm{min} \\
\text { flow rate of hydrogen gas } & =200 \mathrm{~mL} / \mathrm{min} \\
\text { flow rate of solution } & =16 \mathrm{~mL} / \mathrm{hr} \\
\text { concentration of ferrocene } & =5 \% \mathrm{by} \text { weight } \\
\text { process time } & =60 \mathrm{~min} .
\end{aligned}
$$

Under these process parameters, consistent and repeatable growth of CNT forests has been achieved with all three carbon sources.

The growth occurs from iron catalyst particles that form on the substrate as it is heated. Carbon atoms then diffuse through the particle to form the CNT. As more carbon diffuses through the catalyst particle, the CNT begins to grow upwards in a root-based growth mechanism. More iron from the injected ferrocene diffuses to the base of the forest and forms new catalyst nanoparticles, which allows the growth to continue despite the older catalyst particles becoming deactivated by various means such as amorphous carbon encapsulation.

This root-growth behavior (as opposed to top-growth) can be verified by a repeated CVD process with different process times (Li et al. 2005). It can also be verified by releasing the solution of ferrocene dissolved in a carbon source for fixed time then restricting the flow to zero and holding it at this value for a set time. Growth can be reinitiated by resuming flow of the solution. Ferrocene dissolved in $\mathrm{m}$-xylene was pumped into the quartz tube allowing CNT growth for a duration of $45 \mathrm{~min}$, under the same process parameters detailed above. At the end of this period, the flow was shut off for $15 \mathrm{~min}$ and then resumed for $15 \mathrm{~min}$ more. After scratching a narrow section of CNT off the Si substrate and imaging the cross-section of the CNT forest using a SEM, a clear line of separation between the 45 and $15 \mathrm{~min}$ periods of growth can be observed. The line occurs at a height of approximately $1 / 4$ the maximum height of the forest indicating that bottom-growth is taking place since the rate of growth is nearly linear in this regime. 
At the end of the CVD process time, some residual iron atoms coalesce on the top of the CNT forest. At higher process temperatures, spaghetti-like ropes of tangled CNTs grow from these clusters of iron (Cao et al. 2001). To reduce this effect, at the termination of CNT processing, a high flow rate of nitrogen is introduced to flush the tube of residual chemical species. The alignment of the top few microns on the surface of the forest is noticeably less aligned than at the lower section. This is because as the CNTs begin to grow, their density is not high enough to force strong vertical alignment. Once the active catalytic site density (and thus the resulting CNT forest density) is high enough, the CNT forest becomes vertically selfaligned due to a reduction in special degrees of freedom and increasing van der Waals force. It is expected that, with a lower concentration of ferrocene, the vertical alignment achieved here would not exist. The van der Waals force also holds the forest together and facilitates the tendency of the CNTs in the forest to form tangled bundles thus affecting the CNT forest structure.

It was found that CNTs grew on all six sides of the silicon sample. This occurs because there are catalytic binding sites on all six surfaces. The growth rate was higher on the four sides of the silicon substrate than on the bottom surface because the four sides have a higher cross-sectional exposure to both the catalyst and the carbon source. The highest growth rate was always found on the top surface due to its high exposure to the catalyst and carbon source and its more nearly ideal surface roughness resulting in more catalytic binding sites. The CNTs that grew on the sides and bottom surfaces were removed by scratching them off with a razor blade so that only the CNTs on the top surface remained and were included in the analysis presented here.

The CNT forests fabricated with $m$-xylene and toluene resulted in aligned forests with heights greater than $1 \mathrm{~mm}$ and a compressible foam-like texture. The forests were firmly attached to the silicon wafer via the Fe catalyst layer. Forests grown from benzene, under the identical conditions, were less than $1 \mathrm{~mm}$ in height and were significantly softer and more easily damaged and had a noticeably weaker connection to the underlying silicon substrate. It is not surprising that the heights of the forests fabricated from each of the three aromatic chemicals are different because each compound will have a different pyrolization energy and thus different ideal temperatures to maximize carbon yield (Das et al. 2006). Due to the experimental 
setup and flow conditions, a slight height gradient in heights was observed on all samples.

The macro structure of the CNT forest including the overall height, quality, and macroscopic alignment of the CNT forests can be obtained using an SEM (Figure 3-1[a-c]). The heights of the CNT forests were measured at a tilt angle of 45 degrees by averaging three individual height measurements near the center of the sample at the same location that the mechanical measurements were conducted. The forests grown with $m$-xylene, toluene, and benzene grew to heights of 1159,1815 , and $579 \mu \mathrm{m}$, respectively. The CNT forests appear to be vertically aligned with high quality and minimal macroscopic defects. Figure 3-1(d-f) shows SEM images at higher magnification.

The CNTs resulting from $m$-xylene as the carbon source reveal a highly entangled yet still vertically aligned forest with small diameter CNTs, while the forest resulting from using toluene has slightly larger diameter tubes with less pronounced entanglement and thus a higher degree of vertical alignment.

The CNTs synthesized using benzene are even more vertically aligned and have much larger diameters. The vertical alignment of CNTs forests is primarily caused by van der Waals forces (Wu and Chang 2009), which tend to restrict the growth directions of CNTs by holding them together. The van der Waals forces between CNTs increase in strength with larger diameter tubes and thus the alignment is expected to be greater as well. This is consistent with the SEM images since the CNTs made with benzene have the largest diameter tubes and the highest degree of vertical alignment.

The CNT diameters of the tubes made with toluene and $m$-xylene decrease, respectively, and so do their respective alignments. This observation shows the consistency between the observed alignment from the SEM images and the average CNT diameter. The decomposition of the catalyst on the walls of existing CNTs can create branching CNT structures and impact the alignment. The SEM image shows that there is a pronounced increase in branching for the CNTs made with benzene, toluene, and $m$-xylene, respectively. There is also an observable bimodal distribution of CNTs for all carbon sources used, which is characteristic of CNTs fabricated at high temperatures where some of the catalyst particles that land on the CNT walls result in smaller diameter CNTs (Singh, Shaffer, and Windle 2003). 
Figure 3-1. SEM images of the side view of CNT forests at a tilt angle of 45 degrees fabricated with (a) $m$-xylene, (b) toluene, and (c) benzene,(d)-(f) SEM images of the CNT forests from (a)-(c) at a higher magnification showing the forest structure for CNTs made from

(d) $m$-xylene, (e) toluene, and (f) benzene.
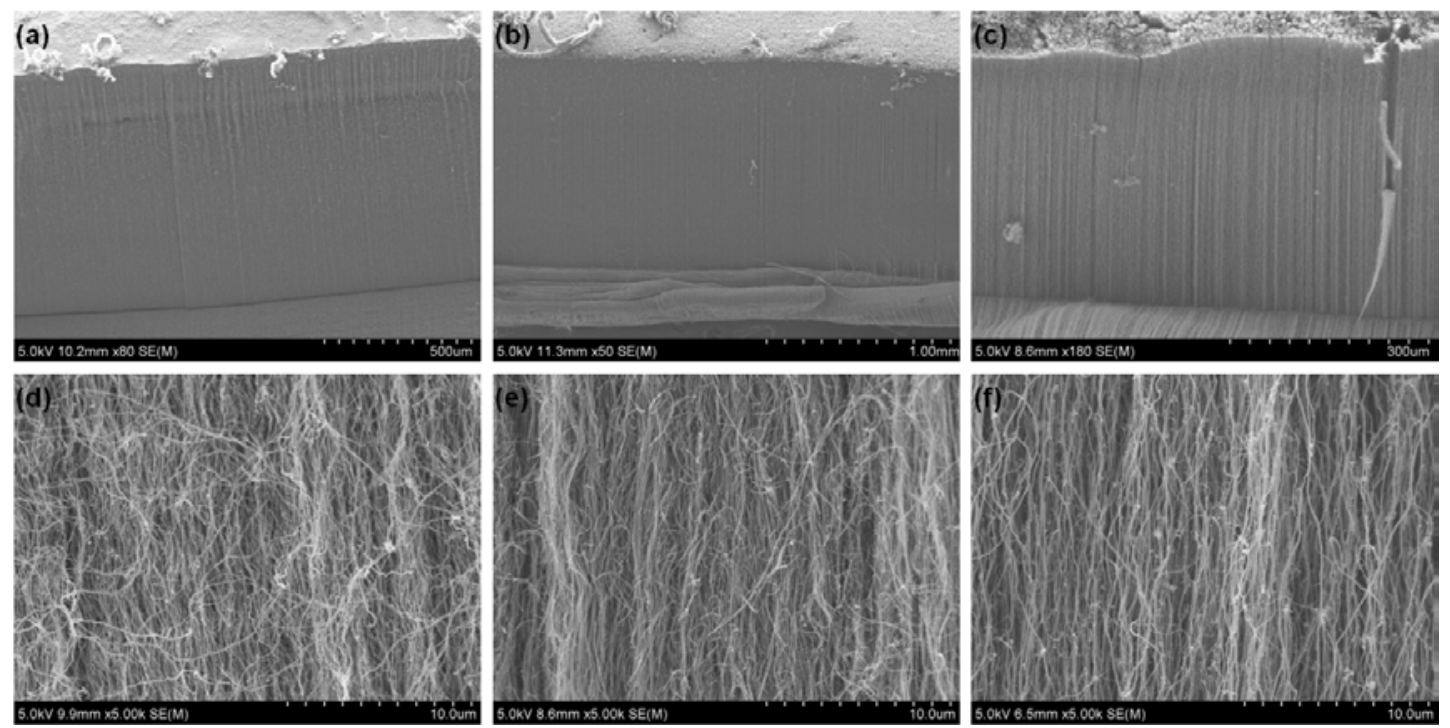

From a higher magnification SEM image, the diameters of the CNTs were measured (not including the smaller set of nanotubes from the bimodal distribution) near the center of the forest height for CNT forests from each carbon source. The average diameters of the CNTs made from $m$-xylene, toluene, and benzene are $57.2 \pm 14.8,60.9 \pm 22.3$, and $69 \pm 28.0 \mathrm{~nm}$, respectively. The growth rates or heights of the CNT forests can be understood as a function of the concentrations of the catalyst and the carbon source and the diffusion rates of these species through the CNT forest to its base. If these parameters were similar for all three carbon sources, then the final heights of the forests should be the same. Both an increase in entanglement and diameter would reduce the overall height of the CNT forest. Thus, it is the combination of the growth rate and the effects of the average diameter and alignment that determine the final forest height.

Figure 3-2 shows TEM images of representative CNTs synthesized using each carbon source. The images verify the quality and the wall structure of the individual CNTs. It is found that the CNTs are all multiwalled nanotubes (MWNTs) of high quality with a well-defined hollow inner core surrounded by concentric graphitic sheets forming concentric walls. Catalytic iron particles are located both on the surface and inside the CNTs fabricated from all three carbon sources (Figure 3-2[a-c.]) 
Figure 3-2. TEM images of CNTs fabricated with (a) $m$-xylene, (b) toluene, and (c) benzene, (d)-(f) TEM images of CNTs at a higher magnification showing a hollow inner core and wall structure for CNTs made with (d) $m$-xylene, (e) toluene, and (f) benzene.
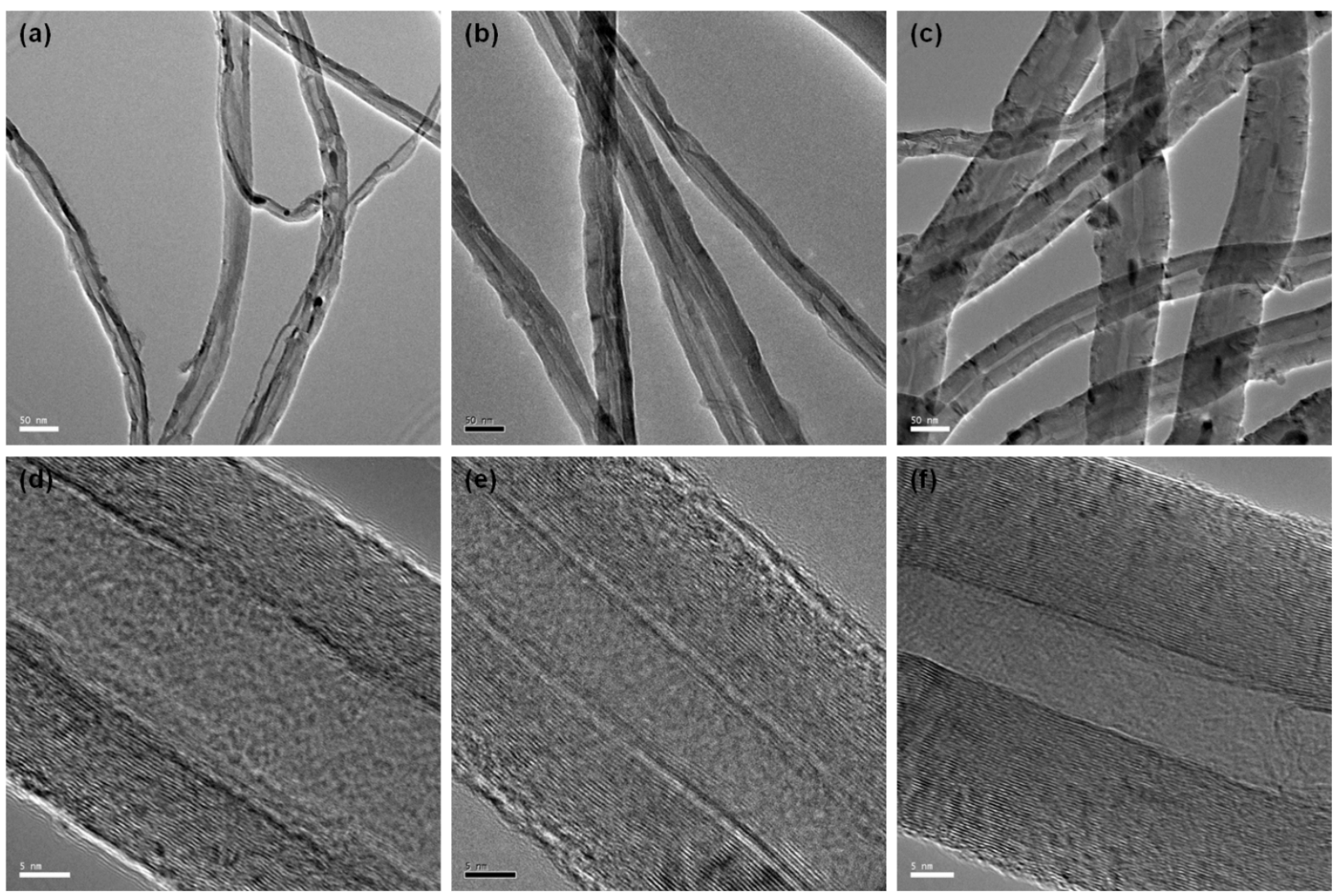

This is typical in the floating catalyst CVD method since both catalyst and carbon atoms are available to form the nanotube walls and to stick to the CNT wall surface. Since in the TEM sample preparation the CNTs have been sonicated to disperse CNTs, they do not retain their original configuration and no information regarding the alignment of the CNT forests can be obtained from the TEM images.

However, Figure 3-2(d-f) also show the integrity of the wall structure, which are representative images of CNTs made from each carbon source. The average number of walls that constitute the CNTs fabricated from the various carbon sources is measured from these representative images to be 39,41 , and 53 walls, for CNTs made using $m$-xylene, toluene, and benzene, respectively. This is consistent with the ordering of the CNT size based on the CNT diameter from the SEM images. Furthermore, the average wall spacing in each set of CNTs is consistent with typical wall spacing values found in the literature of about $0.35 \mathrm{~nm}$. 
The catalyst particle size and the chemical species in the surrounding environment play a role in determining the diameter of the CNTs. The catalyst particles can become deactivated as they become oxidized, or as amorphous carbon accumulates on them, blocking the diffusive path of free carbon. The presence of hydrogen is known to reduce the catalyst particle size at high temperature (Seah, Chai, and Mohamed 2011) and to reactivate it (Lee et al. 2003). The resulting measured average diameter and wall number of the CNTs fabricated with each carbon source is consistent with the amount of hydrogen expected to be present in each experiment. The flow rate of hydrogen sent through the quartz tube is $200 \mathrm{~mL} / \mathrm{min}$. An analysis of the aromaticity of the benzene and its substituted derivatives explains the differences in the amount of hydrogen released from the pyrolysis of each carbon source (Figure 3-3). The concentration of hydrogen released from the pyrolysis of the carbon source increases from benzene, to toluene, to $m$-xylene. As stated above, the diameter and number of walls of the CNTs synthesized from different carbon sources decreases from benzene, to toluene, to $m$-xylene. This shows that the environments with a higher concentration of hydrogen results in thinner diameter and lower wall number CNTs. The dominant factor controlling the average diameter and wall number in CNTs grown using these carbon sources is the catalyst particle size. This claim is further supported by observing no detectable amorphous carbon in the SEM images and small but similar levels of amorphous carbon in the TEM images between the three carbon sources.

Figure 3-3. Chemical structures of the catalyst ferrocene (top) and the three aromatic carbon precursors $m$-xylene, toluene, and benzene (bottom).
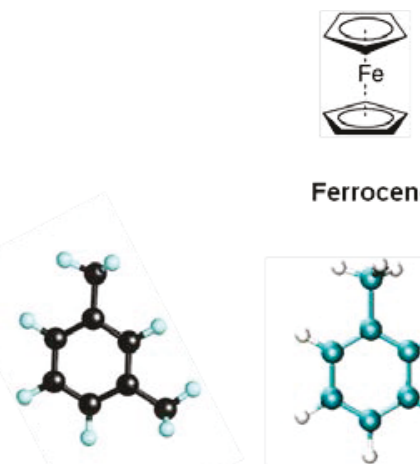

$$
\text { Ferrocene }
$$<smiles>Cc1cccc(C)c1</smiles>

$m$-xylene
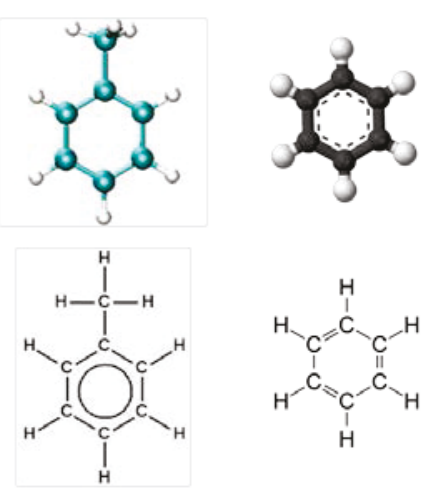

Toluene

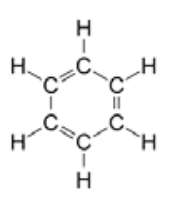

Benzene 
The mechanical properties of the CNT forests fabricated from each of the three carbon precursors is related to the structure of the CNT forest. As each forest is compressed, the axial force increases until either the direction of platen displacement reverses, or buckling or slippage of CNTs occurs. The slippage and plastic deformation of CNTs is most pronounced during the first cycle (inset of Figure 3-4[d-f]) where they are observed as jumps and kinks on the graph. It is the friction between individual CNTs and the buckling of bundles of CNTs that form by self-assembly that account for the large hysteresis in the stress vs. strain graph, which indicates the amount of energy dissipation, observed for the first cycles of all CNT forests studied. After this initial hardening, the remaining cycles show less hysteresis, indicating that less plastic deformation occurs, thus resulting in less energy dissipation compared to the first cycle. Plastic deformation still occurs with subsequent cycles, but it is believed that the proportion of energy dissipated due to frictional effects increases since the CNT forest has been hardened and the forest is denser, resulting in larger contributions of energy dissipation due to friction.

Figure 3-4. Stress vs. strain for CNT forests fabricated from $m$-xylene, toluene, and benzene, (a)-(c) Cycles 2-12 of the stress vs. strain diagrams of CNTs forests compressed to a strain of 0.25 , (d)-(f) Cycles 2-12 of the stress vs. strain diagrams of CNTs forests compressed to a strain of 0.67. Insets: the first cycle of the stress vs. strain diagrams of CNT forests compressed to a strain of 0.67 .
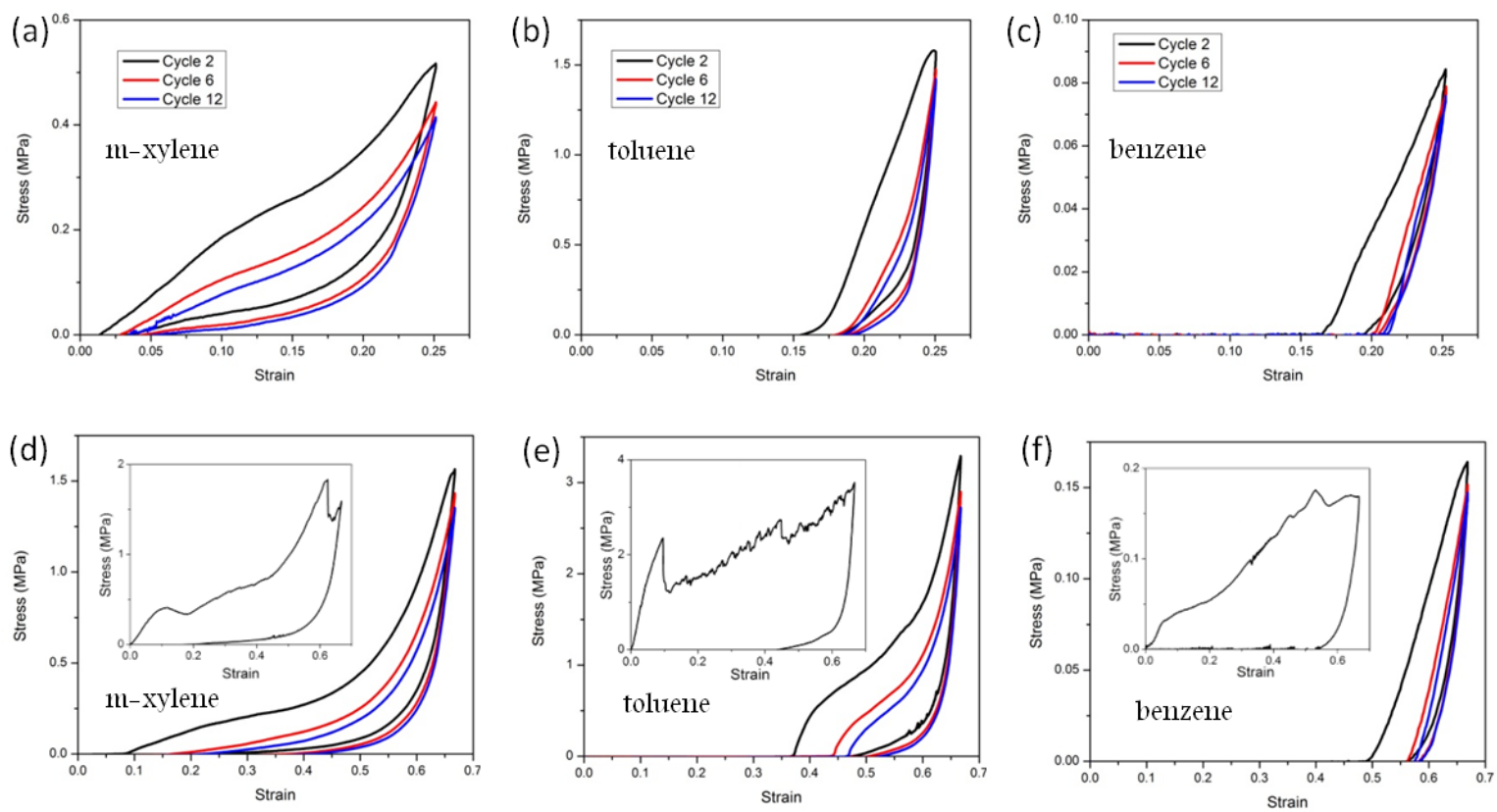
Furthermore, after 12 cycles, the restitution changes by less than $1 \%$ for CNT forests fabricated using each carbon precursor after 15 more cycles, but there is still significant energy dissipation. This indicates that, after many cycles, more energy is dissipated due to entanglement of the CNT forests.

Besides the kinks, jumps, and hysteresis observed in the stress vs. strain graphs, the strongest evidence for plastic deformation through buckling is the SEM image that shows the contrast between the "before" and "after" compressed CNT forests (Figure 3-5). It is clear from the images that, before the CNT forest is compressed, there is no visible buckling in any bundles of CNTs. Near the bottom at least approximately $100 \mu \mathrm{m}$ of the forest there is a noticeable change in overall forest structure. This is typical behavior of CNT forests believed to be related to the termination of the flow of carbon precursor and catalyst. Residual carbon source vapors continue to feed the CNT forest growth under changed conditions resulting in gradient of CNT structure near the bottom of the forest. It is near this interface that at least one major global buckle occurs for CNT forests fabricated from all three carbon precursors studied here. After just one compression cycle, major global buckling occurs for each forest fabricated from a distinct carbon source (see the right hand column of Figure 3-5). While individual CNTs do buckle, the SEM images show that these buckling events are coordinated and occur to whole bundles of CNTs bound together by the van der Waals forces.

The CNT forests synthesized from $m$-xylene showed a remarkable resilience in the compression tests. The forests were compressed to a strain of 0.25 at one location and to 0.67 at a different location (Figure 3-4[a] and [d,] respectively). For all samples, the first cycle shows considerable hysteresis and energy dissipation properties. The energy density (energy per unit volume) dissipated in each cycle is equal to the area enclosed by the cycle in the stress vs. strain diagram. However, only at high strain were sharp jumps in stress observed, which may be attributed to local buckling events (Machmann et al. 2011). The remaining cycles all showed remarkable restitution properties with considerably large energy dissipation. Through the $12^{\text {th }}$ cycle, the curves were smooth, indicating that there was negligible additional local buckling events after the first cycle. These forests dissipate energy well and their entangled structure gives them a more "spring-like" property that allows them to be compressed and rebound to nearly their original length. 
Figure 3-5. SEM images of CNT forests before and after compression at a tilt angle of 45 degrees for forests grown with carbon precursors: (a) m-xylene, (b) toluene, and (c) benzene. The left (right) column is before (after) the first compression cycle. Insets of (b): a zoomed in image at a tilt angle of 55 degrees showing multiple global buckling folds.

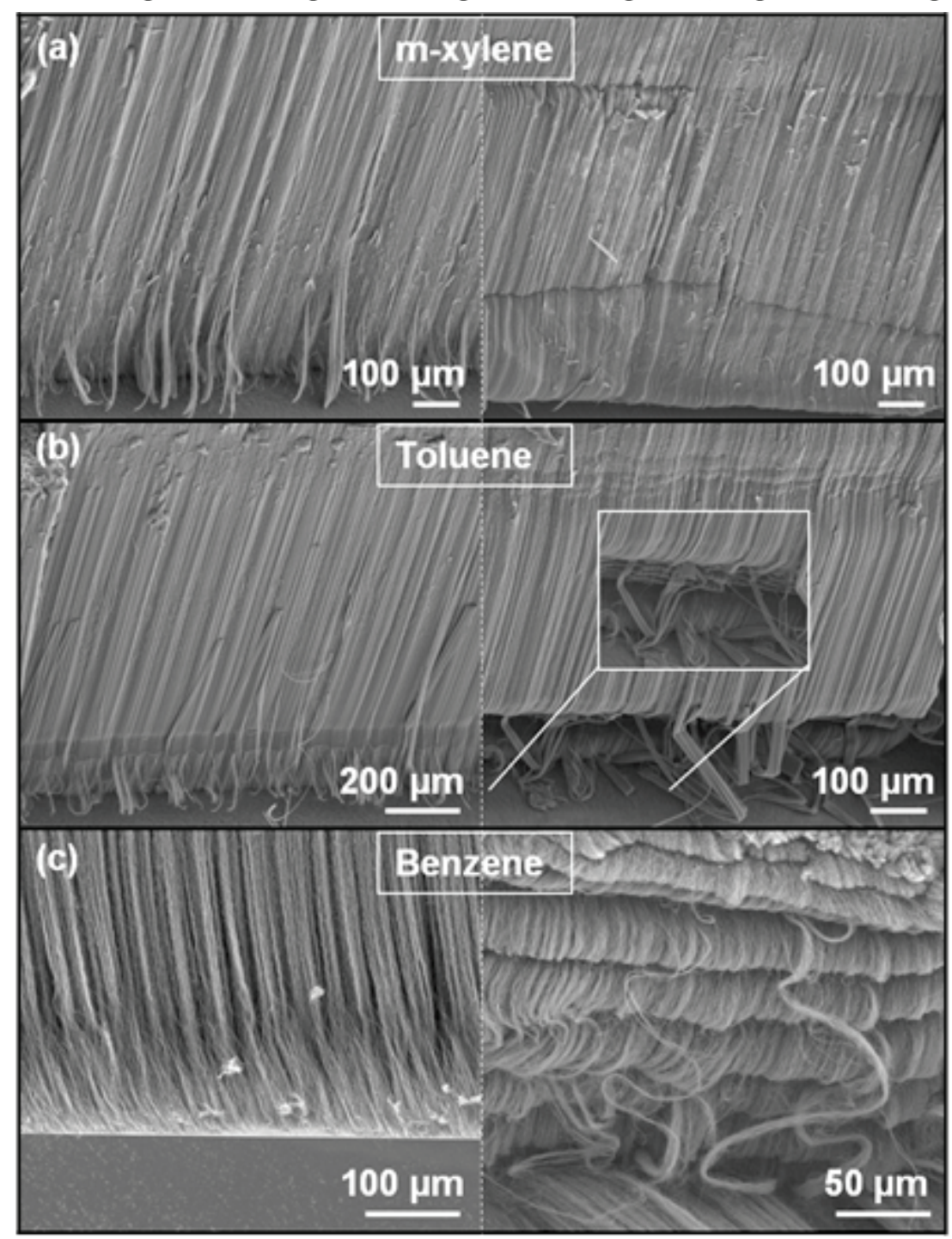

The first cycles of both the toluene and $m$-xylene CNT forests are similar, except there is a larger hysteresis in the toluene CNTs since they experience more buckling. The inset of Figure 3-4(e) shows this behavior as jumps in the stress at various strain values. This is due to a less entangled CNT structure where greater buckling occurs on the less compressible and straighter toluene CNTs. Due to some further plastic deformation, the height of the CNT forest is suppressed for the successive cycles (Figure 3-4[b,e]). However, in the toluene CNTs, a larger force is reached compared to the $m$-xylene CNTs for strains of both 0.25 and 0.67 , possibly as a result of greater CNT forest densification. This compensates for the loss in height to allow 
the toluene CNTs to have larger energy dissipation. The benzene CNTs showed a different behavior from the $m$-xylene or toluene CNTs. The benzene CNTs show a high degree of buckling (Figure 3-5[c]) and a low value of restitution (Figure 3-4[c,f]). Similar to the less entangled toluene CNTs, the first cycle of the benzene CNTs shows many jumps in the stress that are much smaller in magnitude than in the toluene case and difficult to see in the inset of Figure 3-4(f). As a result of the buckling, the benzene CNTs exhibit a large height reduction and a small energy dissipation per cycle.

At small strains such as $0.25, m$-xylene CNTs dissipate a higher energy density than both toluene and benzene CNTs after many cycles (Figure 36[a]). Initially, toluene CNTs have a higher energy density, but after further plastic deformation occurs with repeated cycling, they became less capable of dissipating energy. Benzene CNTs have the lowest energy dissipation at both 0.25 and 0.67 strain (Figure $3-6[a, b])$. At the higher strain of 0.67 , toluene has a higher energy density dissipation than both $m$-xylene and benzene. The $m$-xylene CNTs dissipate significantly more energy than the benzene CNTs. After 12 cycles, the CNTs fabricated from $m$-xylene and toluene lose less than $5 \%$ of their energy per cycle at a strain of 0.25 and less than $3 \%$ of their energy per cycle at a strain of 0.67 .

Figure 3-6(c) and (d) plots the restitution of the CNT forests, which is defined as the ratio of the forest height after each cycle to the original forest height. The restitution is significantly higher for the $m$-xylene CNTs at both strains of 0.25 and 0.67 where the restitution is $96.4 \%$ and $77 \%$, respectively. This is indicative of its more entangled structure, which allows it to act like more like a spring and have a higher elasticity and less buckling and plastic deformation. The $m$-xylene CNTs are able to restore themselves more closely to their original height as there are fewer damaged CNTs (Figure 3-5[a]). Next to $m$-xylene CNTs, toluene CNTs have the next most entangled structure and also have the next highest restitution at both strains of 0.25 and 0.67 , a behavior that supports this conclusion. At a strain of 0.25 , the restitution of the toluene CNTs is $81.5 \%$ and at a strain of 0.67 , the restitution is $53.4 \%$. The benzene CNTs are the least entangled CNTs and thus experience the highest degree of buckling and plastic deformation (Figure 3-5). These CNTs have a low restitution of 79.1 and $41.9 \%$ at strains of 0.25 and 0.67 , respectively. 
Figure 3-6. Energy dissipation and restitution vs. cycle number for CNT forests fabricated from $m$-xylene, toluene, and benzene. (a) Energy dissipation plotted at $25 \%$ compression for the three carbon sources. (b) Energy dissipation plotted at $67 \%$ compression for the three carbon sources, (c) Restitution plotted for the three carbon sources at $25 \%$ compression, (d) Restitution plotted for the three carbon sources at $67 \%$ compression.
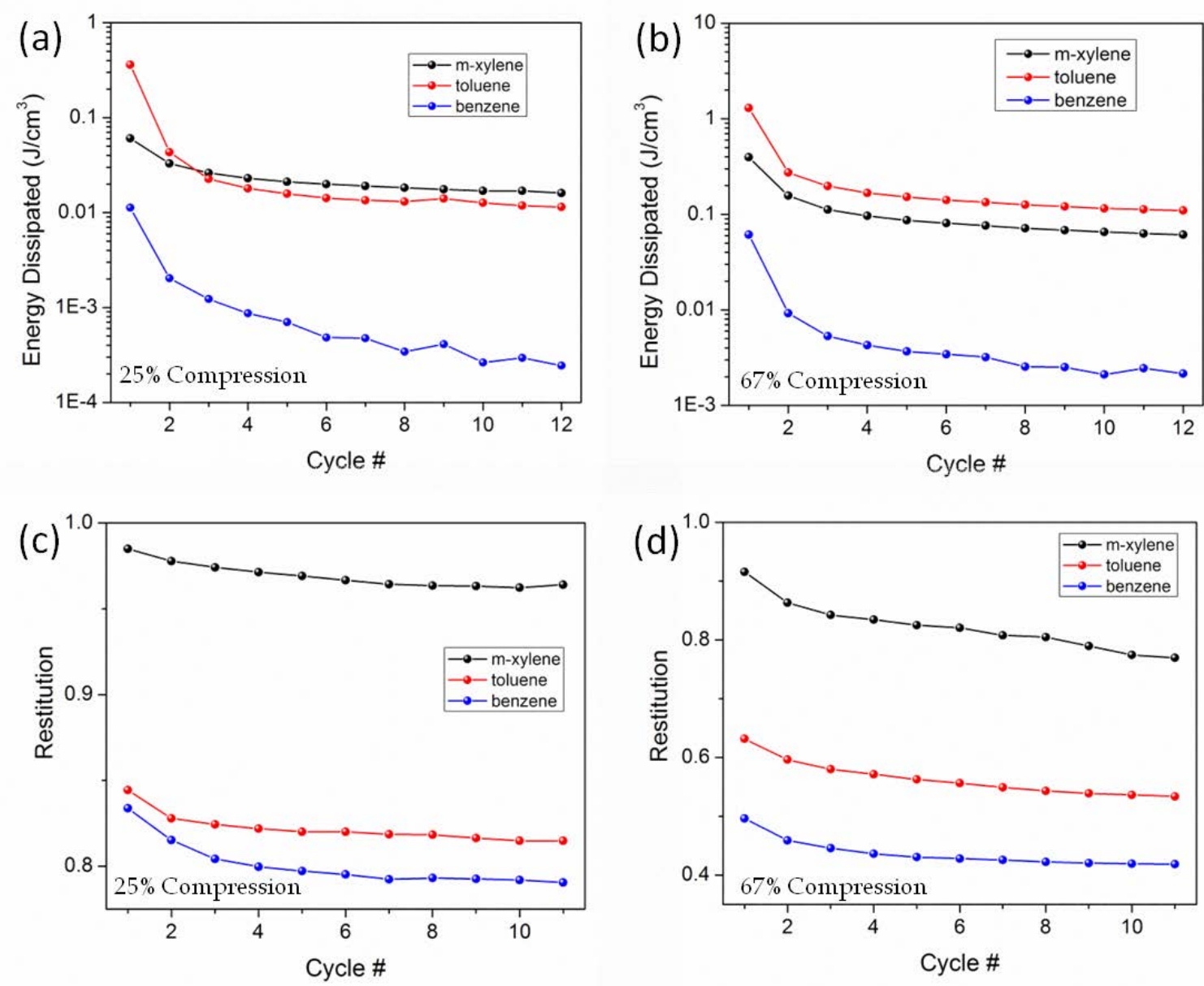

After cycling each forest 15 more times, the $m$-xylene, toluene, and benzene CNT forests each dropped a further $0.9 \%, 0.4 \%, 0.2 \%$, in restitution at a strain of 0.25 and each dropped a further $4.0 \%, 1.7 \%, 1.0 \%$, respectively, in restitution at a strain of 0.67 . Thus, after many more cycles, all CNT forests are still resilient.

\subsubsection{Synthesis from linear carbon precursors}

The synthesis of aligned forests of CNTs was also carried out using carbon precursors with a linear structure. Two linearly structured carbon precursors were used: acetonitrile and acetylene (Figure 3-7). The acetonitrile CNTs were grown at a temperature of $820{ }^{\circ} \mathrm{C}$ with a flow rate of $\mathrm{N}_{2}$ gas of $600 \mathrm{~mL} / \mathrm{min}$ and $\mathrm{H}_{2}$ gas of $200 \mathrm{~mL} / \mathrm{min}$. The process was run for $2.5 \mathrm{hrs}$ 
and used a total of $41 \mathrm{~mL}$ of $2.5 \%$ by weight solution of ferrocene in acetonitrile. Figure 3-8(a) shows the aligned forest of CNTs under different conditions in which significantly less carbon precursor and catalyst were used. Figure 3-8 (b and c) shows the resulting morphology of the grown CNTs. The results show a well aligned forest of CNTs with a remarkably linear morphology. Most of the CNTs fabricated under these conditions result in narrow CNTs with diameters mostly under about $20 \mathrm{~nm}$. These diameters are below those fabricated using similar process parameters but $m$-xylene as the carbon precursor.

The synthesis of aligned forests of CNTs was also carried out using acetylene as the carbon precursor. The acetylene CNTs were grown at a temperature of $820^{\circ} \mathrm{C}$ with a flow rate of $\mathrm{N}_{2}$ gas of $400 \mathrm{~mL} / \mathrm{min}$ and $\mathrm{H}_{2}$ gas of $100 \mathrm{~mL} / \mathrm{min}$. The process was run for $60 \mathrm{~min}$ and used an acetylene flow rate of $5 \mathrm{~mL} / \mathrm{min}$. In this case, the floating catalyst injection method was not used since the acetylene was delivered in a gas form. To deposit a Fe catalyst layer, once the process temperature was reached under the flow of $\mathrm{N}_{2}$ gas, the inlet portion of the quartz tube was loaded with $2 \mathrm{~g}$ of ferrocene and heated to $240^{\circ} \mathrm{C}$ over about $5 \mathrm{~min}$. This vaporized the ferrocene, which was then carried into the hot zone of the furnace by the $\mathrm{N}_{2}$ gas where it decomposed and was deposited on the Si substrate surface. After this, the $\mathrm{H}_{2}$ and acetylene were turned on to begin the process.

Figure 3-7. Chemical structures of two linear molecules: acetonitrile and acetylene used as carbon precursors for the CVD synthesis of CNTs.
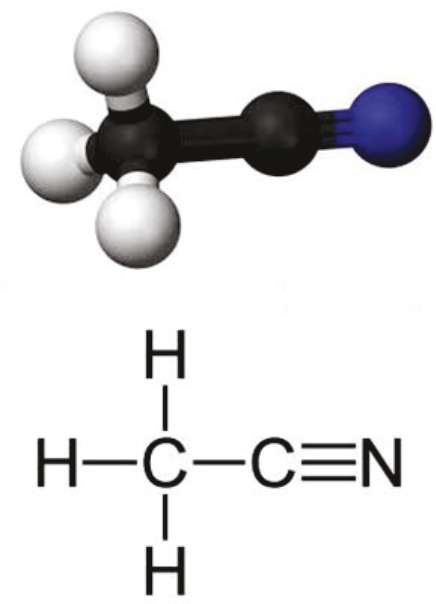

Acetonitrile
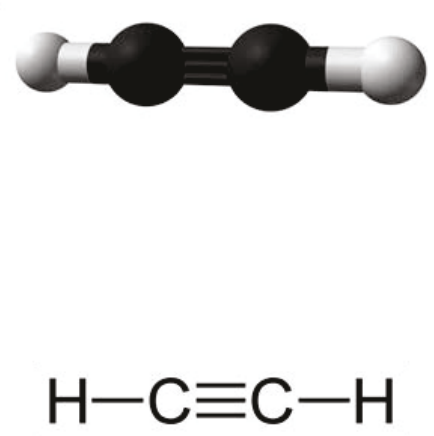
Figure 3-8. SEM images of CNTs grown with acetonitrile as the carbon precursor.

\section{Acetonitrile}
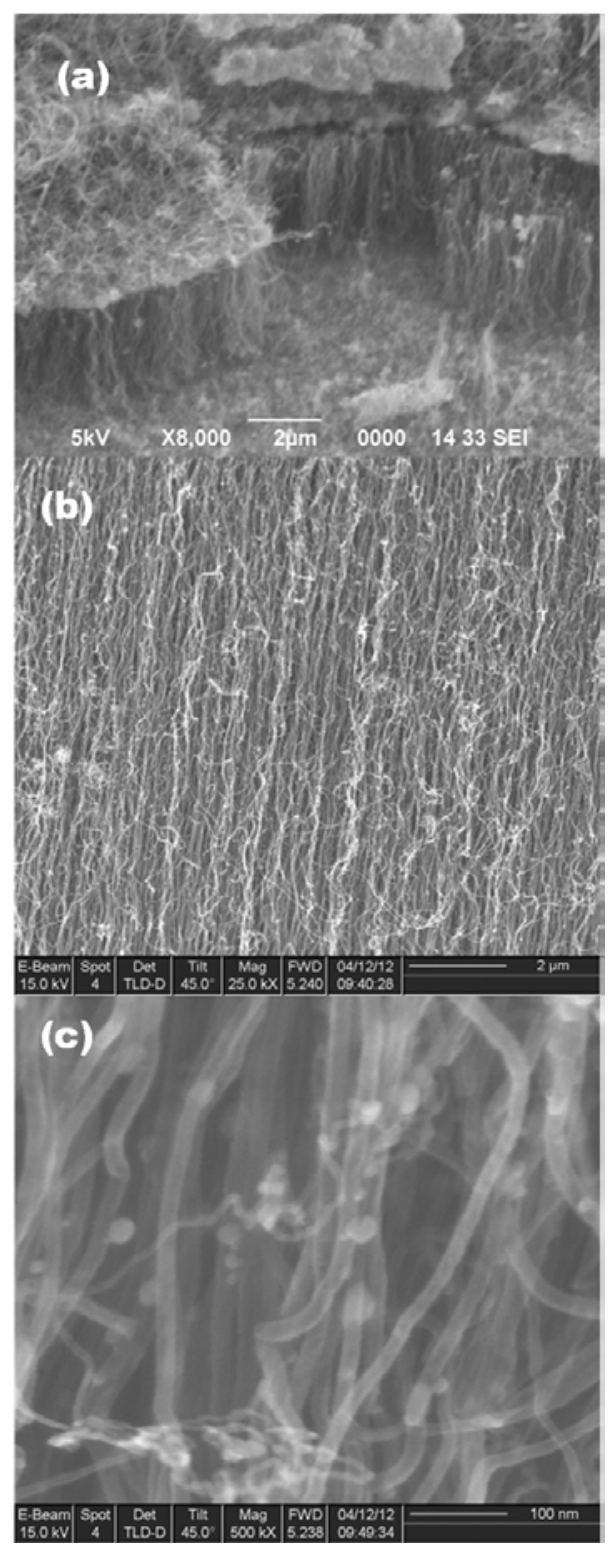

Figure 3-9 shows the resulting morphology of the grown CNTs, which illustrates a well aligned forest of CNTs with a remarkably linear morphology. There is a wide range of CNT diameters that result from the chosen synthesis conditions. Most CNTs have diameters between 10s of nm and about $100 \mathrm{~nm}$. Thus there is a large spread in diameters for the CNTs processed with acetylene under these conditions. This is most likely due to the catalyst distribution method where there is a large distribution of catalyst particle sizes since no pre-treatment was carried out to reduce the catalyst particle size after deposition. 
Figure 3-9. SEM images of CNTs grown with acetylene as the carbon precursor.

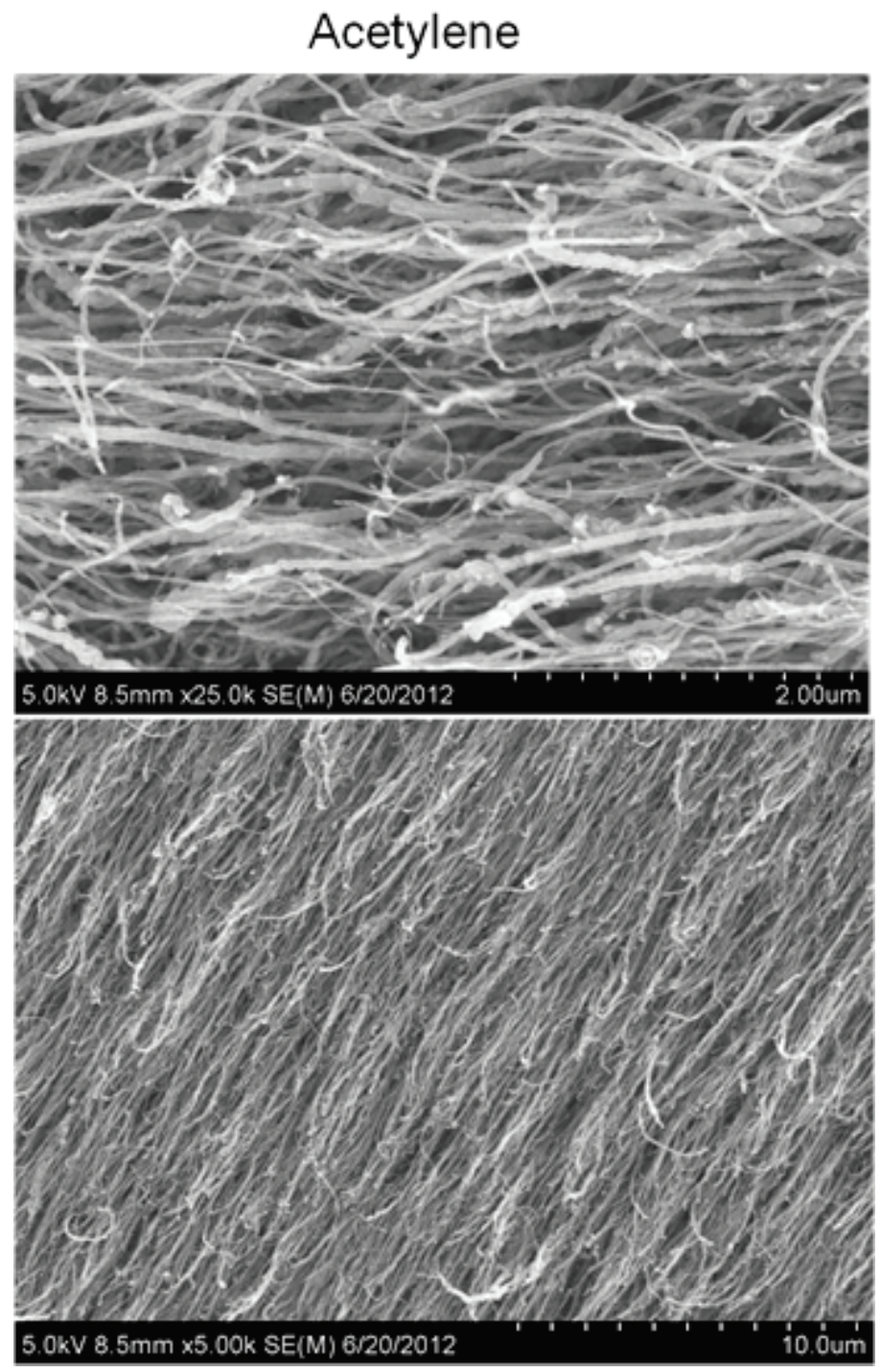

\subsubsection{Synthesis on Si substrates with metal film}

Vertically aligned forests of CNTs can be coated in various materials. Figure 3-10 shows a CNT forest grown using a $5 \%$ by weight solution of ferrocene in toluene. The surface of the forest was sputter coated with a $100 \mathrm{~nm}$ film of $\mathrm{Al}$ using a sputtering system with a base pressure of $4 \times 10^{-7}$ Torr and a power of $150 \mathrm{OW}$, which resulted in a sputter rate of $0.6 \AA / \mathrm{s}$. The $\mathrm{Al}$ particles stick well to the CNT surface and form clusters of a few hundreds of nanometers in size. This thickness was not enough to form a uniform $\mathrm{Al}$ surface across the CNTs. 
Figure 3-10. SEM images of CNTs with $100 \mathrm{~nm}$ of Al sputter coated on the surface.

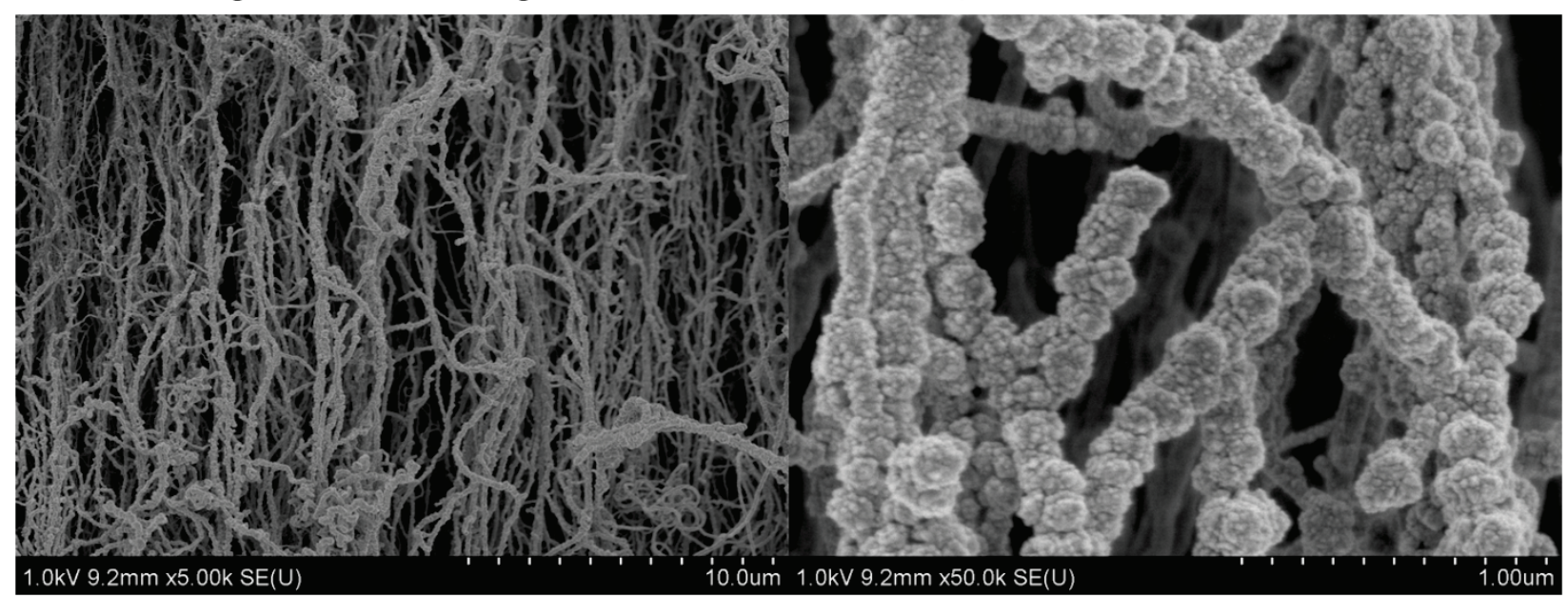

Metals can also be deposited through sputtering on the surface of a Si substrate for use in the synthesis of CNTs. This changes the morphology of the surface and the surface interaction with the Fe catalyst particles, which determines many of the properties of the individual CNTs that make up the forest. Thin layers $(\sim 10 \mathrm{~nm})$ of various metals $(\mathrm{Ag}, \mathrm{Cu}, \mathrm{Ni}, \mathrm{Pt})$ were deposited on a Si substrate through sputter coating using a Desk II (Denton Vacuum, Inc.). The sputtering process time was $180 \mathrm{~s}$ and was done at a current of $45 \mathrm{~mA}$. The sample was then placed in a 2-in. diameter quartz tube and heated to $820^{\circ} \mathrm{C}$ under the flow of $\mathrm{N}_{2}$ gas. The inlet portion of the tube was heated to $150^{\circ} \mathrm{C}$. The flow rates of $\mathrm{N}_{2}$ and $\mathrm{H}_{2}$ gas were both set to $200 \mathrm{~mL} / \mathrm{min} ; 16 \mathrm{~mL}$ of a $5 \%$ by weight solution of ferrocene in $\mathrm{m}$-xylene was continuously pumped into the tube over a 60 min process time.

Figure 3-11 shows representative morphologies of the processed CNTs. A distinct spring-like structure with a constant spatial frequency on the order of $1 \mu \mathrm{m}$ was observed on all samples that contained a thin metal film. This contrasts with CNTs grown on a pure Si substrate where no periodic spring-like structure is observed (e.g., Figure $3-1$ ). This morphology has a potential application in improving the energy dissipation properties of structures with greater recovery. Much work still needs to be done to determine which metals and what thicknesses of these metals give rise to this spring-like structure and if the spatial frequency depends on any controllable parameters. However, it is believed that this structure results from a nonuniform size distribution of the catalyst particles in conjunction with the crowding effect that causes vertical alignment (Zhang et al. 2009). In the future, the energy dissipation and recovery properties of these CNT forests need to be obtained. 
Figure 3-11. SEM images of CNTs grown on various thin films of metals.

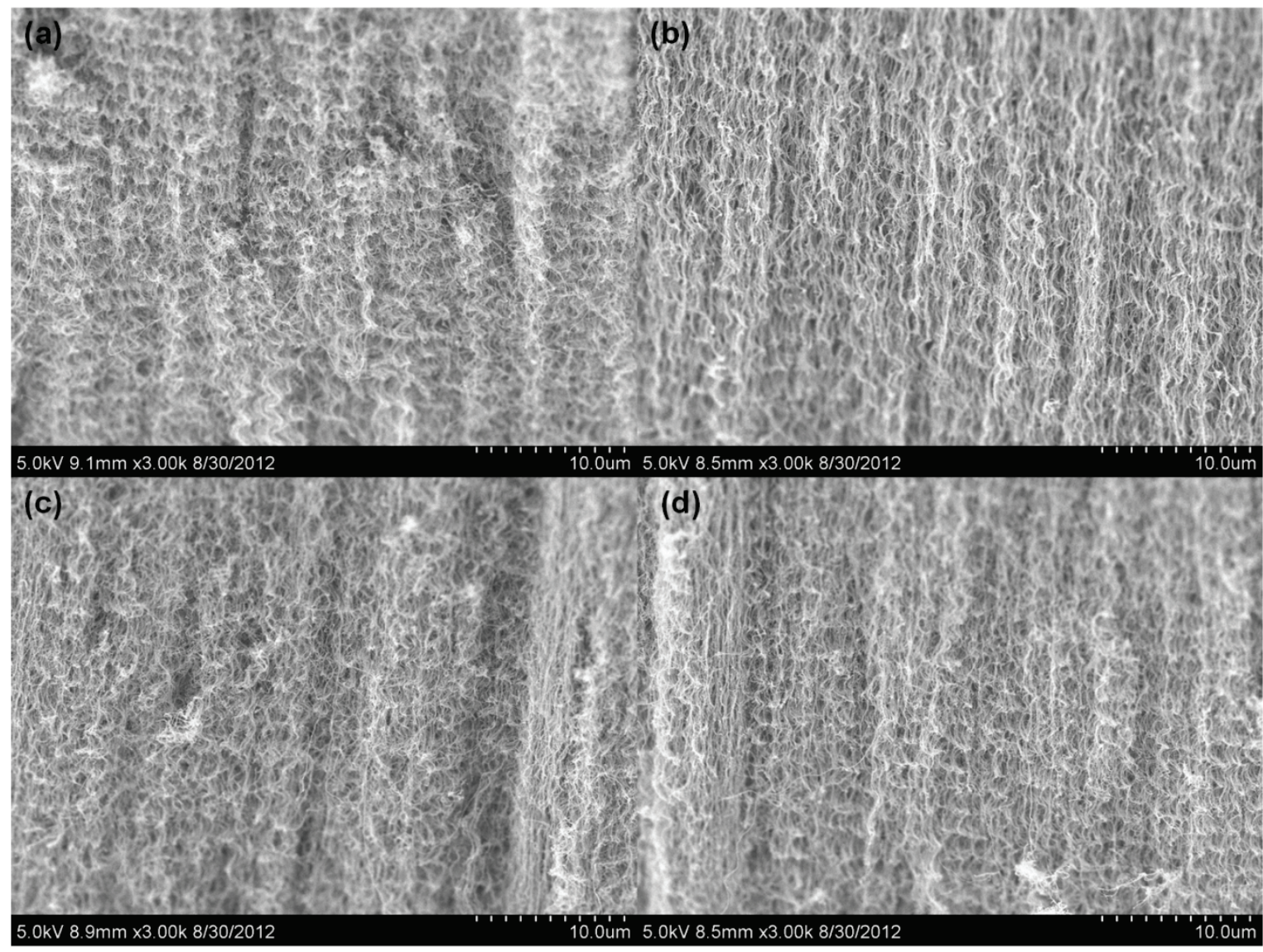

CNTs can also be grown on bulk metal substrates. This leads to differences in the surface morphology of the substrate and the interaction of the surface with the Fe catalyst particles. This can result in various catalyst particle sizes that determine many of the properties of the individual CNTs that make up the forest. The CNT forests were grown on a bulk piece of unfinished stainless steel and a bulk piece of Ti, both of about $1 \mathrm{~cm}^{3}$ in size. The samples were placed in a 2-in. diameter quartz tube and heated to $820^{\circ} \mathrm{C}$ under the flow of $\mathrm{N}_{2}$ gas. The inlet portion of the tube was heated to $150^{\circ} \mathrm{C}$. The flow rates of $\mathrm{N}_{2}$ and $\mathrm{H}_{2}$ gas were both set to $200 \mathrm{~mL} / \mathrm{min}$. The flow rate of a $5 \%$ by weight solution of ferrocene in $\mathrm{m}$-xylene was continuously pumped into the tube over a 60-min (for stainless steel) and 90-min (for Ti) process time at $15 \mathrm{~mL} / \mathrm{hr}$ (for stainless steel) and $16 \mathrm{~mL} / \mathrm{hr}$ (for Ti).

Figure 3-12 shows representative morphologies of the processed CNTs. On both metallic substrates, the CNT forest properties were similar. Vertically aligned CNT forests of over $100 \mu \mathrm{m}$ grew on most regions of the substrates. 
Figure 3-12. SEM images of CNTs grown on bulk stainless steel and titanium.

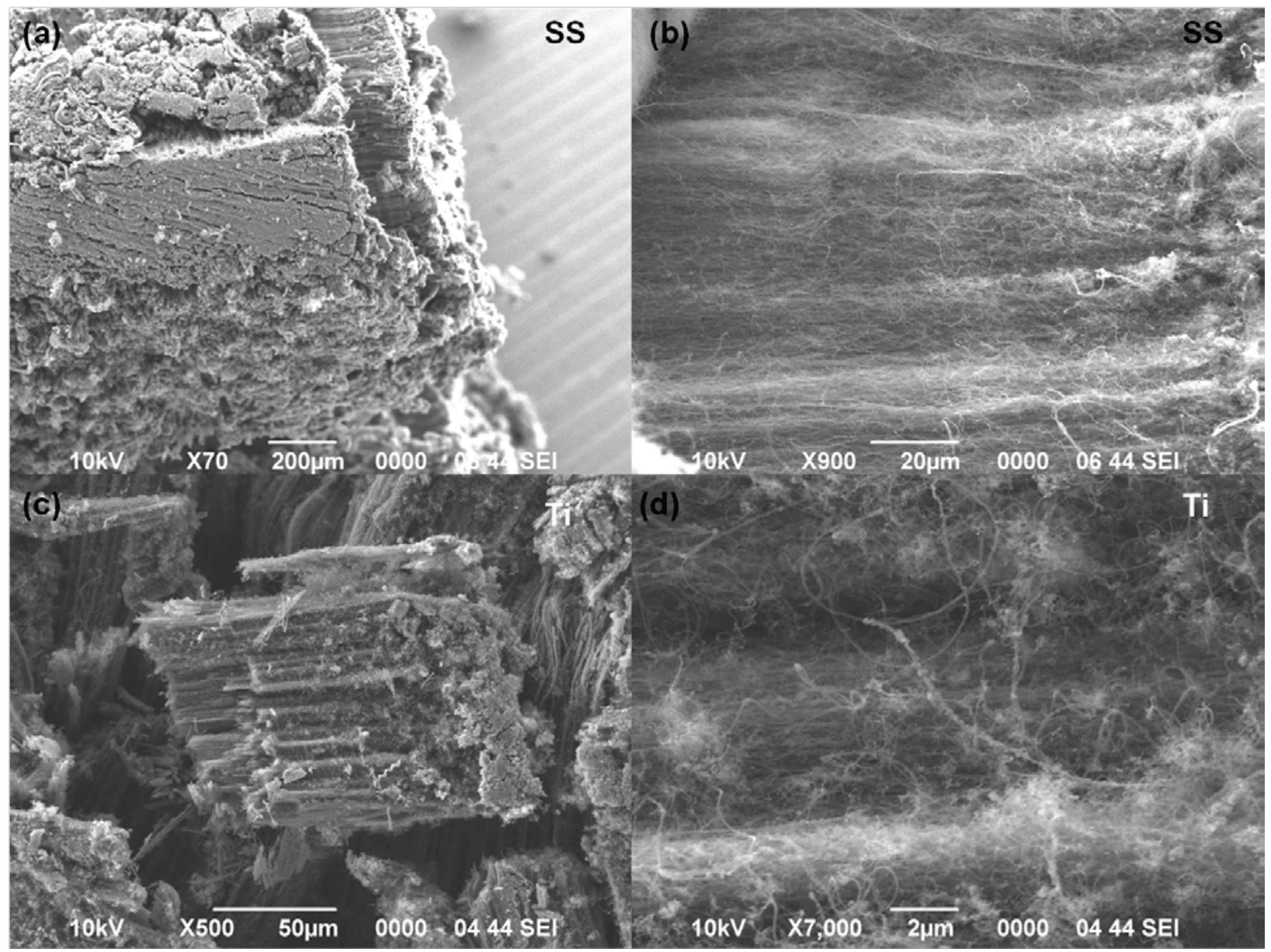

The vertically aligned growth was not uniform across the substrates, but varied depending on the local conditions of the surface such as roughness, orientation, oxidation, etc. Again, much work still needs to be done to determine which metals the CNTs will grow on and what properties of the metals result in different types of growth.

\subsection{Energy dissipation and cushioning in intercalated CNT forests with metal layers}

After separating the CNT forests from the Si substrate, the morphology, height, quality, and alignment of the CNT forests were determined using SEM images. The CNT forests fabricated here resulted in aligned forests with heights of about $1 \mathrm{~mm}$ and a compressible foam-like texture.

While the forests are aligned macroscopically, on the microscopic level there is a highly entangled structure. The vertical alignment of CNTs forests is primarily caused by van der Waals forces (Wu and Chang 2009), 
which tend to restrict the direction of CNTs as they grow. From high magnification SEM images, the average diameter of the CNTs was determined to be $46.3 \pm 10.1 \mathrm{~nm}$. These measurements were taken near the center of the forest height.

The metal layers were applied to the CNT forests either by DC magnetron sputtering, thermal evaporation, or application as a paste; Figure 3-13 shows a top and a tilted side views. The uncoated CNT forest samples are termed "CNT" with either a " $1 \mathrm{~L}$," " $2 \mathrm{~L}$," or " $3 \mathrm{~L}$ " to designate if it was a 1layer, 2-layer, or 3-layered samples, respectively. The metal coated (top and bottom) CNT forests are called "Ag," "Fe," and "In," designating coating with $\mathrm{Ag}, \mathrm{Fe}$, and In, respectively. The surface layer of CNTs in the CNT samples appear to be coated in particles. These particles are expected to be comprised of a thin layer (less than $100 \mathrm{~nm}$ ) of Fe catalyst particles and some amorphous carbon, which settles on the surface of the forest after the growth process during cooling. The density of these particles is not high enough to form a continuous surface and the surface remains porous. The bottom layer also has a similarly high density of Fe particles that are present as Fe particles settle near the Si surface during growth.

When Ag is applied to the CNT forest surface as a paste, a network of silver particles forms $(\sim 1 \mu \mathrm{m})$ and binds to neighboring CNTs (Figure $3-13)$. The silver forms a connected, nonporous layer. The purpose of this layer is to aid in the transfer of axial load in the transverse direction. On the surface, the Ag thickness is about $100-150 \mu \mathrm{m}$ while the middle layers are about 25-75 $\mu \mathrm{m}$ thick. Each layer is well connected to the surrounding CNTs. Iron is applied through sputtering and forms a nearly connected layer of Fe particles $(\sim 1 \mu \mathrm{m})$ on the surface of the CNT forest. The Fe layer is $250 \mathrm{~nm}$ thick and is well connected to the surrounding CNTs. The In is applied through thermal evaporation and forms a well connected mostly nonporous layer of In particles $(\sim 1 \mu \mathrm{m})$ on the CNT forest surface. The In layer is $250 \mathrm{~nm}$ thick and is weakly attached to the CNT surface. Scratching the In layer with a pair of steel tweezers easily removes the In from the CNT forest surface. 
Figure 3-13. SEM images of various metals (none, $\mathrm{Ag}$, $\mathrm{Fe}$, and In) deposited on the surface of a CNT forest. Column 1 shows the surface of metal deposition. Column 2 shows a side view of the CNT-metal interface tilted at $30^{\circ}$. Column 3 shows the tilted side view of the Ag-CNT interface: general view (top), middle layer (row 2), top layer (row 3), and zoomed in view of the middle layer showing the Ag connection to CNTs (bottom).

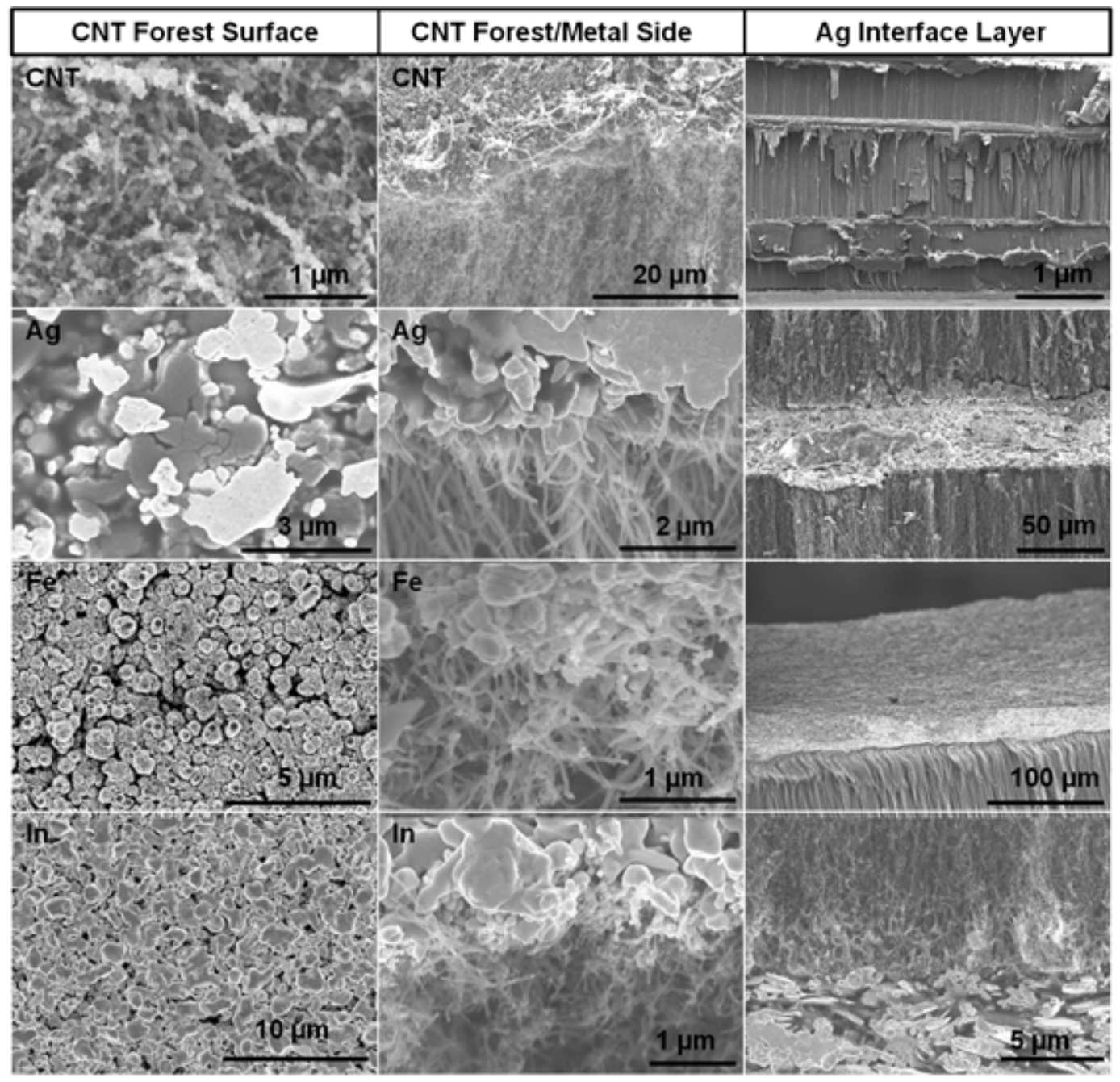

The one-layer, two-layer, and three-layer pure CNT forest as well as the metal coated forests were each compressed to determine their stress vs. strain characteristics. As each CNT forest is compressed, the axial force is measured as a function of displacement, which is converted to stress vs. strain by dividing the force by the area of the sample and dividing the displacement by the thickness. The force platen ( $25 \mathrm{~mm}$ in diameter) is lowered until the load cell reads $0.1 \mathrm{~N}$. This location is defined as the top position of the sample. The sample height is found by repeating this procedure without a sample and subtracting the two values. With a sample in place, as the top platen is lowered, the force begins to increase until either buckling occurs or the direction of the force platen is reversed. Each sample 
was measured to a strain limit of 0.7 at which point the platen direction was reversed and the load was reduced. Each sample was uniformly compressed at a rate of $1.5 \mathrm{~mm} / \mathrm{min}$ for five cycles.

The plastic deformation and buckling of all forests were most pronounced during the loading section of the first cycle where jumps and kinks are observed in the stress vs. strain plot (Figure 3-14). However, this "roughness" in the stress vs. strain plots of the first cycle is largest in the $1 \mathrm{~L}$ samples and decreases with increased layer number. For 2- and 3-layer samples, this roughness is hardly noticeable. This may be due to a cushioning effect provided by the layered structure of the samples. During the $5^{\text {th }}$ loading cycle of all samples, there is minimal observable roughness apart from the noise of the measurement.

As the samples are unloaded, the stress vs. strain follows a different path than that during loading. This indicates that there is energy dissipation, which is equal to the net area enclosed by the entire loading-unloading cycle. Apart from the first cycle where buckling and plastic deformation occurs, this energy dissipation is commonly attributed to frictional losses between individual CNTs. After the initial and most pronounced strain hardening of the first cycle, the subsequent cycles still show a hysteresis; it is believed that most of this energy dissipation is due to these frictional losses from the now densified forest. The hysteretic properties of the samples do not strongly depend on sample type or number of forest layers.

The value of Young's modulus is calculated from the linear portion of the initial section of the unloading curve of the first cycle for all four sample configurations. Figure 3-15 shows Young's modulus plotted as a function of the number of layers or stack number. The value for Young's modulus increases as the number of layers is increased up to a verified stack of three. Even without metal coating, Young's modulus increases in the plain CNT sample when the layer number is increased from 1 to 2, but decreases slightly when the layer number is increased to 3 . With In coating, there is a large increase in Young's modulus when the stack number is increased from 1 to 2, but a much lower increase when going from a stack of 2 to 3 . 
Figure 3-14. Stress vs. strain plots of the first (black) and fifth (red) cycles for all four sample types including $1 \mathrm{~L}, 2 \mathrm{~L}$, and $3 \mathrm{~L}$ samples for the mid-range density samples.
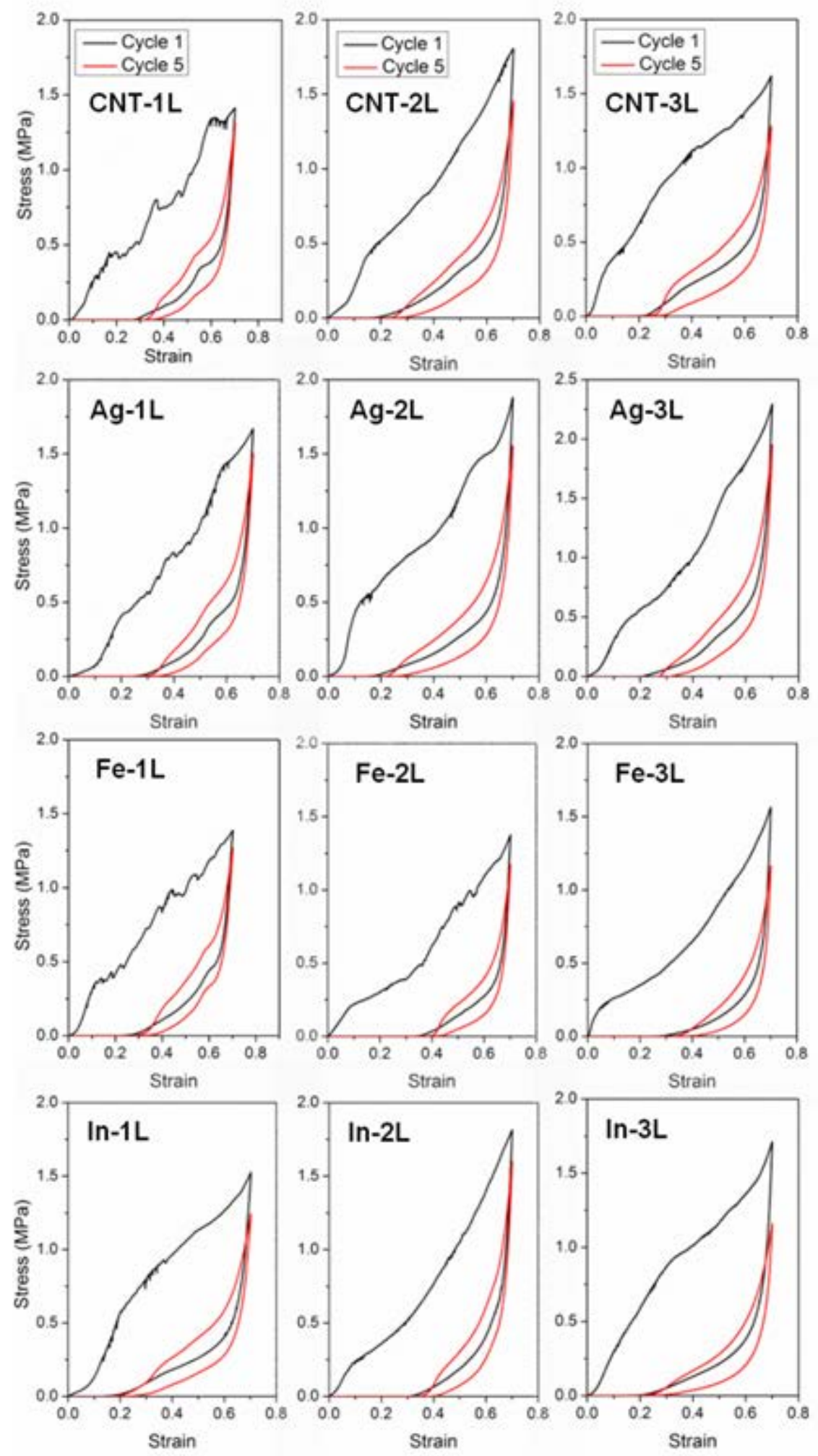
Figure 3-15. Young's modulus vs. stack number for the first cycle for each of four CNT forests, each coated in a different metal.

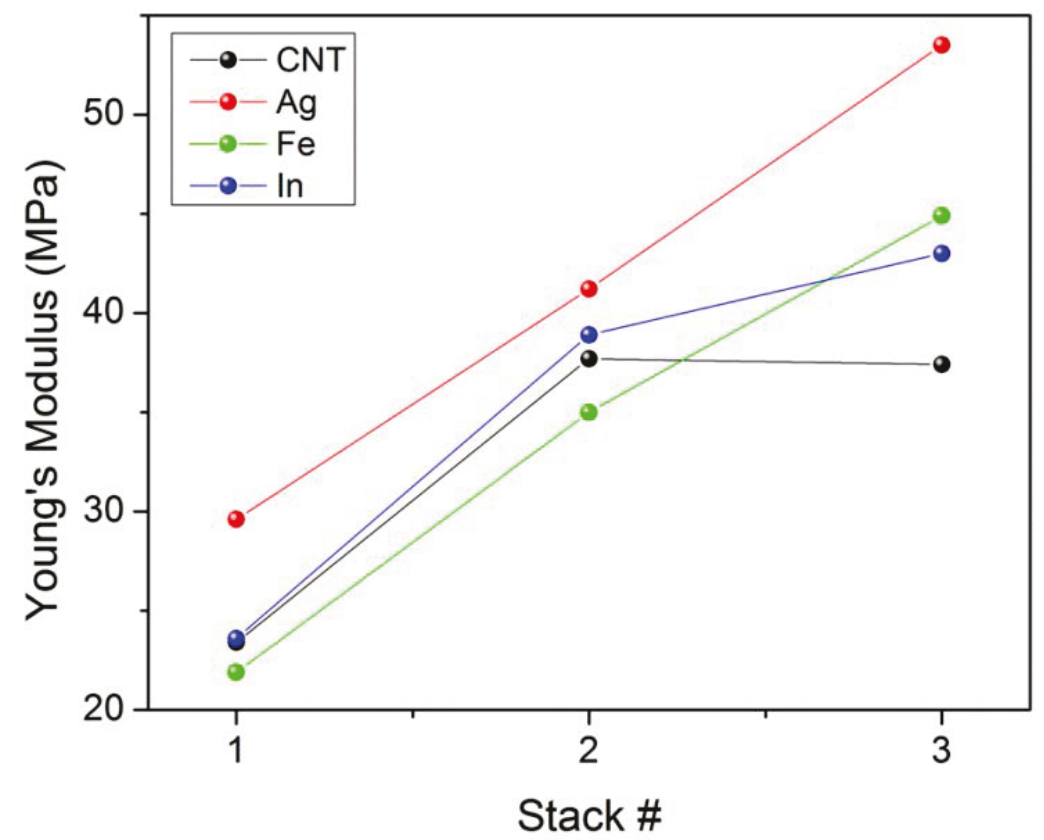

With both Ag and Fe intercalated samples, the value of Young's modulus is almost linearly proportional to the number of layers up to a 3-layered sample. The difference between the behavior of the CNT and In intercalated samples compared to the $\mathrm{Ag}$ and Fe samples may relate to the hardness of the metal coatings. The Ag samples show the highest value of Young's modulus because the total value of Young's modulus is a combination of the stiffness of the CNT forest and the intercalated metal. Since the total Ag film thickness is approximately $10-20 \%$ of the total Ag sample height, the Ag layers play a larger role. Consequently, the sample's value of Young's modulus is higher since the metal is stiffer than the CNT forest that has foam-like properties. The uncertainty in the calculation for each data point in Figure $3^{-15}$ is less than $0.1 \mathrm{MPa}$, demonstrating that the observed increase in Young's modulus with layer number is well above the noise floor.

The energy dissipation can also be calculated from the stress vs. strain curve for each sample as the area enclosed by the curve. This energy dissipation of the samples was calculated for the first and fifth cycle, which show similar results (Figure 3-16). Each data point was calculated by averaging the dissipated energy for a particular sample configuration between the three ranges of densities described earlier. Approximately four times as much energy is dissipated in the first cycle than in the fifth cycle for all sample configurations. 
Figure 3-16. Energy and Energy density vs. layer number for CNT forests coated with no metal, Ag, Fe, and In for the (a) first cycle (b) fifth cycle.
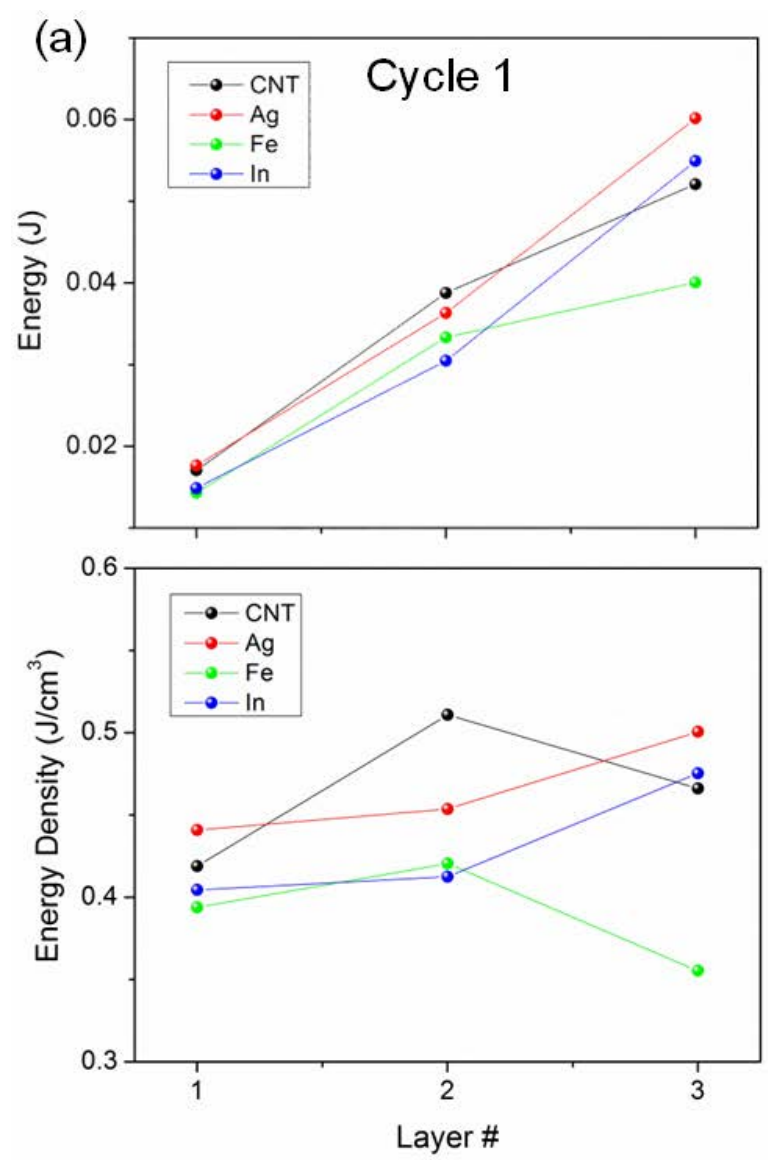
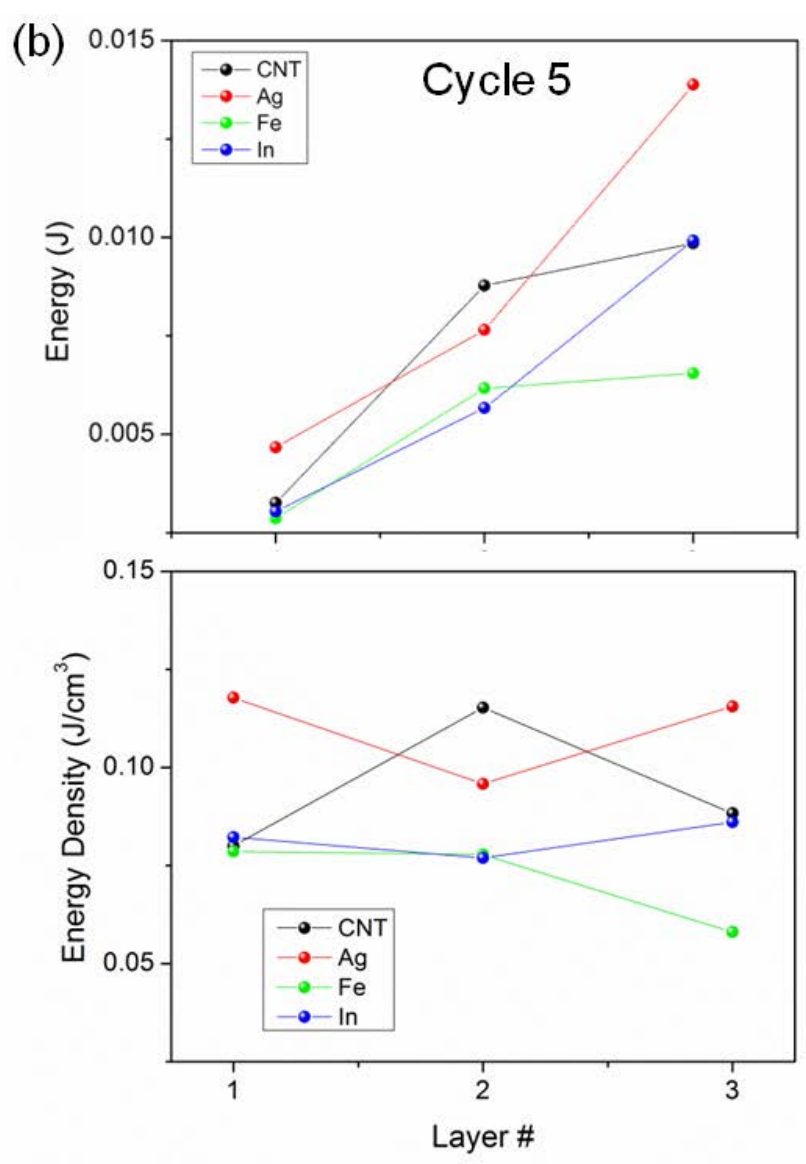

This is due to initial buckling, friction, and other plastic deformation modes. Once the initial hardening has occurred, it is believed that friction is the primary means of energy dissipation. It is observed that, for both the first and fifth cycle, the total energy dissipation is approximately linearly proportional to the number of forest layers, independent of metal coating (except Fe, which shows some flattening at three layers). The energy per unit volume or energy density was also compared for the first and fifth cycles of all sample configurations. It was found that the energy density was approximately constant and thus independent of the number of layers and metal intercalation. This is further supported by analyzing the fluctuation in the data. The standard deviation of the energy density for different intercalated metals and layer number ranged between $0.05-0.16 \mathrm{~J} / \mathrm{cm}^{3}$ and 0.006-0.053 J/ $\mathrm{cm}^{3}$ for the first and fifth cycle, respectively. The energy density data (Figure 3-16[b]) are mostly within this range, which verifies there the energy density does not strongly depend on either metal type or layer number. 
The 2L CNT sample data was compared to a single CNT forest grown under identical conditions, but with twice the process time (termed here as "2T CNT"). This resulted in a single CNT forest with a height equal to about twice the height of the layers studied here. Out of three samples measured, the average energy density for the $1^{\text {st }}$ cycle was $0.802 \pm 0.122 \mathrm{~J} / \mathrm{cm}^{3}$ while for the $5^{\text {th }}$ cycle the average energy density was $0.137 \pm 0.017 \mathrm{~J} / \mathrm{cm}^{3}$. The energy density value for the $1^{\text {st }}$ cycle is higher than the average energy density dissipation measured for the 2L CNT samples, which was $0.510 \pm 0.145 \mathrm{~J} / \mathrm{cm}^{3}$. This is an increase of energy density dissipation by $57 \%$ over the $2 \mathrm{~L}$ CNT samples. This may be a result of the greater continuous length of the $2 \mathrm{~T}$ CNT samples, which causes them to experience a greater degree of plastic deformation. Visually, there was significantly more damage done to the $2 \mathrm{~T}$ CNT samples compared to the $1 \mathrm{~L}$ and $2 \mathrm{~L}$ CNT samples. On the $5^{\text {th }}$ cycle, the energy densities for the $2 \mathrm{~T}$ and 2L CNT samples were approximately the same as they were within the experimental scatter. Thus, after many cycles, the energy density seems to scale linearly with the number of sample layers.

The mode of failure does depend on both the intercalated metal and the layer number. Figure 3-17 shows optical images of typical failure after compression testing. All 1L samples remained intact after compression tests and did not visibly fail except for a slight reduction in thickness. The $\mathrm{Ag}$ and $\mathrm{Fe} 2 \mathrm{~L}$ and $3 \mathrm{~L}$ samples also largely remained intact while the CNT and $\mathrm{In} 2 \mathrm{~L}$ and $3 \mathrm{~L}$ samples showed large fracturing and splintering. This occurs due to inherent surface roughness and variation across the surfaces of all samples that generate shear forces when axial load is applied. The CNT samples have no surface film binding adjacent CNTs together to increase shear strength and toughness. Likewise, the In samples have $250 \mathrm{~nm}$ of In binding adjacent CNTs together, but In is a soft, ductile metal that deforms under even small loads. Thus shear stresses readily fracture the CNT and In $2 \mathrm{~L}$ and $3 \mathrm{~L}$ samples. The Fe samples bond better to the CNTs and is a stronger metal. When shear stresses are present, the $250 \mathrm{~nm}$ Fe layer can prevent most fracture. The least visual damage is done to the Ag samples. This is probably due to the thickness of the Ag layer $(\sim 50 \mu \mathrm{m})$, which both reduces shear forces by smoothing out surface roughness and provides greater shear fracture resistance. Furthermore, the Ag anchors adjacent CNT layers, which is more capable of laterally transferring stress resulting in less damage. 
Figure 3-17. Optical images of typical CNT-metal intercalated samples after compression testing.

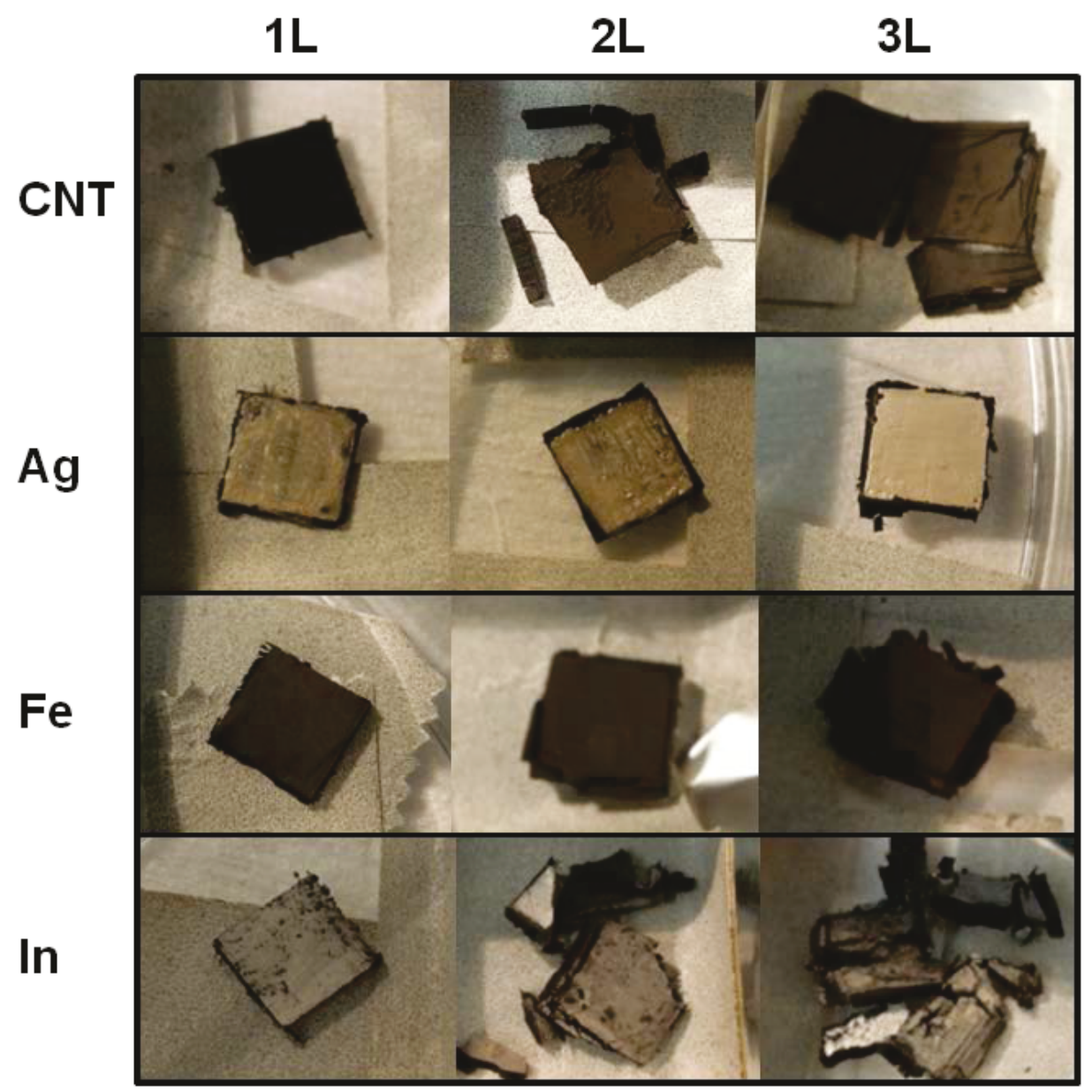

Apart from the jumps, kinks, and hysteresis observed in the stress vs. strain curves, direct evidence of buckling and plastic deformation is found in the SEM images of the samples after five compression cycles (Figure 3-18). All $1 \mathrm{~L}$ samples showed global folds across the whole forest preferentially near the bottom surface where the CNT forest had been separated from the $\mathrm{Si}$ substrate. These are buckling folds and appear as an accordion-like structure with decreasing spatial wavelength. The CNT forests presented here grow through a bottom-up mechanism where catalyst particles sit on the $\mathrm{Si}$ substrate and grow from this point. As the CNTs grow in height, they push the entire forest upward so it grows in a vertically aligned structure with some waviness at the top due to van der Waals forces. At the end of the process time, the carbon precursor flow and catalyst flow are turned off to stop the growth of the forest. Residual carbon precursor and catalyst particles continue the grown process, however, under different conditions. This results in a functionally graded CNT forest structure. 
Figure 3-18. SEM images of typical CNT-metal intercalated samples after compression testing. The scale bar in all images is $100 \mu \mathrm{m}$.

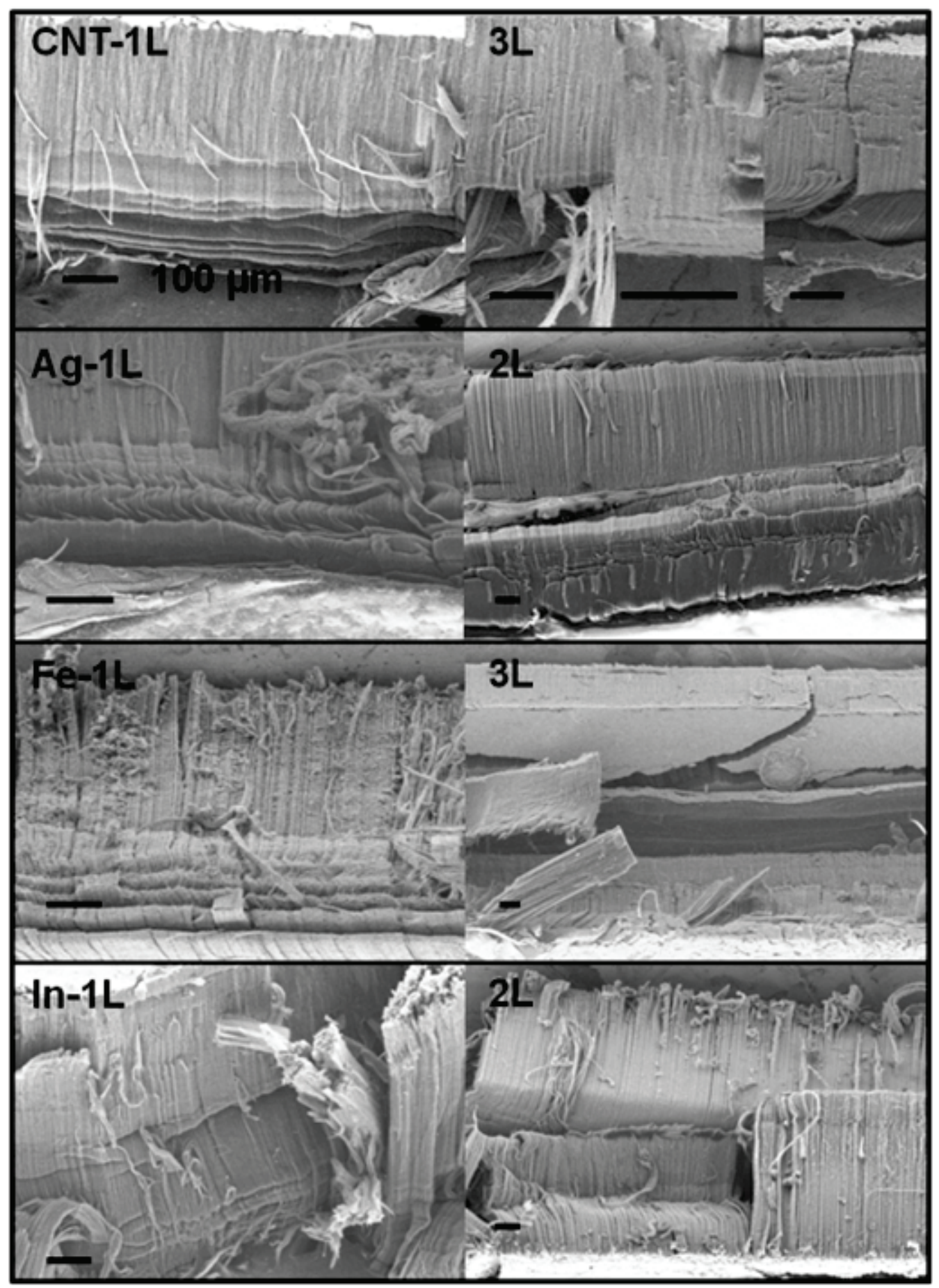

Where the conditions change near the end of the process, a weak spot in the CNT forest occurs. This is the most likely location (near where the $\mathrm{Si}$ substrate was) for the global buckling events where the CNTs stick to- 
gether due to van der Waals forces. These global buckling events only occur when the stress has reached a critical value, which is also where the roughness in the first cycle appears in the stress vs. strain curves in Figure 3-14 (p 37). After the first cycle, the roughness in the stress vs. strain curves significantly decreases indicating that most of these folds are developed during the first cycle.

These global folds are also observed in the $2 \mathrm{~L}$ and $3 \mathrm{~L}$ samples-with some differences. In the $2 \mathrm{~L}$ and $3 \mathrm{~L} \mathrm{CNT} \mathrm{sample,} \mathrm{there} \mathrm{are} \mathrm{fewer} \mathrm{buckling} \mathrm{folds}$ per layer compared to the $1 \mathrm{~L}$ sample, but each layer in the stack contains them. The same is true for the In sample, except it has slightly fewer folds per layer. The Fe sample is similar to the In sample in that it has slightly fewer buckling folds than do the $2 \mathrm{~L}$ and $3 \mathrm{~L} \mathrm{CNT}$ samples. The multilayered Ag samples show a remarkably different behavior. The buckling folds show a slightly higher occurrence near the bottom of the forest layer in the bottom layer. However, there are still many folds that occur through the center of the bottom layer and even toward the Ag interface, due to the anchoring effect (Figure 3-18). The middle and top layers show either no or relatively few global buckling folds. The thick Ag layer provides a mechanism for the stress field to be laterally dispersed and effectively cushions the middle and top layers.

\subsection{Morphology of CNT forests grown on glass fibers in a two-zone furnace}

Experiments were performed to characterize the growth properties of CNTs on glass fabric substrates at low temperatures for application in glass fabric reinforced polymer composites with anchored CNTs. Typical CVD process temperatures are in the range of $600-800{ }^{\circ} \mathrm{C}$, which exceed the softening point of typical glass fabrics. These high temperatures also cause thermal degradation and oxidation effects that weaken the fibers. The goal of these experiments then, was to achieve high quality CNT forests on glass fibers at low temperatures. To achieve this, a preheating zone was added (Zone 1) where a high temperature was used to decompose the carbon precursor and the continuously fed catalyst. A second zone, Zone 2, was kept at a lower temperature to reduce thermal damage to the glass fibers but still aid in CNT growth and catalyst particle generation.

At first, Zone 1 was kept at a constant temperature of $800{ }^{\circ} \mathrm{C}$ while the Zone 1 temperature was varied between 515 and $665^{\circ} \mathrm{C}$. Optical and SEM 
images were used to characterize the quality and morphology of the resulting CNT growth. As the temperature was reduced from 665 to $515{ }^{\circ} \mathrm{C}$, the processed glass fabric visually changed from a dark black to a gray color (Figure 3-19). This is because the amount of CNT synthesis gradually decreased as the Zone 2 temperature was lowered. When the transition was made from a Zone 2 temperature of 540 to $515{ }^{\circ} \mathrm{C}$, there was no growth of CNTs. Based on the Zone 2 temperatures used here, with a Zone 1 temperature of $800^{\circ} \mathrm{C}$, the lowest Zone 2 temperature that results in CNT synthesis was $540{ }^{\circ} \mathrm{C}$. Above this, the CNT synthesis occurs; below this, CNT growth does not take place.

The resulting CNT morphology is a function of the Zone 2 temperature. The rate of CNT growth is higher at higher Zone 2 temperatures as is evidenced in Figure 3-20. Since the CNTs were grown under identical conditions (other than the Zone 2 temperature, in this case), the longer forests of CNTs translate into a higher rate of growth. Of all the Zone 2 temperatures used here, the highest one (where $\mathrm{T}_{2}=665^{\circ} \mathrm{C}$ ) resulted in the longest CNTs of about $10 \mu \mathrm{m}$ in height. The CNTs mainly grew in two horizontal radial directions (Figure 3-20[a]). At a Zone 2 temperature of $615{ }^{\circ} \mathrm{C}$, the CNTs were slightly shorter and did not have as much of the pronounced two-direction radial growth. Instead, the CNTs primarily grew as "fuzzy fibers" of about equal density in all radial directions (Figure 3-20[b]). 
Figure 3-19. Optical images of CNTs grown on glass fabrics in a two tmperature zone furnace at a Zone 1 temperature of $800^{\circ} \mathrm{C}$ and various Zone 2 temperatures.

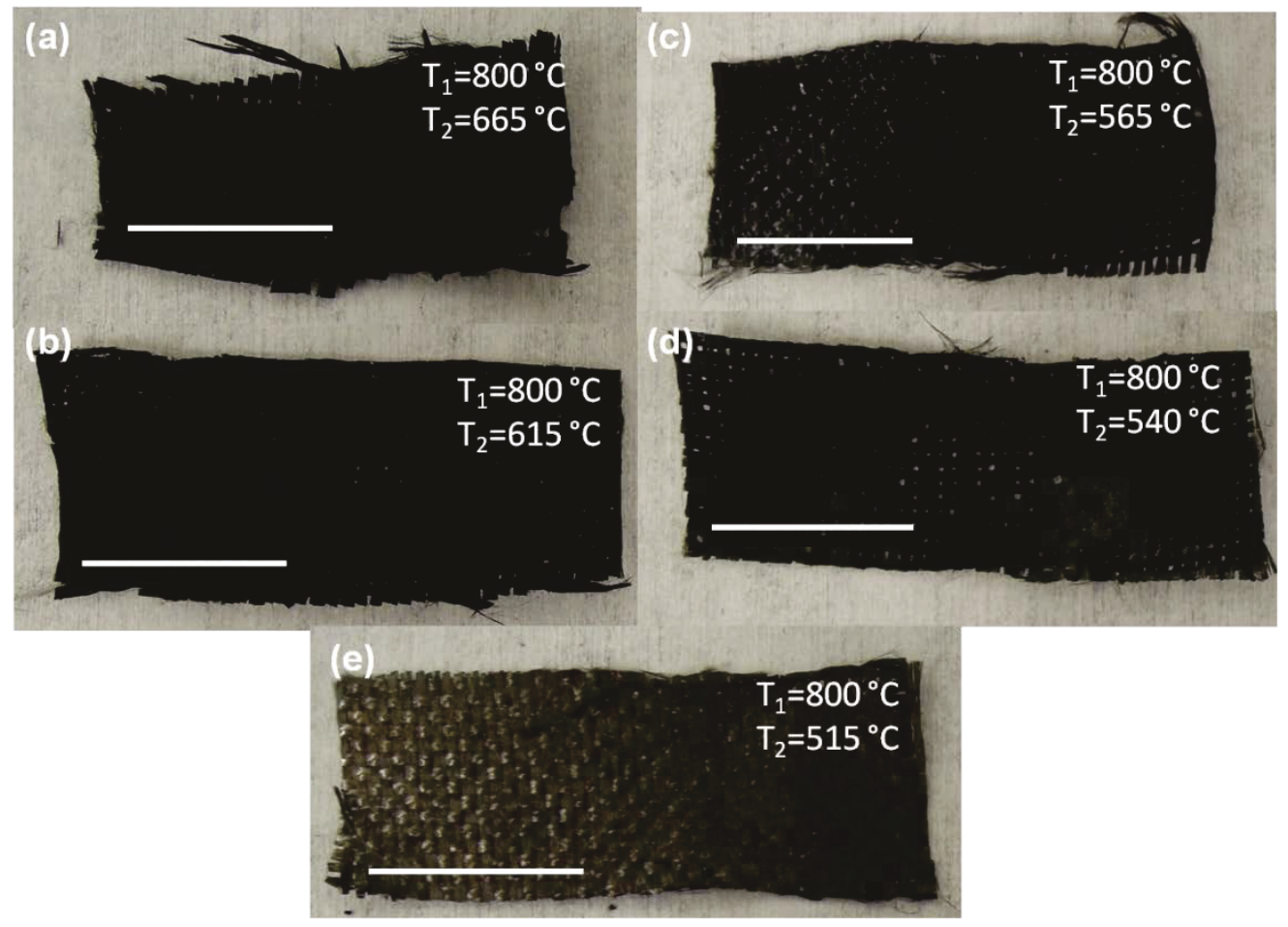


Figure 3-20. SEM images of CNTs grown on glass fabrics in a two temperature zone furnace at a Zone 1 temperature of $800^{\circ} \mathrm{C}$ and various Zone 2 temperatures.

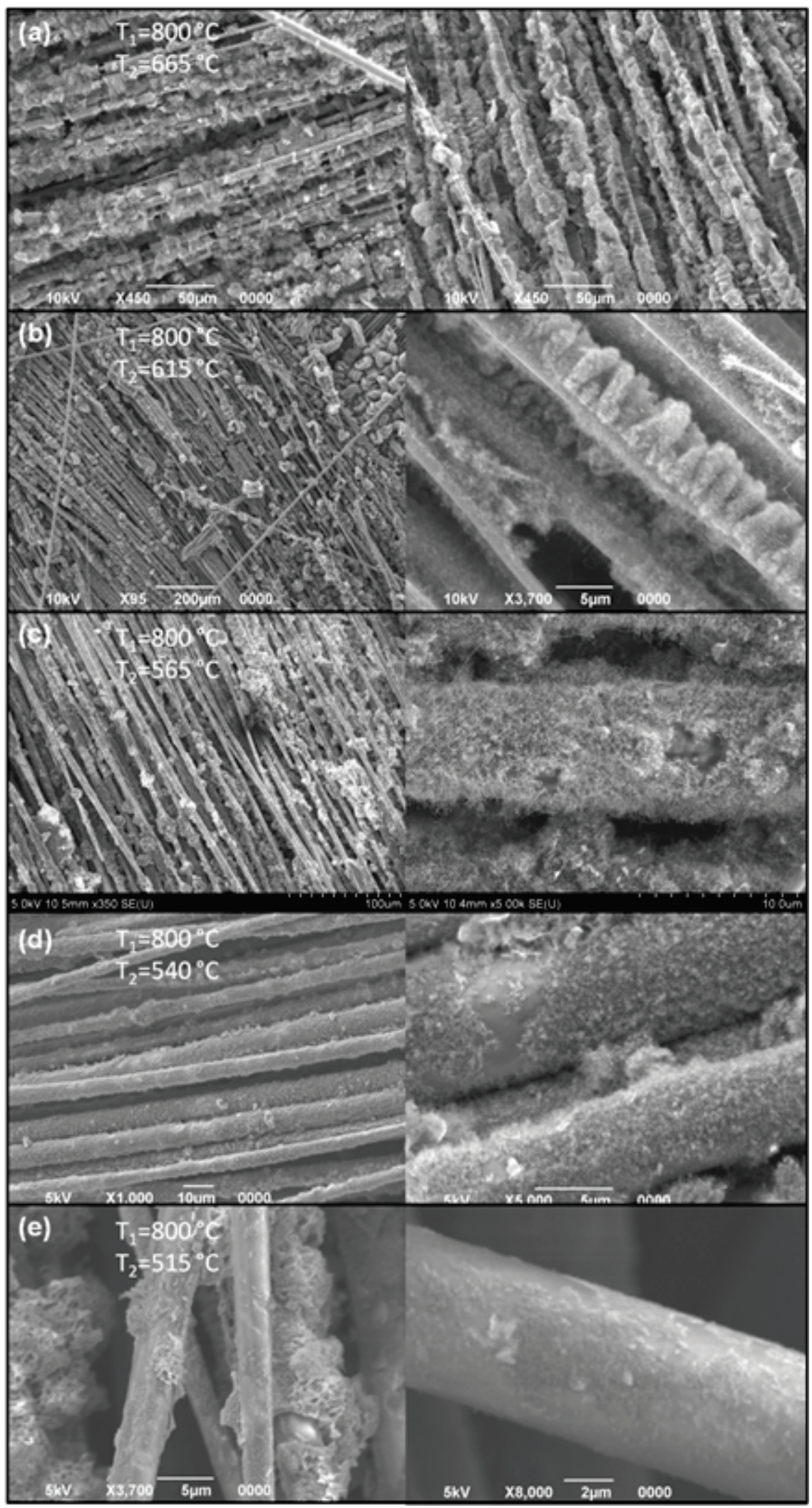


At a Zone 2 temperature of $565{ }^{\circ} \mathrm{C}$, the CNTs were approximately 2-4 $\mu \mathrm{m}$, shorter than the ones grown at $615{ }^{\circ} \mathrm{C}$, but with the same type of radial growth (Figure 3-20[c]). At an even lower Zone 2 temperature of $540^{\circ} \mathrm{C}$, the CNT growth was very uniform across the entire sample. The CNTs were approximately $1 \mu \mathrm{m}$ in height and grew with an equal density in all radial directions (Figure $3-2 \mathrm{O}[\mathrm{d}]$ ). Finally, at a Zone 2 temperature of $515{ }^{\circ} \mathrm{C}$, CNTs were not observed to grow (Figure $3-20[\mathrm{e}]$ ). These results are not surprising since it is generally known that CNTs grow at higher rates at higher temperatures up to a certain temperature (Aksak, Kir, and Selamet 2009).

To determine the effect that the Zone 1 temperature had on the properties of the CNT morphology, the Zone 1 temperature was varied between 500 and $900{ }^{\circ} \mathrm{C}$ while the Zone 2 temperature was fixed at $540{ }^{\circ} \mathrm{C}$. The Zone 2 temperature was chosen because this is slightly above the low temperature threshold for CNT growth. The range of Zone 1 temperatures was chosen because these are the typical range of temperatures at which decomposition of the carbon precursor occur and CNT synthesis is possible. Optical and SEM images were used to characterize the quality and morphology of the resulting CNT growth. As the Zone 2 temperature was reduced from 900 to $500{ }^{\circ} \mathrm{C}$, minimal CNT growth was observed at both the high and low ends of the spectrum. The best growth occurred near the middle of this temperature range. This behavior is typical of what is found in the literature ( $\mathrm{Li}$, Wen, and Ren 2002). Figure 3-21 shows this where the samples produced at both high and low Zone 1 temperatures are only lightly shaded "black"; this blackness does not cover the majority of the sample area. However, the samples produced at mid-range Zone 1 temperatures have a darker "blackness" and this blackness does cover the majority of the sample area.

The resulting CNT morphology including CNT height is a function of Zone 1 temperature. At high Zone 1 temperatures of 850 and $900{ }^{\circ} \mathrm{C}$, very few CNTs are formed at very short heights (Figure 3-22) and most of the material deposited on the GF surface is amorphous carbon with some Fe catalyst particles. This is consistent with literature that shows a high temperature limit for the synthesis of CNTs. This is due in part to the possibility of the catalyst particles alloying with the GF substrate at these high temperatures. At low temperatures such as 500 and $550{ }^{\circ} \mathrm{C}$, the CNT production was also very low, and very short CNTs were found on a small fraction of the glass fibers. 
Figure 3-21. Optical images of CNTs grown on glass fabrics in a two temperature zone furnace at a Zone 2 temperature of $540^{\circ} \mathrm{C}$ and various Zone 1 temperatures.

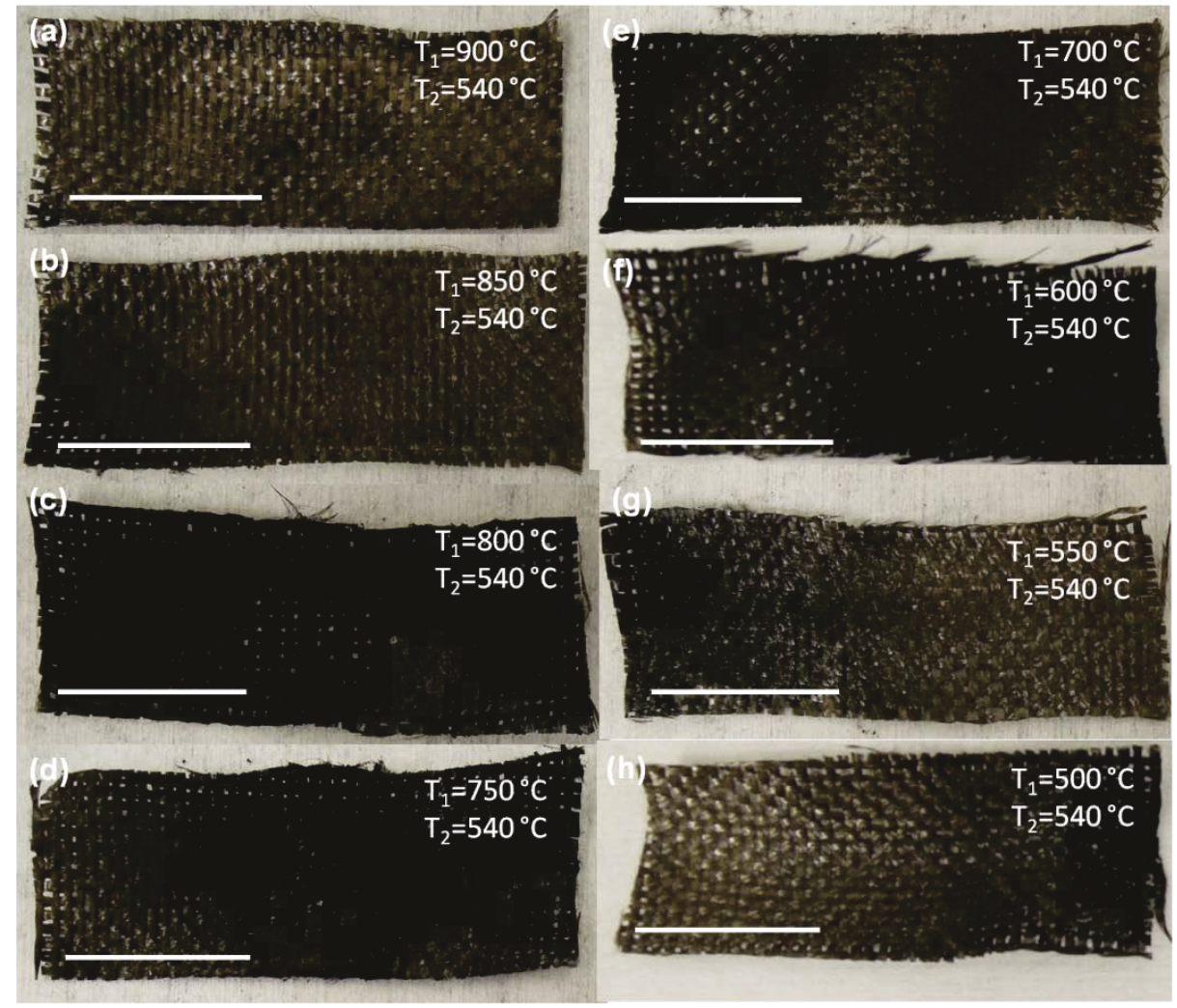

This is also consistent with literature and is mostly due to the carbon precursor not undergoing decomposition and the carbon not being able to diffuse through the catalyst particles to generate CNTs. The overall CNT coverage of the GFs grown at high and low Zone 1 temperatures was not uniform and only small fractions of the GFs had any CNTs.

In the Zone 1 temperature range of $600-800{ }^{\circ} \mathrm{C}$, the $\mathrm{CNT}$ growth was both uniform and taller than the low and high temperature range outlined above. The resulting "fuzzy fiber" growth in this temperature range had equal density in all radial directions (Figure 3-23). There was a slight temperature dependence to the height of the resulting CNT forests. The CNTs at higher temperatures grew to be slightly greater than $1 \mu \mathrm{m}$ in height while the CNTs at the lowest temperatures grew to be between $500 \mathrm{~nm}$ and $1 \mu \mathrm{m}$. The last row in Figure 3-23 shows high resolution SEM images of CNTs attached to the glass fibers. The catalyst particle can even be seen at the CNT-GF interface, which shows that these CNTs grow through a bottom-up process. 
Figure 3-22. SEM images of CNTs grown on glass fabrics in a two temperature zone furnace at Zone 1 temperatures of $850,900,550$ and $500{ }^{\circ} \mathrm{C}$ with a Zone 2 temperature of $540{ }^{\circ} \mathrm{C}$.

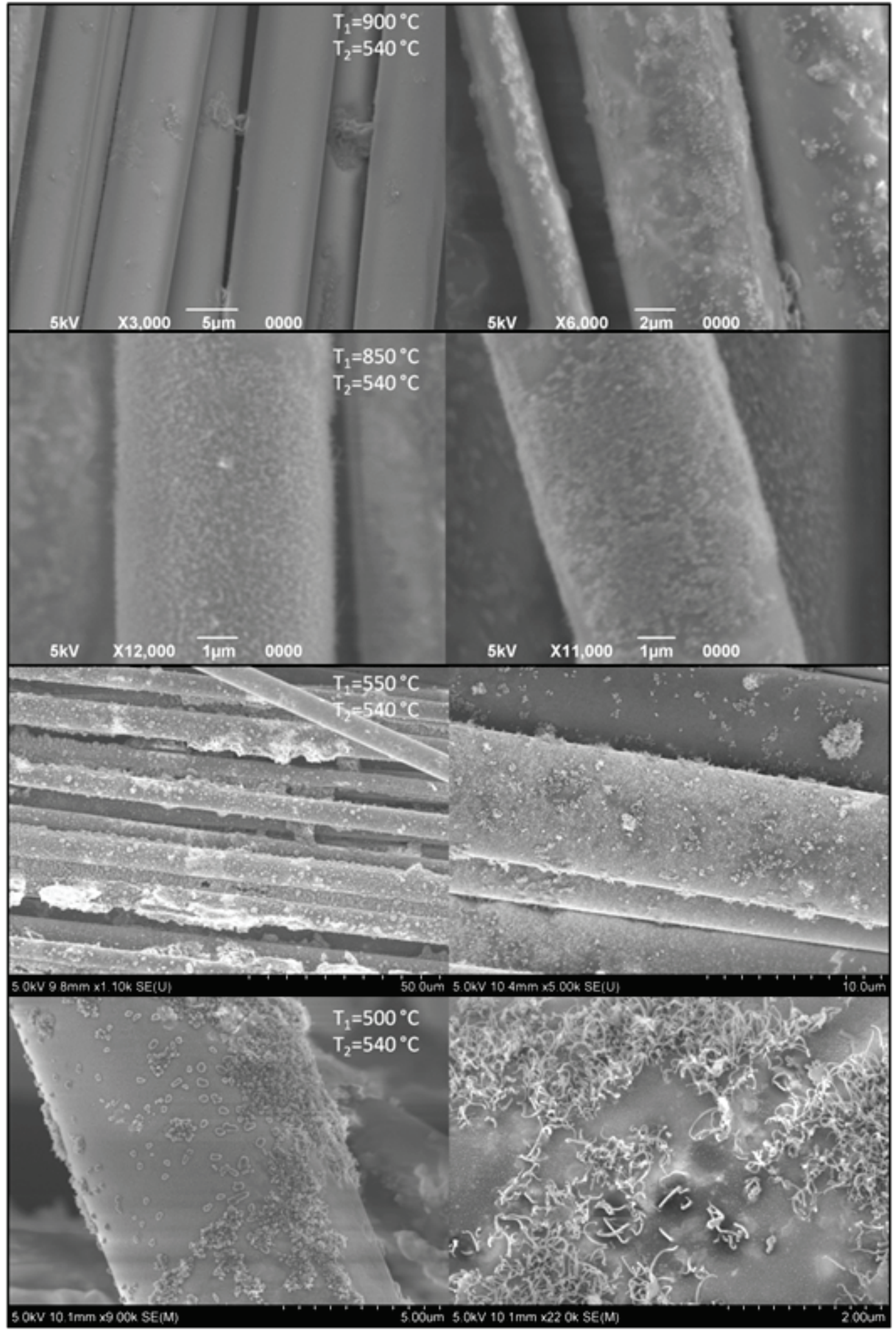


The CNT growth is enhanced by using a higher Zone 1 temperature compared to the Zone 2 temperature. The best enhancement in CNT density, length, and quality can be achieved by using a preheating Zone 1 temperature between $600-800{ }^{\circ} \mathrm{C}$ with a Zone 2 temperature of $540{ }^{\circ} \mathrm{C}$. This preheating allows proper decomposition of the catalyst and carbon precursor for the synthesis of CNTs while the cooler Zone 2 temperature reduces the thermal degradation and oxidation of the GF substrate.

Figure 3-23. SEM images of CNTs grown on glass fabrics in a two temperature zone furnace at Zone 1 temperatures of $600,700,750$, and $800^{\circ} \mathrm{C}$ with a Zone 2 temperature of $5400^{\circ} \mathrm{C}$.

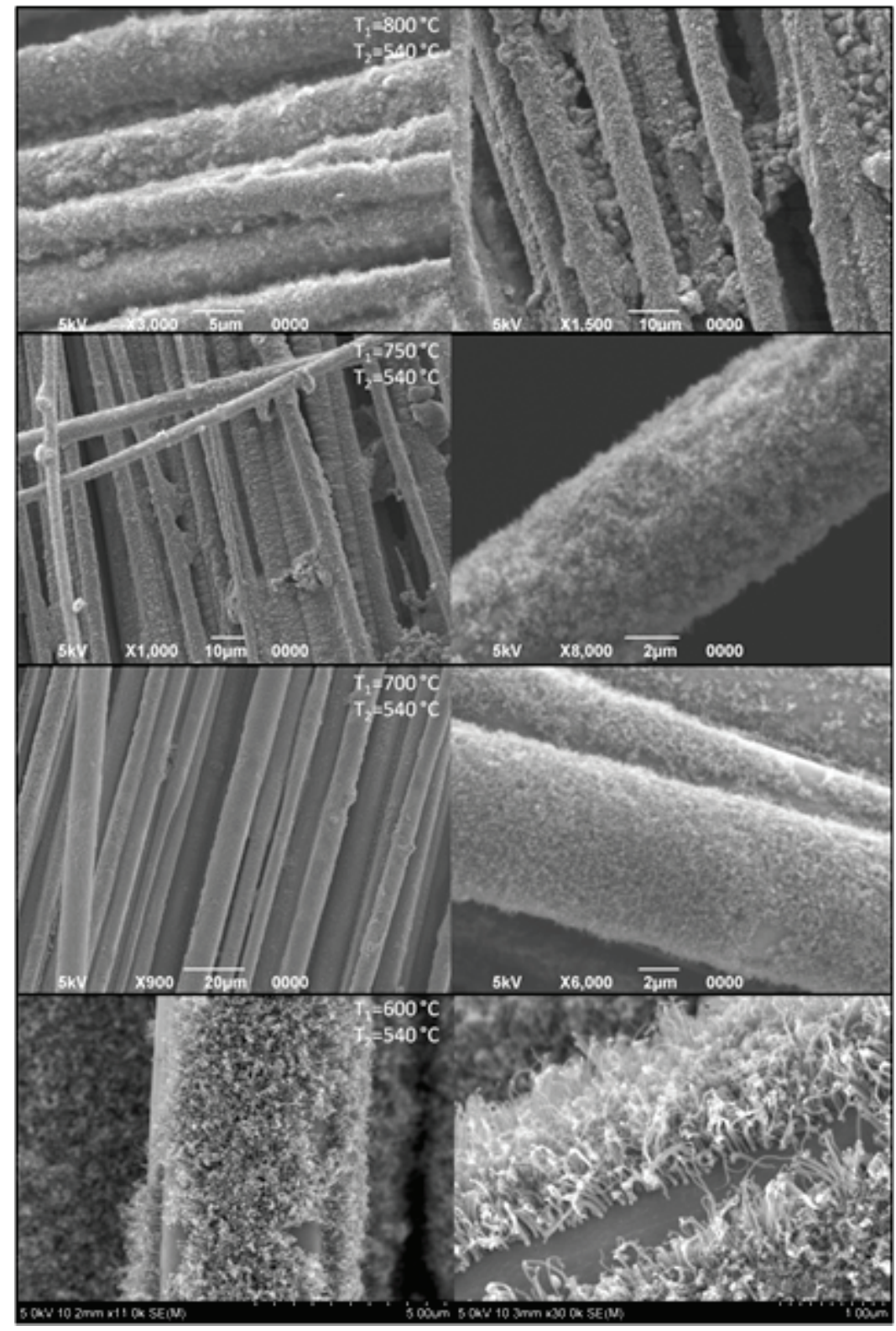




\section{Conclusions and Recommendations}

This work investigated the effect of process parameters on the energy dissipation and other mechanical properties of forests of carbon nanotubes grown on various substrates. Specifically, this work synthesized vertically aligned CNT forests under the same conditions using three different carbon sources: $m$-xylene, toluene, and benzene. The CNT forests were grown using the FCCVD method with ferrocene as the catalyst source. The diameter and average number of walls of the individual CNTs fabricated from each carbon source were $57.2 \mathrm{~nm}, 39$ walls; $60.9 \mathrm{~nm}, 41$ walls; and $69.0 \mathrm{~nm}, 53$ walls, respectively for $m$-xylene, toluene, and benzene. It is concluded that this ordering can be accounted for by considering both the entanglement of the CNTs and the amount of hydrogen present, which etches both iron and carbon.

The structure of each forest was observed using SEM images to verify that the carbon precursors with more substituted benzene derivatives result in CNT forests with a larger entangled structure. Stress vs. strain was measured in compression to correlate the structure of the forests to their mechanical properties. The CNT forests with higher entanglement had greater restitution at both strains of 0.25 and 0.67 . Thus, the CNTs in the highly entangled forest made from $m$-xylene behave most like springs that can be elastically compressed and then restored to near the original height with less plastic deformation. The total energy dissipated was similar for the $m$-xylene and toluene CNTs and significantly lower for the benzene CNTs.

These results open up a new path in the design of materials with high energy absorption capacity and a correspondingly large restitution value. Further work is recommended in the following areas:

- The effects of process parameters (such as temperature, catalyst concentration, flow rates, etc.) on the degree of entanglement within the CNT forests fabricated from each carbon precursor need to be analyzed.

- Additional work is needed to optimize the growth conditions necessary to improve the energy absorption and restitution properties. The interaction of these entangled CNT structures with other materials such as ceramics should be investigated for potential ballistic armor applications.

- Finally, further work is needed to determine the effect of the forest structure on the high strain rate response for potential applications in blast wave protection. 
Vertically aligned CNT forests were also synthesized and separated from their underlying Si substrate. Various metals including Ag, Fe, and In were deposited on the top and bottom of these CNT forests by paste, sputtering, and thermal evaporation, respectively. Stacks of one, two, and three of these metalized CNTs were arranged and compressed to explore their mechanical properties. These were then compared to nonmetalized CNTs stacks. The energy dissipation varied approximately linearly with respect to the number layers and was mostly independent of metallization. The energy per unit volume was constant (within the scatter) for all samples. After compression to a strain of 0.7, there was less fracturing and splintering with the Ag and Fe samples.

All samples showed less roughness in the stress vs. strain plot of $2 \mathrm{~L}$ and $3 \mathrm{~L}$ indicating some reduction in global buckling. Furthermore, SEM analysis of the cross-section of the compressed $2 \mathrm{~L}$ and $3 \mathrm{~L} \mathrm{Ag}$ samples showed a great reduction in global buckling on the top layers of the stacks. Finally, Young's modulus increased, especially in the In and Fe samples, as the number of layers was increased.

These results open up a new path in the design of composite materials for high energy absorption and high stiffness applications. It is recommended that the coupling of these CNT forests with other materials such as ceramics be further investigated, especially in the dynamic mode for cushioning properties and for potential ballistic armor applications. 


\section{Acronyms and Abbreviations}

$\begin{array}{ll}\text { Term } & \text { Definition } \\ \text { ACS } & \text { American Chemical Society } \\ \text { ANSI } & \text { American National Standards Institute } \\ \text { ASME } & \text { American Society of Mechanical Engineers } \\ \text { CEERD } & \text { U.S. Army Corps of Engineers, Engineer Research and Development Center } \\ \text { CERL } & \text { Construction Engineering Research Laboratory } \\ \text { CNT } & \text { Carbon Nanotube } \\ \text { CVD } & \text { Chemical Vapor Deposition } \\ \text { EMI } & \text { Electro Magnetic Interference } \\ \text { ERDC } & \text { U.S. Army Engineer Research and Development Center } \\ \text { ERDC-CERL } & \text { Engineer Research and Development Center, Construction Engineering } \\ \text { FC-CVD } & \text { Research Laboratory } \\ \text { GF } & \text { Floating Catalyst Chemical Vapor Deposition } \\ \text { GFRP } & \text { Glass Fabric } \\ \text { MWNT } & \text { Glass Fiber Reinforced Polymer } \\ \text { NSN } & \text { Multiwalled Nanotube } \\ \text { OMB } & \text { National Supply Number } \\ \text { PDMS } & \text { Office of Management and Budget } \\ \text { PE-CVD } & \text { Polydimethylsiloxane } \\ \text { SAR } & \text { Plasma-Enhanced - Chemical Vapor Deposition } \\ \text { SEM } & \text { Same as Report } \\ \text { SF } & \text { Scanning Electron Microscope } \\ \text { SPI } & \text { Standard Form } \\ \text { TEM } & \text { Superior Products International } \\ \text { TR } & \text { Transmission Electron Microscopy } \\ \text { URL } & \text { Technical Report } \\ & \text { Universal Resource Locator } \\ & \end{array}$




\section{References}

Ajayan, P. M., and J. M. Tour. 2007. Materials science: Nanotube composites. Nature 447(7148):1066-1068.

Aksak, M., S. Kir, and Y. Selamet. 2009. Effect of the growth temperature on carbon nanotubes grown by thermal chemical vapor deposition method. Journal of Optoelectronics and Advanced Materials Symposia 1(3):281-284.

Andrews, R., D. Jacques, A. M. Rao, F. Derbyshire, D. Qian, X. Fan, E. C. Dickey, and J. Chen. 1999. Continuous production of aligned carbon nanotubes: A step closer to commercial realization. Chemical Physics Letters 303(5-6):467-474.

Arash, B., Q. Wang, and V. K. Varadan. 2014. Mechanical properties of carbon nanotube/polymer composites. Scientific Reports 4:6479-6487.

Askari, D., and M. N. Ghasemi-Nejhad. 2012. Effects of vertically aligned carbon nanotubes on shear performance of laminated nanocomposite bonded joints. Science and Technology of Advanced Materials 13(4):045002.

Baughman, R. H., A. A. Zakhidov, and W. A. de Heer. 2002. Carbon nanotubes-The route toward applications. Science 297(5582):787-792.

Boddu, Veera M., and Matthew W. Brenner. 2016. Energy dissipation in intercalated carbon nanotube forests with metal layers. Applied Physics A: Materials Science \& Processing 122(88), doi:10.1007/s00339-015-9571-8.

Cao, A. Y., X. F. Zhang, C. L. Xu, J. Liang, D. H. Wu, X. H. Chen, and P. N. Ajayan. 2001. Grapevine-like growth of single walled carbon nanotubes among vertically aligned multiwalled nanotube arrays. Applied Physics Letters 79(9):1252-1254.

Cao, A., P. L. Dickrell, W. G. Sawyer, M. N. G.-Nejhad, and P. M. Ajayan. 2005. Supercompressible foamlike carbon nanotube films. Science 310(5752)1307-1310.

Chen, J., I. M. Hutchings, T. Deng, M. S. A. Bradley, and K. K. K. Koziol. 2014. The effect of carbon nanotube orientation on erosive wear resistance of CNT-epoxy based composites. Carbon 73:421-431.

Chou, T.-W., L. Gao, E. T. Thostenson, Z. Zhang, and J.-H. Byun. 2010. An assessment of the science and technology of carbon nanotube-based fibers and composites. Composites Science and Technology 70(1):1-19.

Ci, L., J. Suhr, V. Pushparaj, X. Zhang, and P. M. Ajayan. 2008. Continuous carbon nanotube reinforced composites. Nano Letters 8(9):2762-2766.

Coleman, J. N., U. Khan, and W. J. Blau. 2006. Small but strong: A review of the mechanical properties of carbon nanotube-polymer composites. Carbon 44(9):1624 (2006).

Coleman, J. N., U. Khan, and W. J. Blau. 2006. Small but strong: A review of the mechanical properties of carbon nanotube-polymer composites. Carbon 44(9):1624. 
Daraio, C., V. F. Nesterenko, S. Jin, W. Wang, and A. M. Rao. 2006. Impact response by a foamlike forest of coiled carbon nanotubes. Journal of Applied Physics 100(6):064309.

Das, N., A. Dalai, J. S. S. Mohammadzadeh, and J. Adjaye. 2006. The effect of feedstock and process conditions on the synthesis of high purity CNTs from aromatic hydrocarbons. Carbon 44(11)2236-2245.

Ebbesen, T. W., and P. M. Ajayan. 1992. Large-scale synthesis of carbon nanotubes. Nature 358(6383):220-222.

Endo, M., K. Takeuchi, K. Kobori, K. Takahashi, H. W. Kroto, and A. Sarkar. 1995. Pyrolytic carbon nanotubes from vapor-grown carbon fibers. Carbon 33(7):873881.

Falvo, M. R., G. J. Clary, R. M. Taylor, V. Chi, F. P. Brooks, S. Washburn, and R. Superfine. 1997. Bending and buckling of carbon nanotubes under large strain. Nature 389(6651):582-584.

Fan, S., M. G. Chapline, N. R. Franklin, T. Tombler, A. M. Cassell, and H. Dai. 1999. Selforiented regular arrays of carbon nanotubes and their field emission properties. Science 283(5401)512-514.

Garcia, E. J., B. L. Wardle, A. J. Hart, N. Yamamoto. 2008. Fabrication and multifunctional properties of a hybrid laminate with aligned carbon nanotubes grown in situ. Composites Science and Technology 68(9):2034-2041.

Ginga, N. J., W. Chen, and S. K. Sitaraman. 2014. Waviness reduces effective modulus of carbon nanotube forests by several orders of magnitude. Carbon 66(2014):57-66.

Hafner, J. H., C. L. Cheung, and C. M. Lieber. 1999 Growth of nanotubes for probe microscopy tips. Nature 398(6730):761-762.

Hafner, J. H., C. L. Cheung, T. H. Oosterkamp, and C. M. Lieber. 2001. High-yield assembly of individual single-walled carbon nanotube tips for scanning probe. Journal of Physical Chemistry B 105(4):743-746.

Han C., and C. T. Sun. 2001. Attenuation of stress wave propagation in periodically layered elastic media. Journal of Sound and Vibration 243(4):747-761.

Huang, J.-Q., Q. Zhang, M.-Q. Zhao, and F. Wei. 2010. Oxidant during Aligned Carbon Nanotube Growth: a Powerful Tool in Structure Modulation and Release of Arrays. Beijing, China: Beijing Key Laboratory of Green Chemical Reaction Engineering and Technology, Department of Chemical Engineering, Tsinghua University, www.acs.omnibooksonline.com

Iijima, S. 1991. Helical microtubules of graphitic carbon. Nature 354(6348):56-58.

Joseyacaman, M., M. Mikiyoshida, L. Rendon, and J. G. Santiesteban. 1993. Catalytic growth of carbon microtubules with fullerene structure. Applied Physics Letters 62(6):657-659. 
Khan, S. U., and J.-K. Kim. 2011. Impact and delamination failure of multiscale carbon nanotube-fiber reinforced polymer composites: A review. International Journal of Aeronautical \& Space Science 12(2):115-133.

Kong, J., N. R. Franklin, C. Zhou, M. G. Chapline, S. Peng, K. Cho, and H. Dai. 2000. Nanotube molecular wires as chemical sensors. Science 287(5453):622-625.

Lachman, N., H. Qian, M. Houllé, J. Amadou, M. S. P. Shaffer, and H. D. Wagner. 2013. Fracture behavior of carbon nanotube/carbon microfiber hybrid polymer composites. Journal of Materials Science 48(16):5590-5595.

Lannucci, L., and M. L. Willows. 2007. An energy based damage mechanics approach to modeling impact onto woven composite materials: Part II. Experimental and numerical results. Composites Part A: Applied Science and Manufacturing 38(2):540-554.

Lattanzi, L., J. R. Raney, L. D. Nardo, A. Misra, and C. Daraio. 2012. Nonlinear viscoelasticity of freestanding and polymer-anchored vertically aligned carbon nano-tube foams. Journal of Applied Physics. 111(7):074314.

Lattanzi, L., L. D. Nardo, J. R. Raney, and C. Daraio. 2014. Geometry-induced mechanical properties of carbon nanotube foams. Advanced Engineering Materials 16(8):1026-1031.

Lee, C. J., K. H. Son, J. Park, J. E. Yoo, Y. Hug, and J. Y. Lee. 2001. Low temperature growth of vertically aligned carbon nanotubes by thermal chemical vapor deposition. Chemical Physics Letters 338(2-3):113-117.

Lee, T. Y., J.-H. Han, S. H. Choi, J.-B. Yoo, C.-Y. Park, et al. 2003. Effects of source gases on the growth of carbon nanotubes. Diamond and Related Materials 12(37):851-855.

Lee, T. Y., J.-H. Han, S. H. Choi, J.-B. Yoo, C.-Y. Park, Taewon Jung, SeGi Yu, W. K. Yi, I. T. Han, and J. M. Kim. 2003. Comparison of source gases and catalyst metals for growth of carbon nanotube. Surface and Coatings Technology 2003(169170):348-352.

Li, N., Y. Huang, F. Du, X. B. He, X. Lin, H. J. Gao, Y. Ma, F. Li, Y. Chen, and P. C. Eklund. 2006. Electromagnetic interference (EMI) shielding of single-walled carbon nanotube epoxy composites. Nano Letters 6(6):1141-1145.

Li, N., Y. Huang, F. Du, X. B. He, X. Lin, H. J. Gao, Y. Ma, F. Li, Y. Chen, and P. C. Eklund. 2006. Electromagnetic interference (EMI) shielding of single-walled carbon nanotube epoxy composites. Nano Letters 6(6):1141-1145.

Li, W. Z., J. G. Wen, and Z. F. Ren. 2002. Effect of temperature on growth and structure of carbon nanotubes by chemical vapor deposition. Journal of Applied Physics A 74(3):397-402.

Li, X., A. Cao, Y. J. Jung, R. Vajtai, and P. M. Ajayan. 2005. Bottom-up growth of carbon nanotube multilayers: Unprecedented growth. Nano Letters 5(10):1997-2000. 
Ma, P. C., N. A. Siddiqui, G. Marom, and J. K. Kim. 2010. Dispersion and functionalization of carbon nanotubes for polymer-based nanocomposites: A review. Composites Part A: Applied Science and Manufacturing 41(10):13451367.

Machmann, M. R., Q. Zhang, F. Du, L. Dai, and J. Baur. 2011. Length dependent foamlike mechanical response of axially indented vertically oriented carbon nanotube arrays. Carbon 49(2):386-397.

Meysami, S. S., A. A. Koos, F. Dillon, and N. Grobert. 2013. Aerosol-assisted chemical vapour deposition synthesis of multi-wall carbon nanotubes: II. An analytical study. Carbon 58(2013):159-169.

Misra, A., J. R. Raney, A. E. Craig, and C. Daraio. 2011. Effect of density variation and non-covalent functionalization on the compressive behavior of carbon nano-tube arrays. Nanotechnology 22(42)425705.

Misra, A., J. R. Raney, L. D. Nardo, A. E. Craig, and C. Daraio. 2011. Synthesis and characterization of carbon nanotube-polymer multilayer structures. ACS Nano 5(10):7713-7721.

Nessim, G. D., M. Seita, D. L. Plata, K. P. O'Brien, A. J. Hart, E. R. Meshot, C. M. Reddy, P. M. Gschwend, and C. V. Thompson. 2011. Precursor gas chemistry determines the crystallinity of carbon nanotubes synthesized at low temperature. Carbon 49(3):804-810.

Padaki, N. V., R. Alagirusamy, B. L. Deopura, B. S. Sugun, and R. Fangueiro. 2008. Low velocity impact behavior of textile reinforced composites. Indian Journal of Fibre \& Textile Research 33(2):189-202.

Pandya, K. S., and N. K. Nail. 2015. Analytical and experimental studies on ballistic impact behavior of carbon nanotube dispersed resin. International Journal of Impact Engineering 76:49-59.

Peipetis, A., and C. Galiotis. 1996. Effect of fibre sizing on the stress transfer efficiency in carbon/epoxy model composites. Composites Part A: Applied Science and Manufacturing 27(9):755-767.

Pinault, M., V. Pichot, H. Khodja, P. Launois, C. Reynaud, and M. M.-L’Hermite. 2005. Evidence of sequential lift in growth of aligned multiwalled carbon nanotube multilayers. Nano Letters 5(12):2394-2398.

Rakov, E. G. 2013. Materials made of carbon nanotubes. The carbon nanotube forest. Russian Chemical Reviews 82(6):538.

Rakov, E. G. 2013. Materials made of carbon nanotubes. The carbon nanotube forest. Russian Chemical Reviews. 82(6):538.

Raney, J. R., F. Fraternali, A. Amendola, and C. Daraio. 2011. Modeling and in situ identification of material parameters for layered structures based on carbon nano-tube arrays. Composite Structures 93(11):3013-3018. 
Ren, Z. F., Z. P. Huang, J. W. Xu, J. H. Wang, P. Bush, M. P. Siegal, and N. Provencio. 1998. Synthesis of large arrays of well-aligned carbon nanotubes on glass. Science 282(5391):1105-1107.

Seah, C.-M., S.-P. Chai, and A. R. Mohamed. 2011. Synthesis of aligned carbon nanotubes. Carbon 49(14):4613-4635.

Singh, C., M. S. P. Shaffer, and A. H. Windle. 2003. Production of controlled architectures of aligned carbon nanotubes by an injection chemical vapour deposition method. Carbon 41(2):359-368.

Strong, A. Brent., and Catherine A. Ploskonka. 2008. Fundamentals of Composites Manufacturing: Materials, Methods, and Applications. 2d ed. Dearborn, MI: Society of Manufacturing Engineers, Publications Development Dept., Reference Publications Division, 2008.

Sun, L., R. F. Gibson, F. Gordaninejad, and J. Suhr. 2009. Energy absorption capability of nanocomposites: A review. Composites Science and Technology 69(14):23922409.

Takeda, G. L., Pan, S. Akita, and Y. Nakayama. 2005. Vertically aligned carbon nanotubes grown at low temperatures for use in displays. Japanese Journal of Applied Physics 44(7B):5642-5645.

Tans, S. J., A. R. M. Verschueren, and C. Dekker. 1998. Room-temperature transistor based on a single carbon nanotube. Nature 393(6680)49-52.

Tans, S. J., M. H. Devoret, H. Dai, A. Thess, R. E. Smalley, L. J. Geerligs, and C. Dekker. 1997. Individual single-wall carbon nanotubes as quantum wires. Nature 386(6624):474-477.

Thess, A., R. Lee, P. Nikolaev, H. J. Dai, P. Petit, J. Robert, Chunhui Xu, Young Hee Lee, Seong Gon Kim, Andrew G. Rinzler, Daniel T. Colbert, Gustavo E. Scuseria, David Tománek, John E. Fischer, and Richard E. Smalley. 1996. Crystalline ropes of metallic carbon nanotubes. Science 273(5274):483-487.

Thevamaran, Ramathasan, Namiko Yamamoto, and Chiara Daraio. 2012. Wave Propagation in Multilayered Structures Composed of Carbon Nanotubes and Rigid Inter-Layers under Small Velocity Impacts. 23rd International Congress of Theoretical and Applied Mechanics ICTAM2012, Beijing, China, August 2012.

Thostenson, E. T., C. Li, and T. W. Chou. 2005. Nanocomposites in context. Composites Science and Technology 65(3-4):491-516.

Thostenson, E. T., W. Z. Li, D. Z. Wang, Z. F. Ren, and T. W. Chou. 2002. Carbon nanotube/carbon fiber hybrid multiscale composites. Journal of Applied Physics 91(9):6034-6037.

Thostenson, E. T., Z. Reng, and T. W. Chou. 2001. Advances in the science and technology of carbon nanotubes and their composites: A review. Composites Science and Technology 61(13):1899-1912.

Treacy, M. M. J., T. W. Ebbesen, and T. M. Gibson. 1996. Exceptionally high Young's modulus observed for individual carbon nanotubes. Nature 381(6584):678-680. 
Vander Wal, R. L., T. M. Ticich, and V. E. Curtis. 2000. Diffusion flame synthesis of single-walled carbon nanotubes. Chemical Physics Letters 323(3-4):217-223.

Veedu, V. P., A. Cao, X. Li, K. Ma, C. Soldano, S. Kar, P. M. Ajayan, and M. N. GhasemiNejhad. 2006. Multifunctional composites using reinforced laminae with carbon nanotube-forests. Nature Materials 5(6):457-462.

Wong, E. W., P. E. Sheehan, and C. M. Lieber. 1997. Nanobeam mechanics: Elasticity, strength, and toughness of nanorods and nanotubes. Science 277(5334):19711975 .

Wu, T. C., and S. H. Chang. 2009. Temperature enhanced growth of ultralong multiwalled carbon nanotubes forest. Current Applied Physics 9(5):1117-1121.

Yamamoto, N., A. J. Hart, E. J. Garcia, S. S. Wicks, H. M. Duong, A. H. Slocum, and B. L. Wardle. 2009. High-yield growth and morphology control of aligned carbon nanotubes on ceramic fibers for multifunctional enhancement of structural composites. Carbon 47(3):551-560.

Yamamoto, N., R. Thevamaran, and C. Daraio. 2012. Dynamic Behavior of Periodic Structures Consisting of Vertically Aligned Carbon Nanotubes and Rigid Interlayers. 53rd Structures, Structural Dynamics, and Materials and Co-located Conferences, American Institute for Aeronautics and Astronautics, (AIAA/ASME/ASCE/AHS/ASC) Honolulu, HI April 2012.

Yang, F., and R. Pitchumani. 2000. Modeling of interphase formation on unsized fibers in thermosetting composites. Proceedings of the ASME Heat Transfer Division, ASME-HTD-366-3:329-337.

Zeng, Y., L. Ci, B. J. Carey, R. Vajtai, and P. M. Ajayan. 2010. Design and reinforcement: Vertically aligned carbon nanotube-based sandwich composites. ACS Nano 4(11):6798-6804.

Zhang, Q., M. Zhao, Y. Liu, A. Cao, W. Qian, Y. Lu, and F. Wei. 2009. Energy-absorbing hybrid composites based on alternate carbon-nanotube and inorganic layers. Advanced Materials 21(28):2876-2880.

Zhang, Y., G. Zou, S. K. Doorn, H. Htoon, L. Stan, M. E. Hawley, C. J. Sheehan, Y. Zhu, and Q. Jia. 2009. Tailoring the morphology of carbon nanotube ar-rays: From spinnable forests to undulating foams. ACS Nano 3(8):2157-2162. 


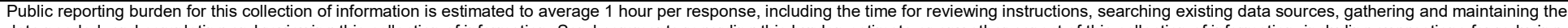

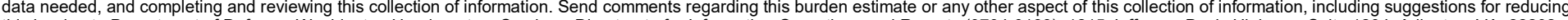

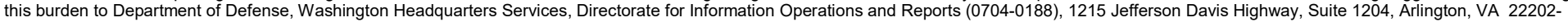

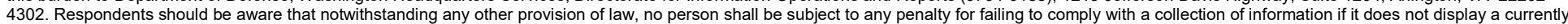
4302. Respondents should be aware that notwithstanding any other provision of law, no person shal
valid OMB control number. PLEASE DO NOT RETURN YOUR FORM TO THE ABOVE ADDRESS.

\begin{tabular}{l|l} 
valid OMB control number. PLEASE DO NOT RETURN YOUR FORM TO THE ABOVE ADDRESS. \\
\hline 1. REPORT DATE (DD-MM-YYYY) & 2. REPOR
\end{tabular}

\begin{tabular}{|c|c}
\hline 24-08-2016 & Final \\
\hline
\end{tabular}

\section{TITLE AND SUBTITLE}

Energy Dissipation in Carbon Nanotube Forests through the Control of Morphology and Layered Forests with Intercalated Metal Films

Matthew W. Brennerand Veera M. Boddu

\section{AUTHOR(S)}

3. DATES COVERED (From - To)

5a. CONTRACT NUMBER

\section{5b. GRANT NUMBER}

\section{5c. PROGRAM ELEMENT}

6.1 Basic Research

\section{5d. PROJECT NUMBER}

\section{5e. TASK NUMBER}

\section{5f. WORK UNIT NUMBER}

\section{PERFORMING ORGANIZATION NAME(S) AND ADDRESS(ES)}

U.S. Army Engineer Research and Development Center (ERDC)

Construction Engineering Research Laboratory (CERL)

PO Box 9005,

Champaign, IL 61826-9005

\section{PERFORMING ORGANIZATION REPORT NUMBER}

ERDC/CERL TR-16-18

10. SPONSOR/MONITOR'S ACRONYM(S) CEERD-GSL

U.S. Army Engineer Research and Development Center (ERDC)

Geotechnical and Structures Laboratory

3909 Halls Ferry Road

Vicksburg, MS 39180-6199

11. SPONSOR/MONITOR'S REPORT NUMBER(S)

\section{DISTRIBUTION / AVAILABILITY STATEMENT}

Approved for public release; distribution is unlimited.

\section{SUPPLEMENTARY NOTES}

\section{ABSTRACT}

The high mechanical strength and low density of carbon nanotubes (CNTs) make them ideal candidates to be incorporated into composites to increase their mechanical strength. This work investigated the effect of process parameters on the energy dissipation and other mechanical properties of forests of carbon nanotubes grown on various substrates by synthesizing vertically aligned CNT forests under the same conditions using three different carbon sources: m-xylene, toluene, and benzene. Results indicate that substituents on the benzene ring increase entanglement in the CNT forests. When compressed to a strain of 0.67 , the toluene CNTs absorbed more energy than the m-xylene CNTs. Vertically aligned forests of CNTs were also synthesized to study their quasi-static mechanical properties in a layered configuration with metallization. The top and bottom surfaces of CNT forests were metalized with Ag, Fe, and In using paste, sputtering, and thermal evaporation, respectively. Stacks of one, two, and three layers of these forests were assembled and compressed to measure their mechanical properties. Successive stacking of CNT forests was found to reduce global buckling events, which is enhanced with a thick Ag deposition on the CNT forest surface. Young's modulus increased as the number of layers was increased.

\section{SUBJECT TERMS}

Materials-Testing, Energy dissipation, Carbon nanotubes-- Mechanical properties

\begin{tabular}{|l|c|}
\hline \multicolumn{2}{|c|}{ 16. SECURITY CLASSIFICATION OF: } \\
\hline $\begin{array}{c}\text { a. REPORT } \\
\text { Unclassified }\end{array}$ & b. ABSTRACT \\
Unclassified & c. THIS PAGE \\
Unclassified
\end{tabular}

\begin{tabular}{|c|c|c|}
$\begin{array}{c}\text { 17. LIMITATION } \\
\text { OF ABSTRACT }\end{array}$ & $\begin{array}{c}\text { 18. NUMBER } \\
\text { OF PAGES }\end{array}$ & \begin{tabular}{c} 
19a. NAME OF RESPONSIBLE PERSON \\
\cline { 3 - 3 } SAR
\end{tabular} \\
\cline { 3 - 3 } & 68 & $\begin{array}{c}\text { 19b. TELEPHONE NUMBER } \\
\text { (include area code) }\end{array}$ \\
\hline
\end{tabular}

Standard Form 298 (Rev. 8-98)

Prescribed by ANSI Std. 239.1 